Western University

Scholarship@Western

Digitized Theses

Digitized Special Collections

1987

\title{
Frequency Analysis Of The Rapidly Oscillating Ap Star Hd 60435
}

Jaymie Mark Matthews

Follow this and additional works at: https://ir.lib.uwo.ca/digitizedtheses

\section{Recommended Citation}

Matthews, Jaymie Mark, "Frequency Analysis Of The Rapidly Oscillating Ap Star Hd 60435" (1987). Digitized Theses. 1658.

https://ir.lib.uwo.ca/digitizedtheses/1658

This Dissertation is brought to you for free and open access by the Digitized Special Collections at Scholarship@Western. It has been accepted for inclusion in Digitized Theses by an authorized administrator of Scholarship@Western. For more information, please contact tadam@uwo.ca,

wlswadmin@uwo.ca. 
Ottawa Caneda

KIA ONA

\section{CANADIAN THESES}

\section{THESES CANADIENNES .}

\section{NOTICE}

The quality of this microfiche is heavily dependent upon the quality of the original thesis submitted for microfilming. Every effort has been made to ensure the highest quality of repmoduction possible

If pages are missing. contact the university which granted the degree.

Some pages may have indistinct print especially if the original peges were typed with a poor typewriter ribbon or if the univer. sity sent us an inferior photocopy.

Previousty copyrighted materials (journal articles. published tests, etc.) are not filmed

Reproduction in full or in part of this film is governed by the Canadian Copyright ACt. R.S.C 1970, C C-30

\begin{abstract}
AVIS
La qualite de celte microfiche depend grandement de la qualte de la these soumise au microfimege Nous avons tout fait pour assurer une qualité superieure de reproduction

S'll martique des pages, vevillez communiquer avec luniversité qui a conferé le grade.

La qualite dimpression de certaines peges peut laisser a desirer, surton si les peges originates ont eté dactylooraphibes à l'aide d"un ruban use ou si l'université nous a fait parvenir. une photocopie de qualité interteure

Les documents qui font deja l'objet ó un droit of auteur (artices de revue, examens publies. eic ) ne sont pas microfilmos.
\end{abstract}

La reproduction. meme partielle. de ce microfitm est soumiteo a Ta Loi canadienne sur le droit d'auteur, SRC 1970. c. C-30.

\section{THIS DISSERTATION HAS BEEN MICROFILMED. EXACTLY AS RECEIVED}

\author{
LA THESE A ETE \\ MICROFILMEE TELLE QUE \\ NOUS L'AVONS RECUE
}


1.1 Lighe curves of the rapid oscillations of HR $1217 \ldots \ldots \ldots$

1.2 Amplitude modulation and magnetic varfation of HR $1217 \ldots 4$

1.3 Phase shifes of the roAp star HR $3831 \ldots \ldots \ldots \ldots \ldots$ s

$1.4 c_{1}$ vs. (b-y) diagram for the roAp stars $\ldots \ldots \ldots \ldots \ldots \ldots$

1.5 Schematic representation of the oblique pulsator model . 17

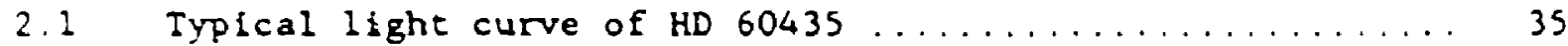

3.1 Structure of a simplified astronomical observing window in the time and frequency domains ............ 46

3.2 An actual window from the HD 60435 observations ....... 48

3.3 Amplitude spectrum of a typical spline filter used

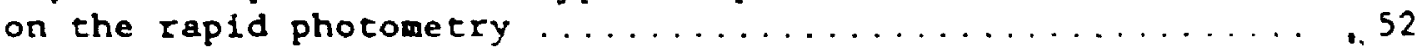

4.1 Amplitude spectrum of 1984 data of HD 60435:

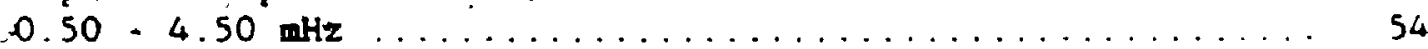

4.2 Amplitude spectra from two individual nights showing $1.4 \mathrm{mHz}$ oscillation(s) $\ldots \ldots \ldots \ldots \ldots \ldots \ldots \ldots$ ss

4.3 Modulation of oscillation amplitude of HD 60435 during 1984 campaign

4.4 Amplitude spectrum of 1984 data:

$1.24-1.53 \mathrm{mHz}$

4.5 Amplitude spectrum of SAAO and LCO data from JD 2445728 showing resolved equally-spaced peaks

4.6 Schematic representation of frequency pattern near $1.4 \mathrm{mHz}$ Identifled in 1984 data ................61

4.7 Amplitude spectrum of one night of 1984 data showing peaks near 1.1 and 4.2 nitz

4.8 Amplitude spectrun of 1984 data:

$0.98-1.22 \mathrm{mHz}$

4.9 Amplitude spectrun of 1984 daes: $4.04-4.28 \mathrm{aHz} \ldots \ldots \ldots \ldots \ldots \ldots \ldots \ldots \ldots \ldots \ldots \ldots \ldots \ldots$

4.10 A sample of 10 anplitude spectra fron the 1985 campaign ...

4.11 a. Schenatic representation of frequencles observed in HD $60433^{\circ}$

b. High-resolution amplitude spectrum of data frov the 1985 campalgn: $0.70-1.50=\mathrm{Hz} \ldots \ldots \ldots \ldots \ldots \ldots \ldots$

$4.12 \log i$ vs. $\log T_{\text {eff }}$ diagran with contoura of consent $\nu_{0} \ldots 77$ 
Permission has been granted to the National Library of Canada to microfilm this thesis and to lend or sell copies of the film.

The author (copyright owner) has reserved other publication rights, and neither the thesis nor extensive extracts from it - may be printed or otherwise reproduced without his/her written permission.
Lautorisation a été accordée
à la Bibliothèque nationale
du canada de microfilmer
cette thèse et de preter ou
de valdide des exemplaires du
film.

Lauteur (titulaire du droit d'auteur) se réserve -les autres droits dé publication: ni la thèse ni de longs extraits de celle-ci ne doivent être imprimés ou autrement reproduits sans son autorisation écrite.

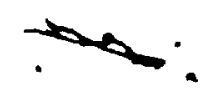


CHAPTER VI - HD 60435 AND THE OBLIQUE PULSATOR MODEL $\ldots \ldots \ldots \ldots . .88$

Existence of an ablique nagnetic fleld/

The rotation pertod of HD $60435 \ldots \ldots \ldots \ldots \ldots \ldots . \ldots \ldots$

Anplitude modulation and phase shifts .............. 97

Splitting of frequencles in the Fourier spectrum ........ 102

Inclination and obliquieg of HD $60435 \ldots \ldots \ldots 107$

The global magnetic field of HD $60435 \ldots \ldots \ldots 113$

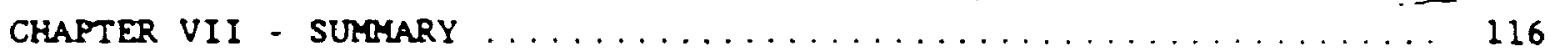

HD 60435 as a test of the Oblique Pulsator Model ......... 117

Pecomendations for future observations ............... 119

The importance of HD 60435 to stellar astrophysics ........ 122

APPENDIX A. NONRADIAL PULSATION IN STARS $\ldots \ldots \ldots \ldots \ldots \ldots \ldots \ldots \ldots 124$

Pulsation modes....................... 126

Pressure $(p-)$ modes ................... 127

Gravity $\left(\mathrm{g}^{-}\right)$modes ...................... 129

Pulsational driving .................... 130

APPENDIX B. PERIQD-FINDING COMPUTER PROGRAMMES $\ldots \ldots \ldots \ldots \ldots \ldots \ldots 132$

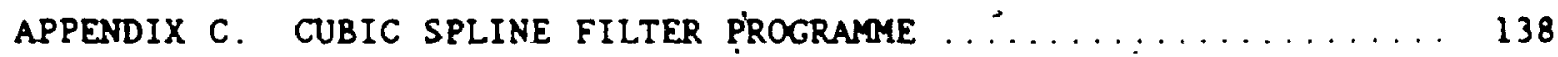

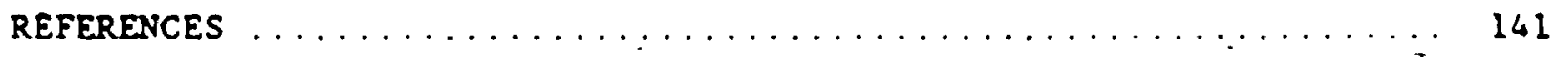

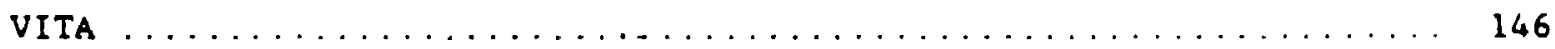




\section{ABSTRACT}

The rapidly oscillating Ap (rodp) star HD 60435 has been nonitored In a programe of rapid Johnson B photonetry during which approxiactely 355 hours of observations vere collected from the Ifs Canpanas Observatory, Cerro Tololo Inter-Anerlcan Observatory, ape South African Astrononical Observatory in two coordinated campaigds from January 1984 to March 1985.

Fourles analysis of these data indleate that the star undergoes osclilation in a sectrum of nearly equally spaced frequencles, corresponding to a range of perlods frón about 12 to 20 minutes. Typlcal aplitudes are only a few mlltimagnitudes. The doninant oscillations occur nedi a frequency of $1.4 \mathrm{mhz}(P=12 \mathrm{~min})$. Fourler peaks at frequencles near 2.8 and 3.6 aHz have also been detected sporadically; these may be $2: Y$ and $3: 1$ resonances with the first oscillation, or barDonice produced by the nonsinusoldal shape of the 11 ght curve.

Comptison of the overall frequency pitcern to the asymptotic theopy off nonradial acoustic pulaacion has led to Identiflcation of the qucilletions as a seriej of high-overtone $(13 \leq n \leq 38)$ p-modes of degree 1 and 2 . The fundarental frequency spacing $\nu_{0}-52 \mu \mathrm{Hz}$ is consiatint with a elightly coolved late A wear whose radius 1 is $2.2 \pm 0.3$. B. The location of HD 60435 In Serongren multi-colour diagrans, arid oleselffication epectre of the ser oberined at Lae Camenas, are in general agreanent with that result.

The aplitudes of the dosinant osclilations are modulated over a long timẹcale naar elght daye, and also show rapid bodulation in only

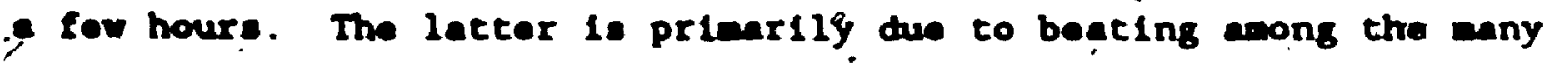


frequencles present in HD 60435 , but there is ovidence that actual growth and decay of modes occur in the star in less than a day, as postulated by Dolez and Gough (1984) for rapld pulsations in angnetic A stars.

The rotation period of HD 60435, based on the star's long-tern light curve, is $7.6662 \pm 0.0001$ days. (HD 60435 also appears to be a ald spectroscopic variable with a simflar timescale) Kurtz' (1982) oblique pulsator model for the roAp stars predicts that the oscillation amplitude of the star should be nodulated with the same period, is is In fact observed. Application of a dynanical version of this model (Dzlembowskl, and Goode 1985) to the fine splftting observed in the Fourler spectrum of the oscillations places constraints on the incilnation of the star and obliqulty of lts (as yet unconfirmed) aagnetic fleld, predicts that any observed fleld variations will exhibit polarity reversal, and suggests that hD 60435 may have a relatively woak Internal fleld compared to some of the other roAp tars.

These latter predictions are consistent with the upper linits set by the only direct agnetic measurements of this star avallable to date, as well as the oblique rotator interpretation of the long-tern If ght varlations. 
On the subject of acknowledgenents, a certain Style Manual for. students I have on my bookshelf states that "a student may without cownt" punction refrain fron expressing thanks, however heartfeit, to his the1. supervisor for routine work. Acknowledgenents should be phrased concisely and circumpectly." Well, I have rarely been accused of circumsection... and even less often of conciseness. And as for the efforts of advisor. I would hardly describe then as routine. Dr. Bill Wehlau has been both an unfalling wellspring of good advice and a vast reservoli of patience during the years of wy doctoral research. This cheal. and 1ts author have benefited enormously fron his expertise.

Although only one nane appears on the jacket of this volume, there are several individuals whose direct contributions deserve both ny gra. titude and the reader's recognition.

First and foremost of these is Dr. Don Kurtz (University of Cape Town), who played key role in the developwent of this thesis. He orlginally suggested HD 60435 as a pronising "centreplece" for a Ph.D. dissertation, and provided the second-site observations of the star wich wad this sudy feasible. HIs early encouragenent and insightful colments In our correspondence and conversations are sincerely appreclated.

Important observations were also supplied by a few others. Dr. John Landetreet and his graduate students Devid Bohlender and Brian veptrudo graciouly eacrifled precious observing tiwe at Las Campanas to attempt fow ingnetic neseureaces of HD 60435 . Bob Slawson, then of the Univeralty of Toronto Southern Observatory (UTSO), agreed to 
collect spectra of the star while I was engaged in rapid photowetry at another location. My own observations would not have been possible were it not for generous allocations of time by Dr. Bob Garrison. Director of UTSO, and Dr. Bob Willians, Director of the Cerro Tololo Inter-American Observatory, and the excellent support provided by the staffs of those facilities.

Technical support for this thesis in the post-observation phase was also plentiful. Much of the coaputing was performed on the Depart. ment's then-fledgling PDP $1123 \mathrm{minl}$-computer. What could have been a frustrating experlence was made fruttful by the expert tutelage and . good humour of Henry Leparskas. Ron Lyons (University of Toronto) and David Bohlender helped with the PDS digltization of the photographic spectra of HD 60435. Many of the figures in this thesis were orlg1nally prepared for publication in scientiflc journals; some of these were the result of the keen eye and skllled hand of Mira Rasche.

Under the category of moral support. I'd like to acknowledge the minds, hearts and elbows of my fellow members of the Tycho Brahe Soc1ety. Their unabated interest in wy progress over the years (e.g. "Aren't you finished yet?". "Do we have to listen to another talk on rapidly oscillating Ap stars?". "Can I have your office space when you leave?") and useful scientific-discussions (aher) at The Graduete Centre helped make my tenure here one I w1ll always recall with fondness. finally... (reaember my"opening coments on conclseness?). I ex. tend my thanks to the Department of Astronomy and The Faculty of Graduate Studies of UWO for their continued financial support. 
CHAPTER VI - HD 60435 AND THE OBLIQUE PULSATOR MODEL

Existence of an ablique magnetic fleld/

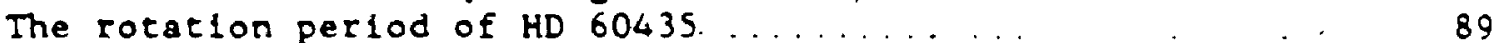

Anplicude modulation and phase shifts ............ . . 97

Spliteing of frequencies in the Fourler spectrum $\quad 102$

Inclination and obliquiey of HD $60435 \ldots . . .107$

The global magnetic field of HD 60435..... . 113

CHAPTER VII - SUMMARY $\ldots \ldots \ldots \ldots \ldots \ldots \ldots \ldots \ldots \ldots \ldots$

HD 60435 as a test of the Oblique Pulsator Model ... ... 117

Pecomendations for future observations ..... ... ... 119

The importance of HD 60435 to stellar astrophysics . 122

APPENDIX A. NONRADIAL PULSATION IN STARS ............. 124

Pulsation modes............... 126

Pressure $(p-)$ modes .................... 127

Gravity $\left(\mathrm{g}^{-}\right)$modes ............. . 129

Pulsational driving ................... . . 130

APPENDIX B. PERIOD-FINDING COMPUTER PROGRAMMES . . . . . . . . 132

APPENDIX C. CUBIC SPLINE FILTER PROGRAMAME $\ldots \ldots \ldots \ldots \ldots \ldots \ldots \ldots \ldots$

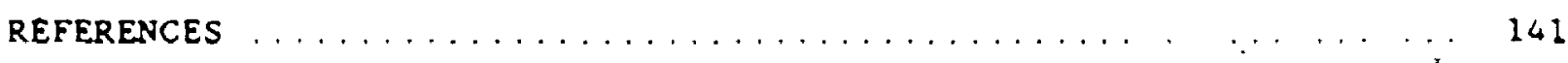

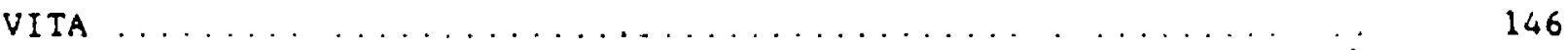




\section{LIST OF TABLES}

Table

Description

Page

1. 1

The Rapidly Oscillating Ap (roAp) Stars

1.2

Observed strongren Indices of the roAp Stars

1. 3

Reddening-free Indices of the roAp Stars

Log of Photometric Observations

Extinction Coefficients at LCO and CTIO.

Phase Relatlons Between Magnetic and Light Curves

of Ap Stars

6.2

Geneva Photonetry of HD 60435

6.3

Paraneters of Magnetic Fields for Four roAp stars

fron Triplet Amplitudes 
11 Lighe curves of the rapid oscillations of HR $1217 \ldots \ldots$

12 Amplitude modulation and magnetic variation of HR 1217

1.3 Phase shifts of the roAp star HR $3831 \ldots$

14 ci vs. (b-y) diagram for the roAp stars

is Schematic representation of the oblique pulsator model

2 : Typfcal lighe curve of MD 60435

3.1 Structure of a simplified astronomical observing window in the time and frequency domains

3.2 An actual window from the HD 60435 observations. 48

3.3 Amplitude spectrum of a typical spline filter used on the rapid photometry

4.1 Amplitude spectrum of 1984 data of HD 60435:

$0.50-4.50 \mathrm{mHz}$

4.2 Amplitude spectra from two individual nights showing

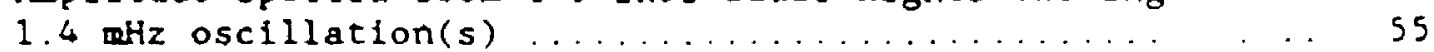

4.3 Modulation of oscillation amplitude of HD 60435 during 1984 campaign

4.4 Amplitude spectrum of 1984 data:

$1.24-1.53 \mathrm{mHz}$

4.5 Amplitude spectrum of SAAO and LCO data from JD 2445728 showing resolved equally-spaced peaks

4.6 Schematic representation of frequency pattern

near $1.4 \mathrm{mHz}$ identifled in 1984 data

4.7 Amplitude spectrum of one night of 1984 data showing peaks near 1.1 and $4.2 \mathrm{mHz}$

4.8 Amplitude spectrum of 1984 data:

$0.98 \cdot 1.22 \mathrm{aHz}$

4.9 Amplitude spectrum of 1984 daca:

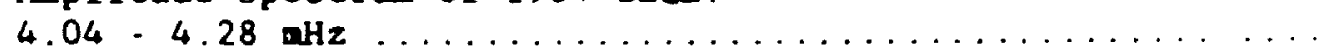

4.10 A sample of 10 anplitude spectra frov the 1985 campalgn

4.11 a. Schenatic representation of frequencies observed in HD 60433

b. High-resolution amplitude spectrus of data fron the 1985 camalgn: $0.70-1.50 \mathrm{aHz} \ldots \ldots \ldots \ldots \ldots \ldots$

$4.12 \log i$ vo. $\log \tau_{\text {eff }}$ diagram with contours of constant $v_{0} \ldots 77$ 


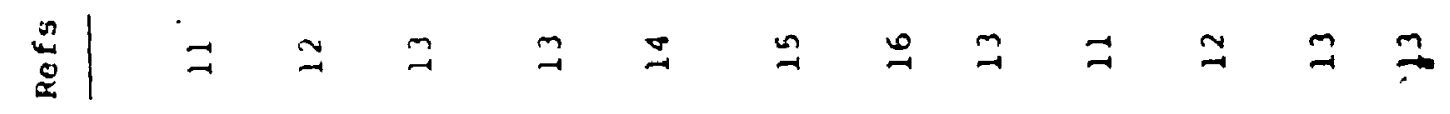

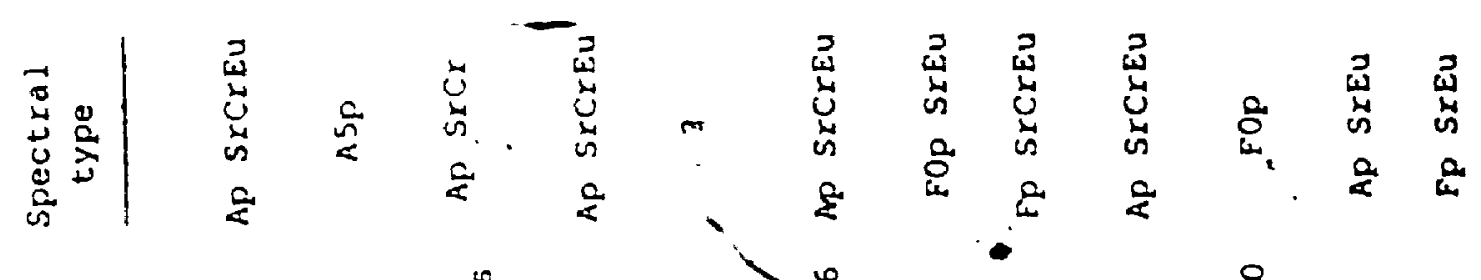

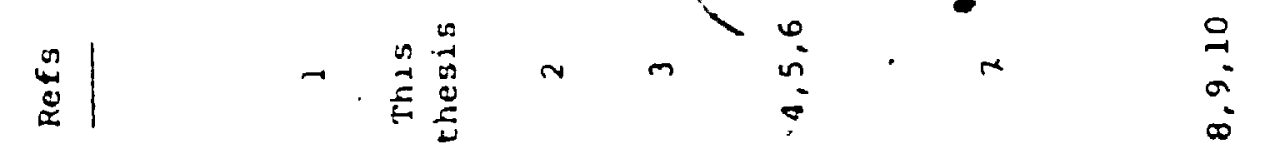

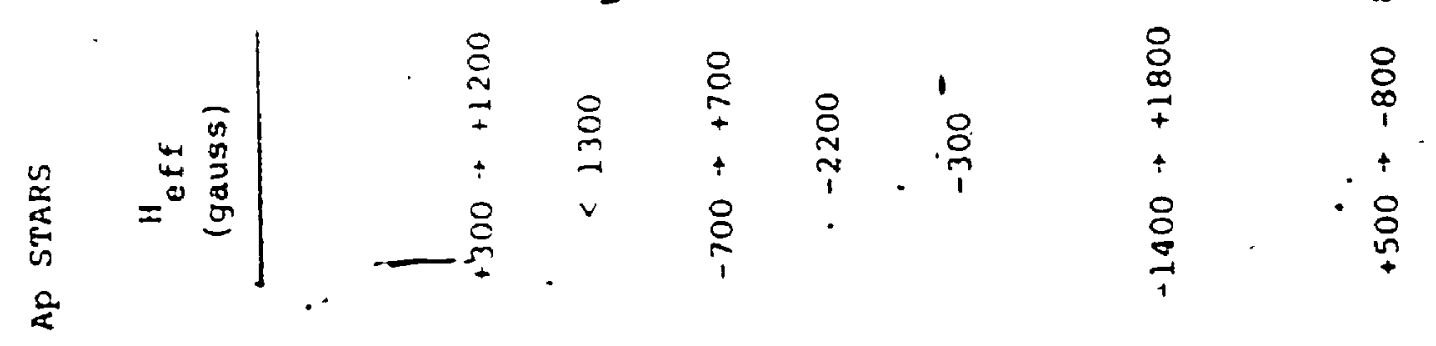

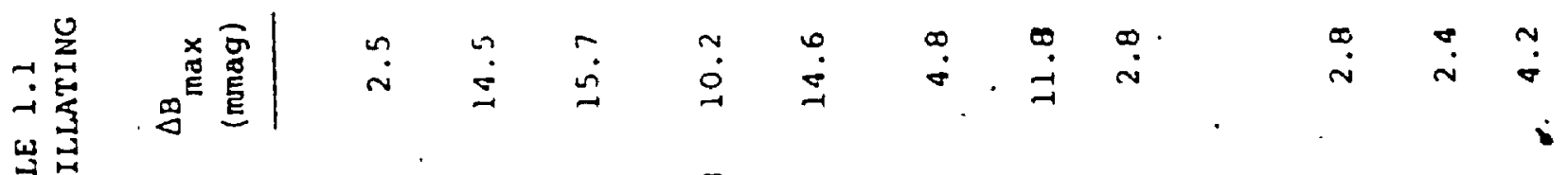

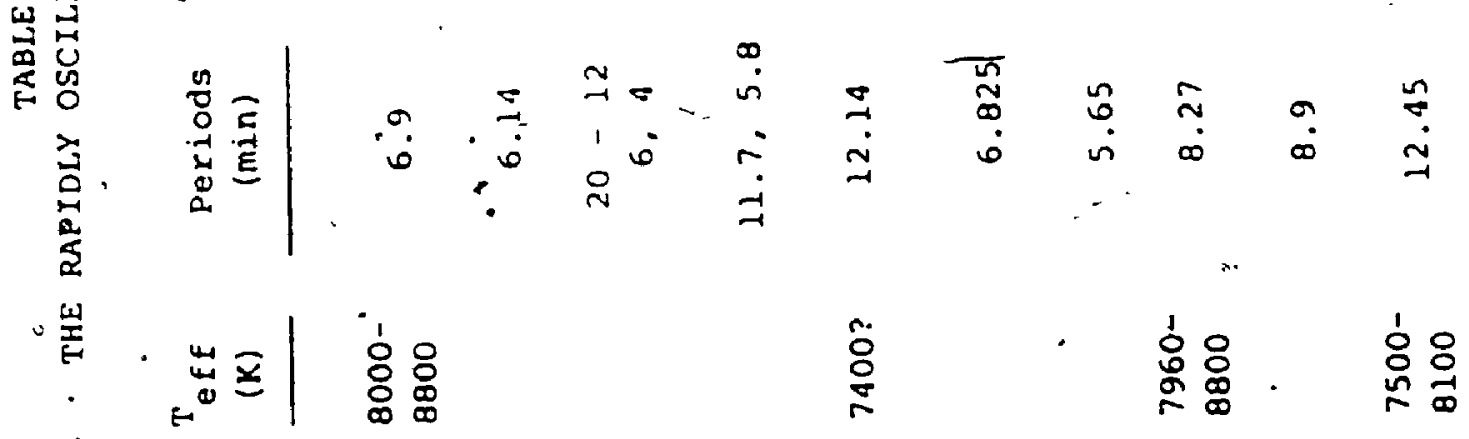

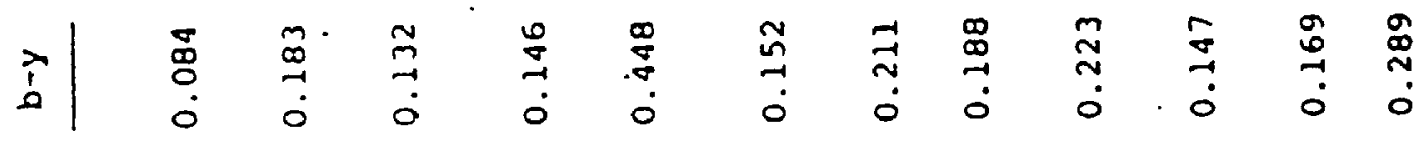

$$
\begin{aligned}
& \text { ด| }
\end{aligned}
$$

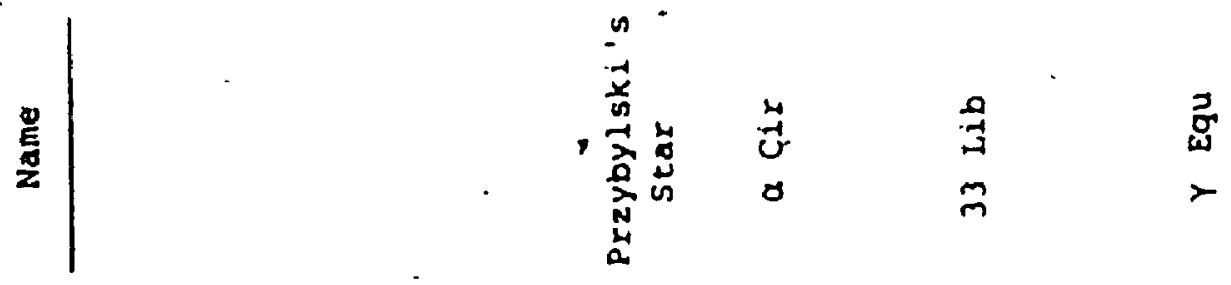

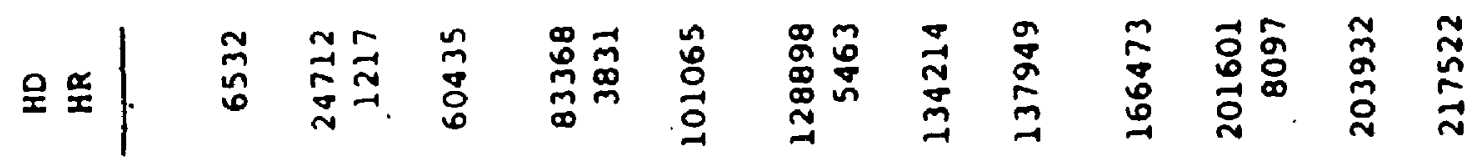


The author of this thesis has granted The University of Western Ontario a non-exclusive license to reproduce and distribute copies of this thesis to users of Western Libraries. Copyright remains with the author.

Electronic theses and dissertations available in The University of Western Ontario's institutional repository (Scholarship@Western) are solely for the purpose of private study and research. They may not be copied or reproduced, except as permitted by copyright laws, without written authority of the copyright owner. Any commercial use or publication is strictly prohibited.

The original copyright license attesting to these terms and signed by the author of this thesis may be found in the original print version of the thesis, held by Western Libraries.

The thesis approval page signed by the examining committee may also be found in the original print version of the thesis held in Western Libraries.

Please contact Western Libraries for further information:

E-mail: libadmin@uwo.ca

Telephone: (519) 661-2111 Ext. 84796

Web site: http://www.lib.uwo.ca/ 


\section{The rapidly oscillating Ap stars}

The rapidly oscillatting Ap (roAp) stars are cool pecullar A-F stars ${ }^{+}$which exhibit rapld variations in broadband light. The oscil. lations of these stars are characterized by (l) their short periods (approximately 4 - 20 minutes), (2) low amplitudes ( $\Delta B<0$ m015; typically only a few millimagnitudes), and (3) amplitude modulation which occurs over timescales from days to weeks. (For stars whose magnetic variations havè been determined, the modulation period equals the magnetic period 0 the star. Maximum osclilation amplitude is observed during the phase of maximum magnetic field strength.) The oscillations sometimes also show (4) splitting in the Fourler spectrum of the dominant frequency into components spaced by the modulation cycle frequency, and (In the case of at least one roAp star, HR 3831) (5) $180^{\circ}$ phase shifts in the dominant oscillation occurring twice per modulation cycie.

The first roAp star. HD 101065 (Przybylski's Star), was discovered. in 1978 by Kurtz (1978). Since then, membershlp in the class has grown to 12, thanks mostly to the efforts of Kurtz and a few of his collaborators (e.g. Kurtz 1983a,b; Kreldl 1985a). All of the known varlables are south of $10^{\circ}$ in declination. which 1 s probably only a selection

+ The Ap stars are main sequence stars roughly betweer $B 8$ and FO ( $15000>T_{\text {eff }}>8000 . \mathrm{K}$ ) whose spectra feature anomalous IIne stengths which are interpreted as atsospheric oper-and underabundances. The coolest nembers are nost overabundant in rare earths (:SrEuCr"); the hottest, In sllicon ("SI"). All are hellum-deflcient. Strong ordered magnetic flelds (up to $20 \mathrm{kG}$ ) are comon - poselbly ublquitous - asong these stars: The brlghtness, spectrum, and nagnetic fleld are observed to vary with perlode greater than one day. The propereles of the Ap class have been revlewad by Wolff (1.983). 


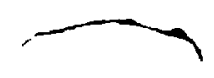

offece of the search observations being so far'conducted priastly at Southern Healsphere observatorles. Recent reviews of the roAp class. have been written by Kurtz (1986), Weiss (1986), and Shibahashi (1987).

All but three of the known roAp stars have persistent oscillations with perlods near 6 and/or 12 minutes. Several are observed to be mitiperiodic; $2: 1$ frequency ratios have been found in three instances.

The characteristics of the oscillations $(1) \cdot(5))$ sumarized above-are 111ustrated by Figures 1.1-1.3. Two typical light curves (obialned six days apart) of a vell-studied roAp star, HD 24712, are presented in Figure 1.1. Note the suall amplitude which never exceeds 0\%01. The dominane period is 6.14 anutes, but this is only one of six" Identfled by Kurtz and Seeman (1983). The beating of those closely spaced frequencies is responsible for the obvious amplitude modulation of the net oscillation on each night. Neglecting this short-term modulation, the difference in the mean amplitudes of the oscillations on the two alghts is quite apparent fron the figure. The two sets of obsarvations, showing the oscillations at maximum and minfmum ampli. tude. are separated by bout half of the magnetic perlod of this star. (12.54 days: Preston (1972)). Flgure 1.2 plots the nightly B anplitude of the net oscillation together with the agnetic curve for HD 24712 , demonstating the phase relationship between the oscillations are field strength.

Figure 1.3 shows the phese shifte detected in the primary osclilation of HR 3831; the sharp changes occur during zero crossover - of the magnetic fleld. These phase shifts and the long-term modulation typified by Figure 1.2 can be explained by the oblique pulsator model (Kurtz 1982), which is described later in this chapter. 

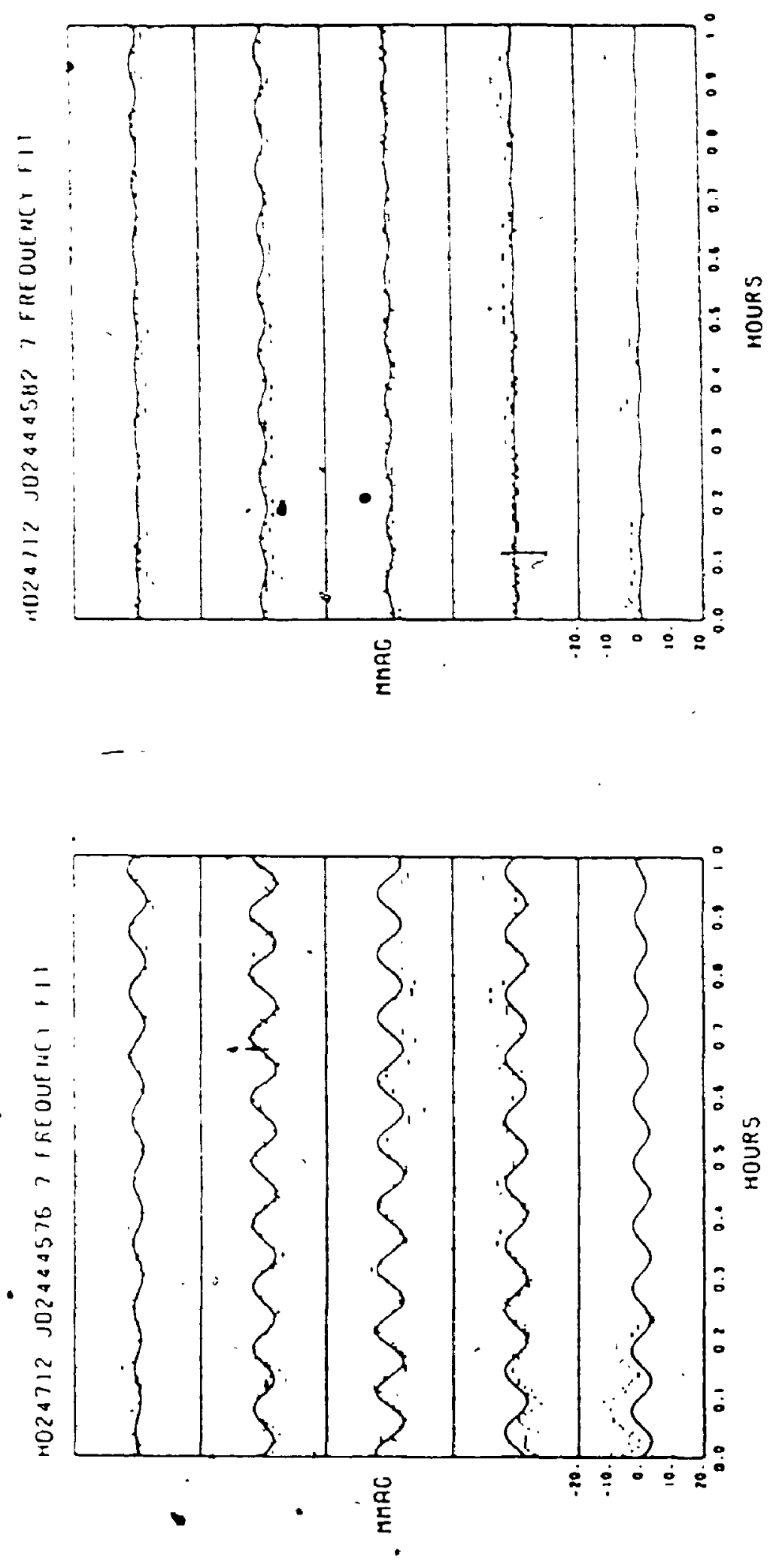

羊可造

舒击吉

동

돈도잉

4

- 너도

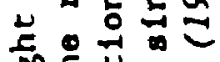

正至芯

-

ᄃ

드눙 도워 그웅 퐁워 ప 1) भิ

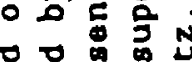

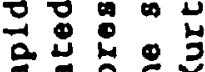

흔 흔

$\infty$ ํํㅇ

둘용

응우

๑

उ달

동

공

- 吉起范

울

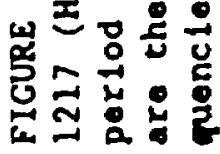




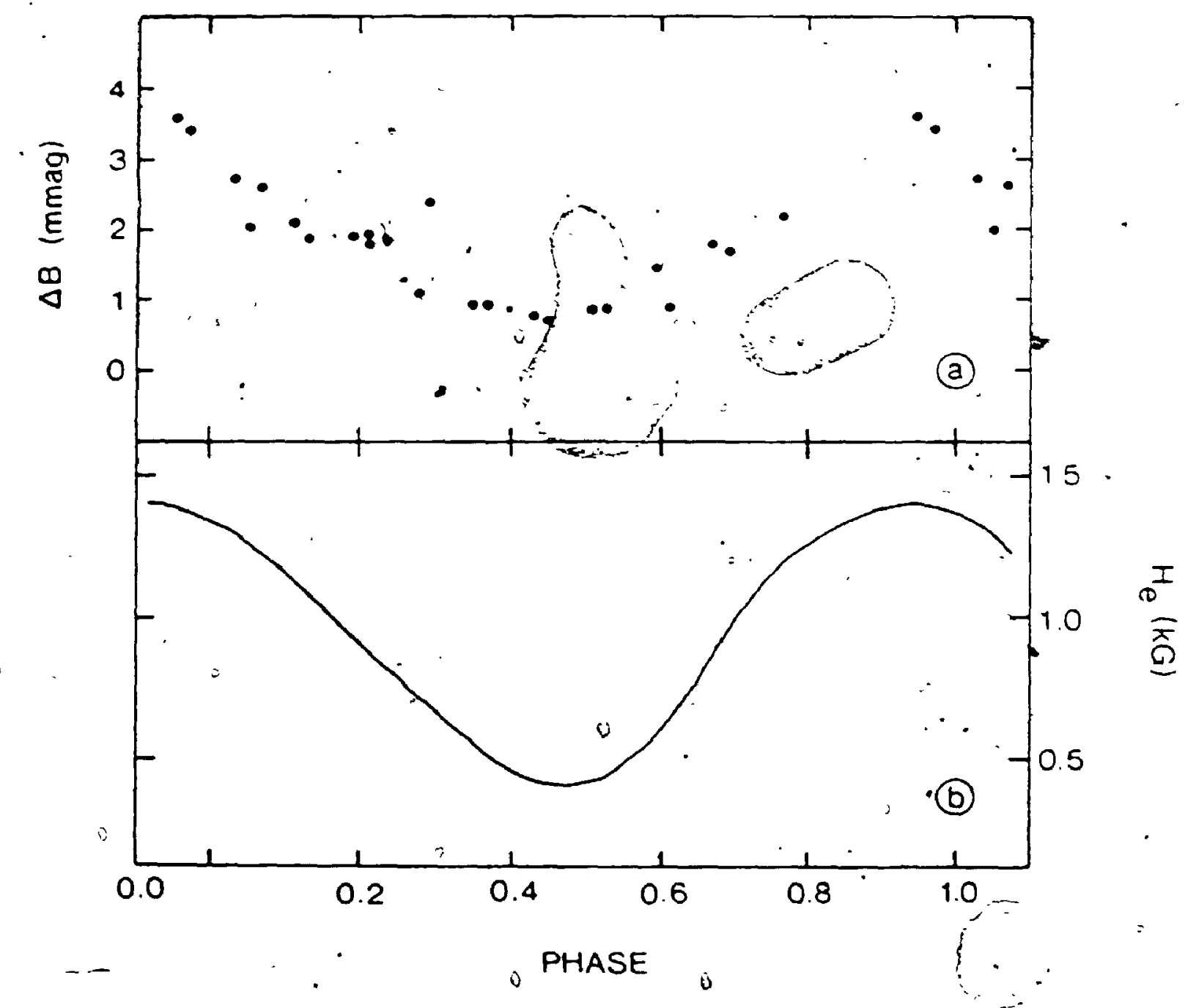

FICURE 1.2 (a) The applitude modulation of the osc1llations of HR 1217 (Kurtz 1982) plotted at the same phases as (b) the magnetlc variations of $a$ the ser (Preston 1972). 


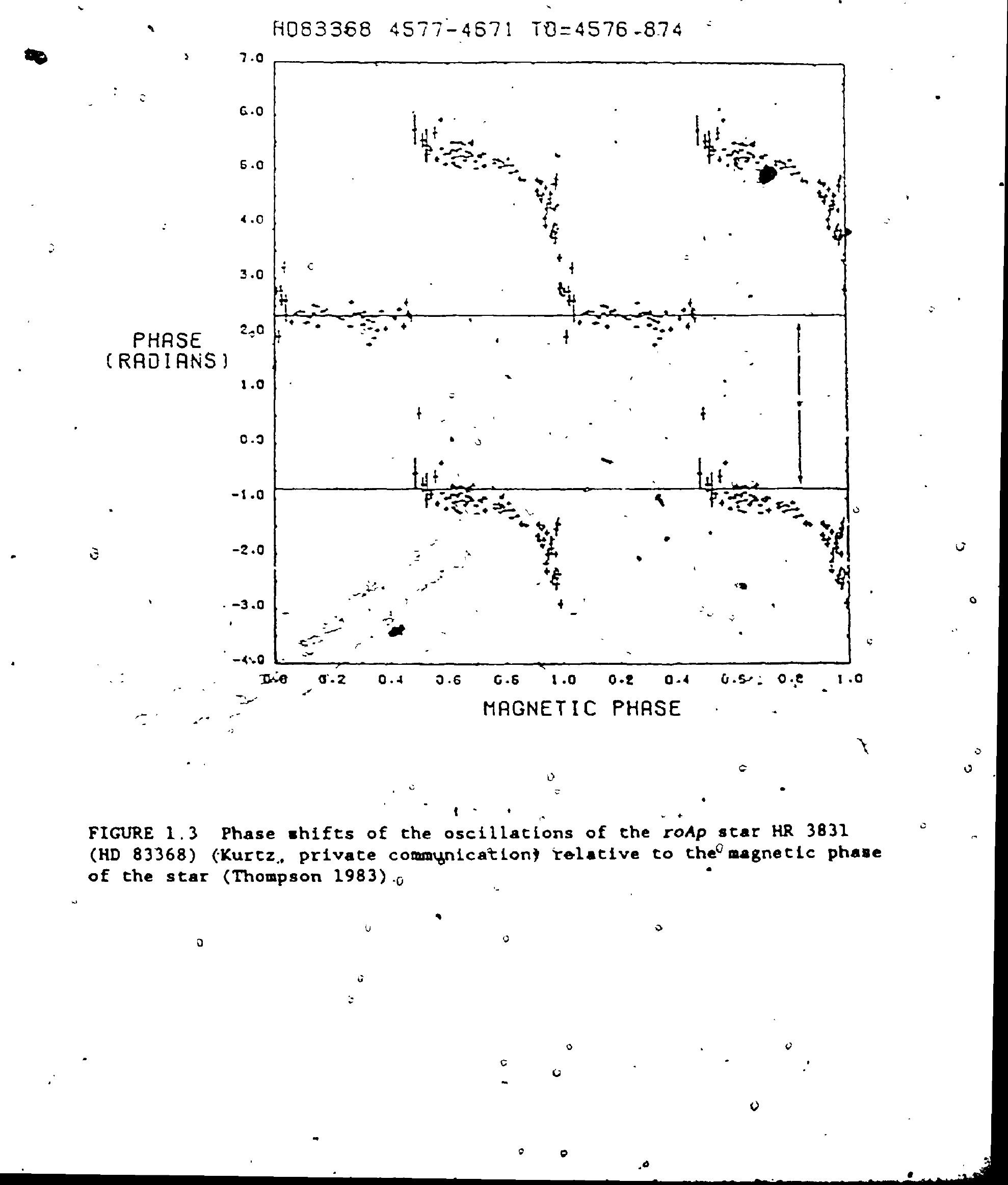


The oscliletions thesselves are thought to be nonradial pulsatlons: speciflcally, acoustic $\left(p^{-}\right)$wodes of low degree and high overtone. (See Appendix A for a brief introduction to the nomenclature of nonradial pulsation.) The visibility of the oscillations in inte. grated light-requires pulsation patterns of low degree ( $l \leq 3)$; thelr short perlods Ioply high radial overcones, since fundanental pulsation perlods of a few hours are expected for $A$ and $F V$ stars. The most complifing evidence for ldentifying the oscillations as p-mode waves cones frod two ropp stars which osflilate in pattegns of frequencies with roughly equal spacing. This type of pattern is predicted by asymptotic theory (Tassoul 1980) and has been observed in the Sun's Eive-miriute osclilations, which are now recognized to be the product of acoustic waves. The roAp stars which exhiblt this behaviour are HD 24712 (Kurtz and Seewan 1983) and HD 60435. The discovery of such a pattern in HD 60435, and the inforation about the star inferred frod 1t, are najor results of thls thesis.

\section{Empliclcal parameters}

Some of the basic observed properties of the known roAp. sars are somerized in Table 1.l. A complete set of observed strongren indices is provided in Tablo 1.2. Several reddening-independent stromgren Indlces $\left([u-b]^{\circ},\left(m_{1}\right)\right.$; and $\left.\left(c_{1}\right\}\right)$, were calculated froe the photowetrico values in that table and are 11 sted in Table 1.3.

The rodp atars appear to be confined to the low temperature end of the Ap range; none have $(b-y)$ colour. less than about 0.08 . As such. they way be restrfeted to the s scuti instabilfty etrip; those blue border falle near $(b \cdot y)-0.06$ on. the viln equence (Bregar 1979). The 


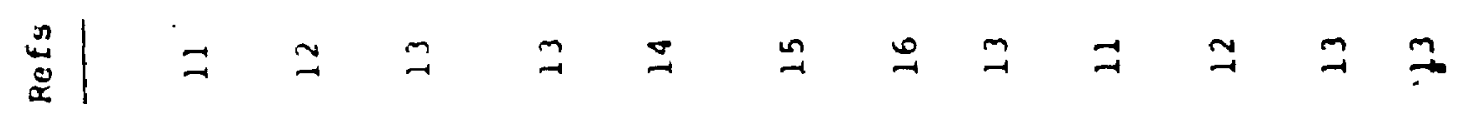

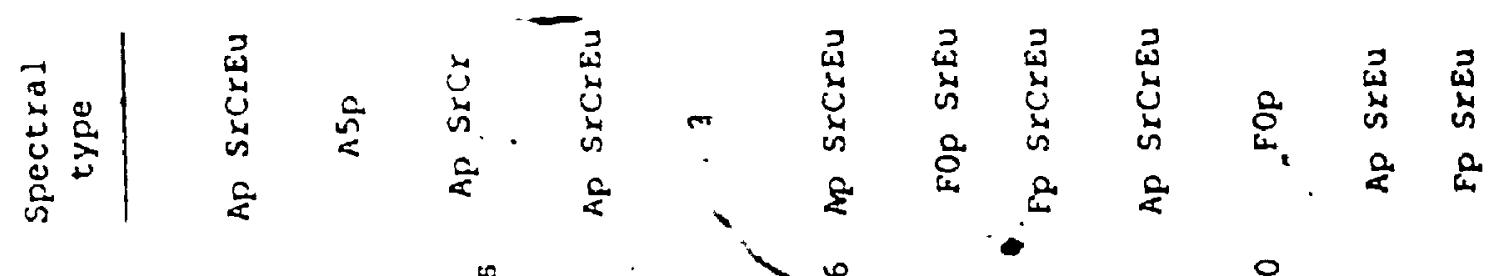

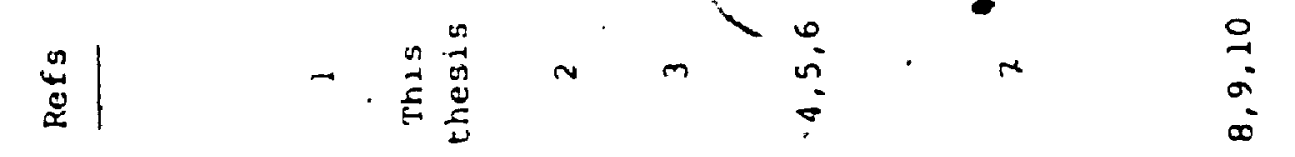

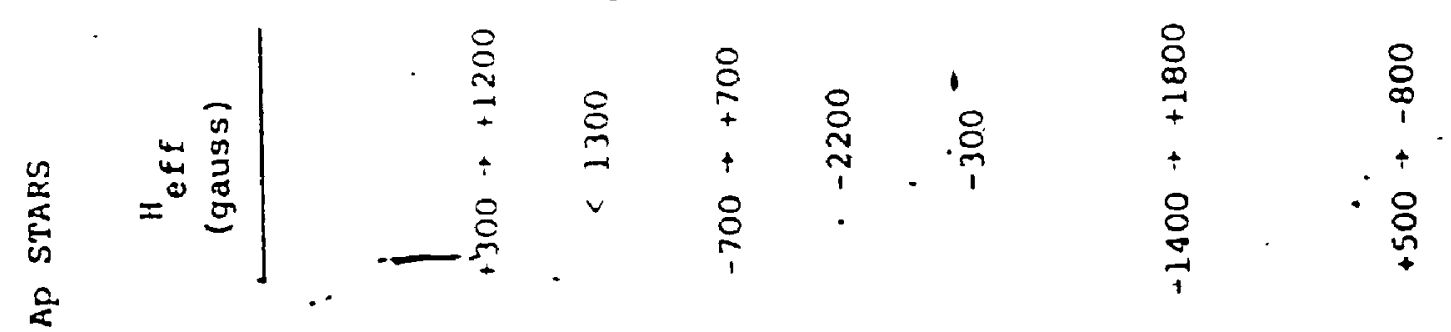

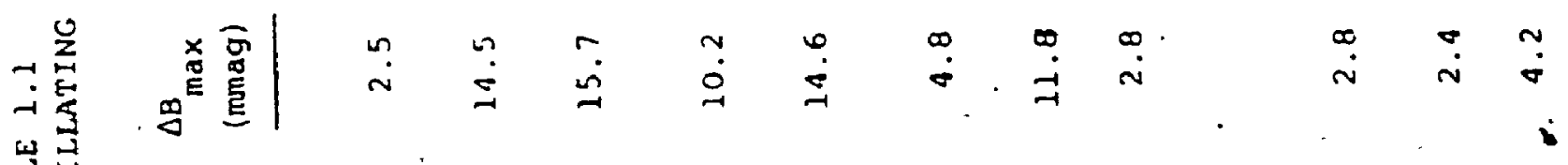

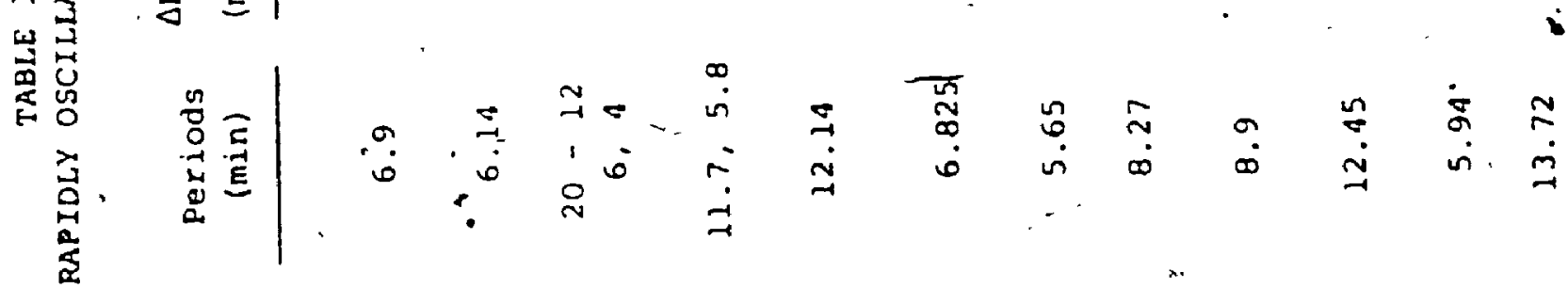

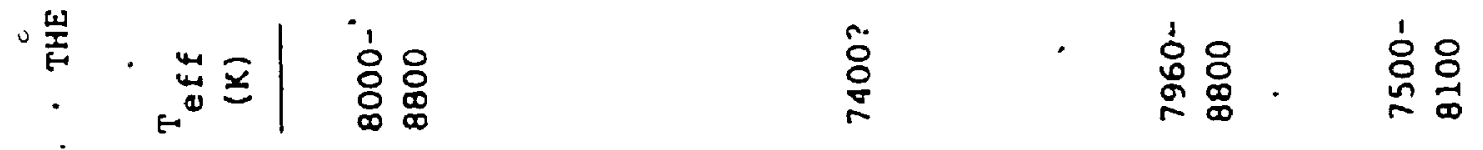

$$
\begin{aligned}
& \text { ฟ| }
\end{aligned}
$$

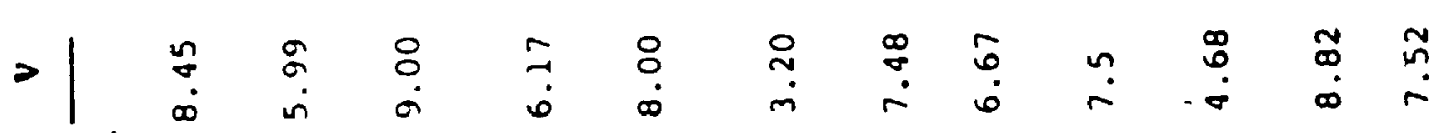

$$
\begin{aligned}
& \text { 量| }
\end{aligned}
$$

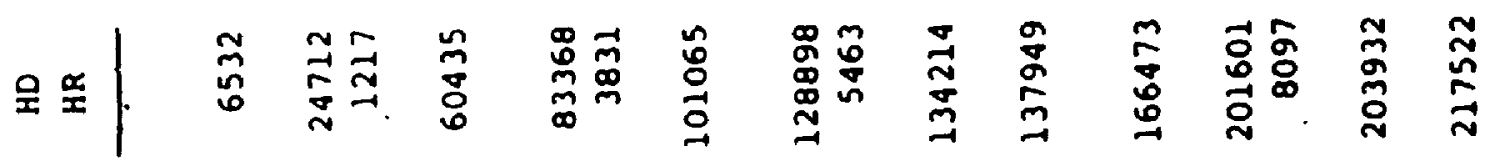




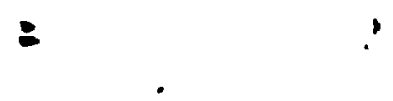

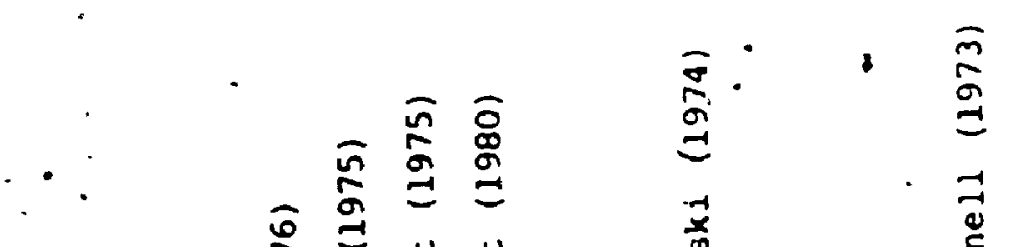

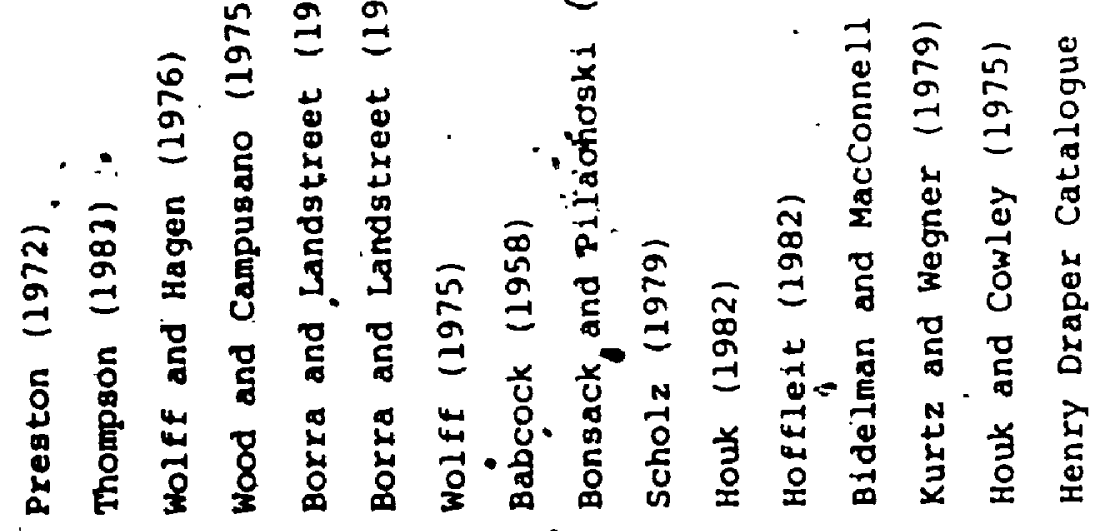

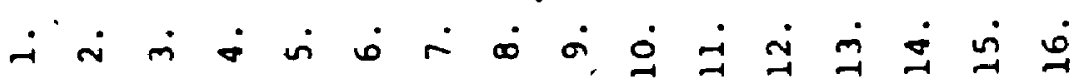
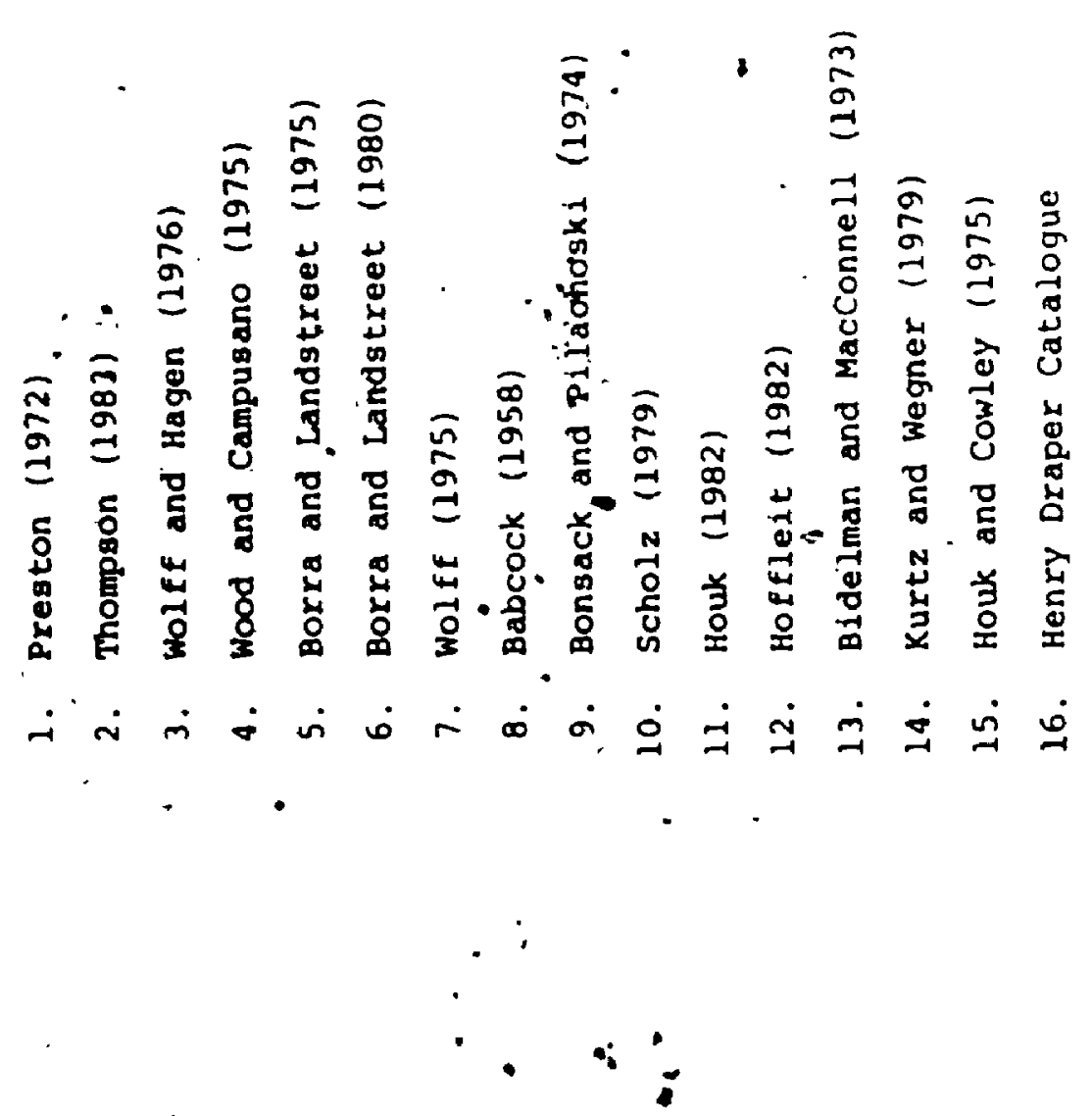

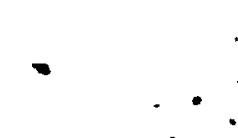


TABLE 1.2

OBSERVED STROMGREN INDICES OF THE TOAP STARS +

\begin{tabular}{r} 
HD \\
\hline 6532 \\
24712 \\
60435 \\
83368 \\
101065 \\
128898 \\
134214 \\
137949 \\
166473 \\
201601 \\
203932 \\
217522
\end{tabular}

217522

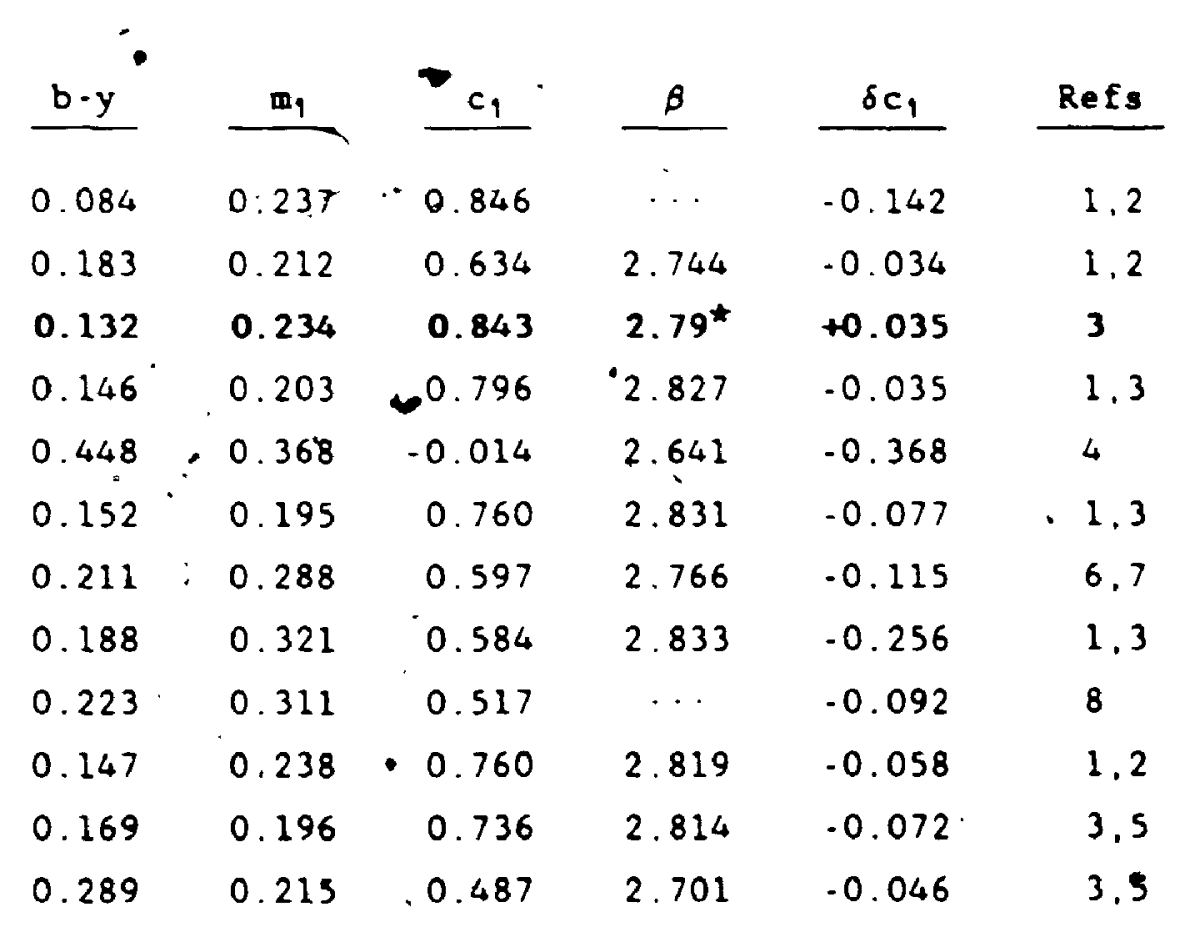

1. Hauck \& Mérmilliod (1980)

2. Blanco et al. (1970)

3. Vogt \& Faundez (1979)

4. Kurtz \& Wegner (1979)

5. Welss (private communication)

6. Olsen \& Perry (1984)

7. Olsen (1983)

8. Kurtz (1986)

+ Adapted from Table 1 of Kurtz (1986)

* Estimated from equivalent width of H $\beta$ by author (Chapter $V$ ) 
TABLE 1.3

REDDENING-FREE STROMGREN INDICES OF THE TOAP STARS

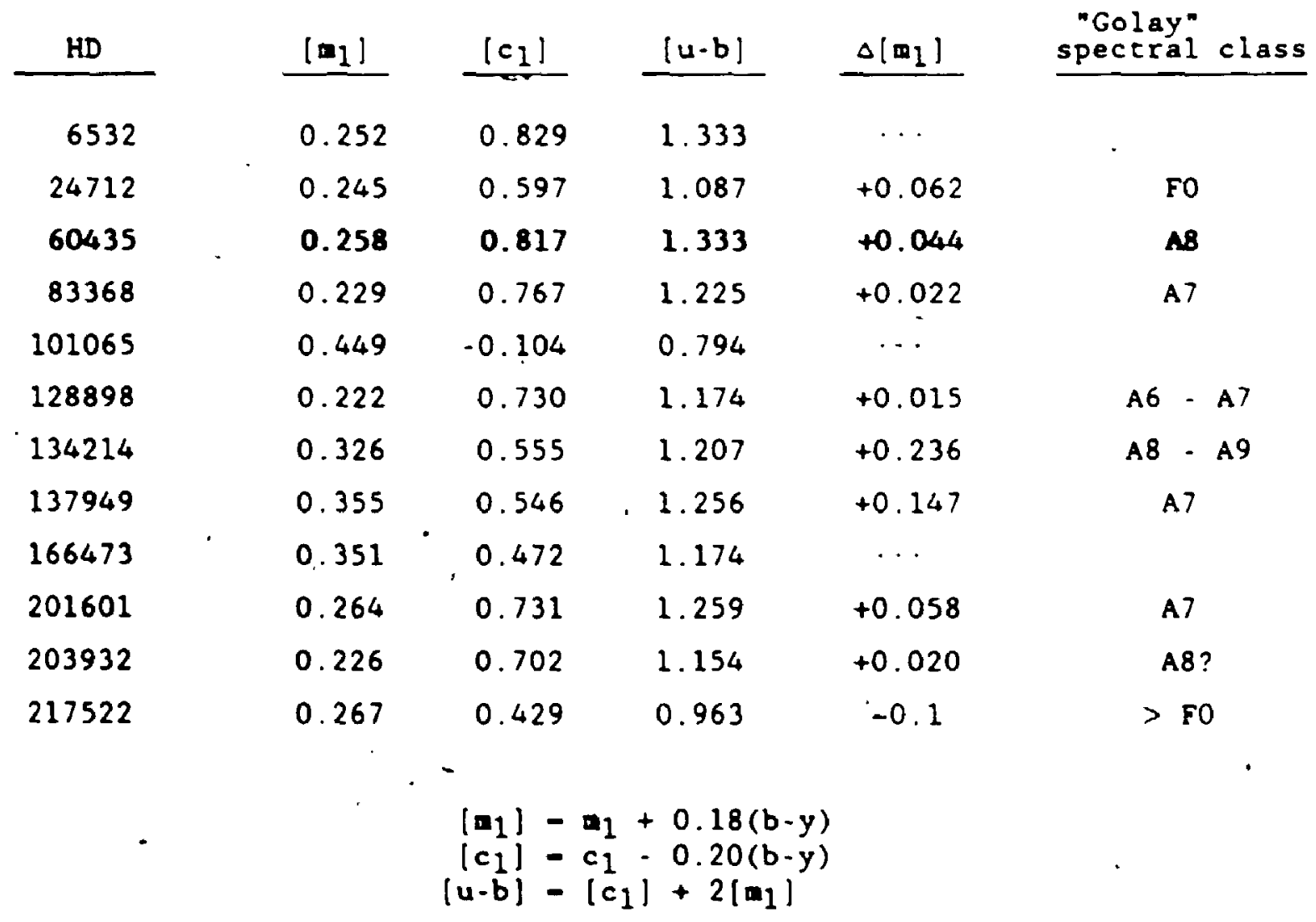


question of whether all of the rodp stars occupy the lower instabllity strip cannot be answered definitely at the monent. given the uncertainties of the derlved $T_{e f f}$ and th values for the pocullar stars. Furthermore, the observed colour boundaries of the $\delta$ scuti strip any not be entirely appropriate for comparison with the location of the roAp stars in the HR diagram. Stepién and Muthsam (1980) have pointed out systematic differences between the temperatures of peculiar and normal A model atmospheres having the sane (B-V) colour. The cooler Ap stars appear to have systematically higher effective temperatures than one would derive for a normal star of the same colour. A simllar effect is probably valid for $(b-y)$.

In fact, the lower (b-y) boundary for the roAp phenomenon is not itself well determined. Most of the surveys for new roAp stars have concentrated on the cooler A-FP stars, introducing a bias to the sample of varlables. Even so, a number of apparently hoter stars with smaller (b-y) have been carefully monitored with rapld photonetry and no oscillations were detected; e.g., the AOP(Si) star HD 92664 (Kurtz, private communication) and the A2p (SrCrEu) star 53 Cam (Matthews and Wehlau 1985; Kreidl 19856).

The $[u-b], \beta$ values of the roAp stars (Tables 1.2 and 1.3 ) fall wthin or close to the main sequence band defined,by Golay (1974a) between $-A 7$ and Fo. A notable exception is Przybylskl's Star (HD 101065). The spectral classes appropriate for "normal" stars with the same values of $[u-b], \beta$ in the Golay scheme are given in the last colum of Table 1.3. All of the roAp stars have $\left[\mathrm{m}_{1}\right]$ values which exceod those of normal stars on Golay's maln sequence and In Crawford's (1979) $m_{1}$ ve. B relation for A-type stars. (This is true of wost, if not all, 
pecullar A stars, since [al] is a netallicity indicator,) All but one of the sars (KD 60435) have $c_{1}$ indices which also fall belot Crawford's standard $c_{1}$ vs. B relation (as skown by $\delta c_{1}$ in Table 1.2). Since $c_{1}$ is usually taken to be a luminosity indicator for A-F stars, this wight seen to suggest that these stars have sub-dwarf luminositles. However, the unusuar lux distributions of the peculiar A stars are likely responsible for the abnormally low $c_{1}$ values.

The reason can be found in the definition of the $c_{1}$ Index:

$$
c_{1}-(u-v) \cdot(v-b)
$$

where the $u$ bandpass mainly samples wavelengths ju'st shortward of the Balner discontinutey of $\lambda 3647$; the $v$ filter, several hundred $\AA$ long ward $\left(\lambda_{e f f} \approx 4100 A\right)$; and the $b$ filter, still further towards the red $\left(\lambda_{\text {eff }} \approx 4700 \AA\right)$. Although the coolest Ap stars do have many absorption ines in the near ultraviolet, they also have relatively little continuw in that region of the spectrum. Therefore, flux redistribution fron the UV is not as important for these stars as it is for the hoter SI Ap stars. However, Baschek' and Oke (1965) and Wolff (1967) found that Iine blanketing in the visible becones significagh for the coolest (or nost pecullar) of the Ap stars. The richness of the absorption spectrum at wavelengths near 4100 a should result in an increase in $(v-b)$ due to blanketing. The increase in $v$ magnitude should also more than cancel the increase in $(u-v)$ due to UV flux redistribution, causIng a net drop in that colour. The end result is a decrease in $c_{1}$ compared to a "norel" star.

If abundance effects were not important, a plot of $c_{1}$ vs. (b-ya) mould essentially be a Leinosity - Teff diegran. Just such a plot of 
the $c_{1}$ and (b-y) indices from Table 1.2 is presented in Figure 1.4 .

Also plotted are lines corresponding to models of aaln sequence stare with solar composition and surface gravities of $\log g-4.0$ and 4.5 (Hauck and Mermilliod 1975), Observe that the roAp stars fall roughly along a line of similar slope to the podels, except for (again) HD 101065. It would appear that any abundance differences among the stars are small enough so as not to destroy the general ain sequence behaviour; rather, the abundance peculfarity manifests itself as an apparent shift of the curve to higher surface gravlty. Therefore, cl (or $\delta c_{1}$ ) way prove to be useful as an indicator of relative iuninosity among the sample of rapid oscillators. (We will returin to this point in relation to HD 60435 in Chapter IV.)

The rapid oscillators all seen to belong to the cooler srCrEu classes of Ap stars, with the possible exception of HD 101065. They are all expected to have the strong ordered algnetic fields norwally associated with peculiar stars. Seven of the 12 stars have been searched for agnetic fields, resulting in positive detections for six (see Table 1.1). The single null detection was obtained for HD 60435 , but this is based on only three measurements of relatively low preci. sion ( \pm 600 gauss). (The magnetic weasurements of $\mathrm{HD} 60435$ and the Ir signiflcance will be discussed in Chapter VI.)

Not all agnetic peculiar stars in the range of colours spanned by the roAp variables are found to be rapid osclllators. Promising candidates which yielded no detectable osciliations after repeaced observations Include $\beta$ ' CrB (Weisg and Kurtz, 1987) and HR 4330

+ This star does exhlbit enhanced rare earths, but the etrongest of these are holniu and dysprosiun. The iron peak eleants are very weak in the apectru, or perhaps missing altogether. 


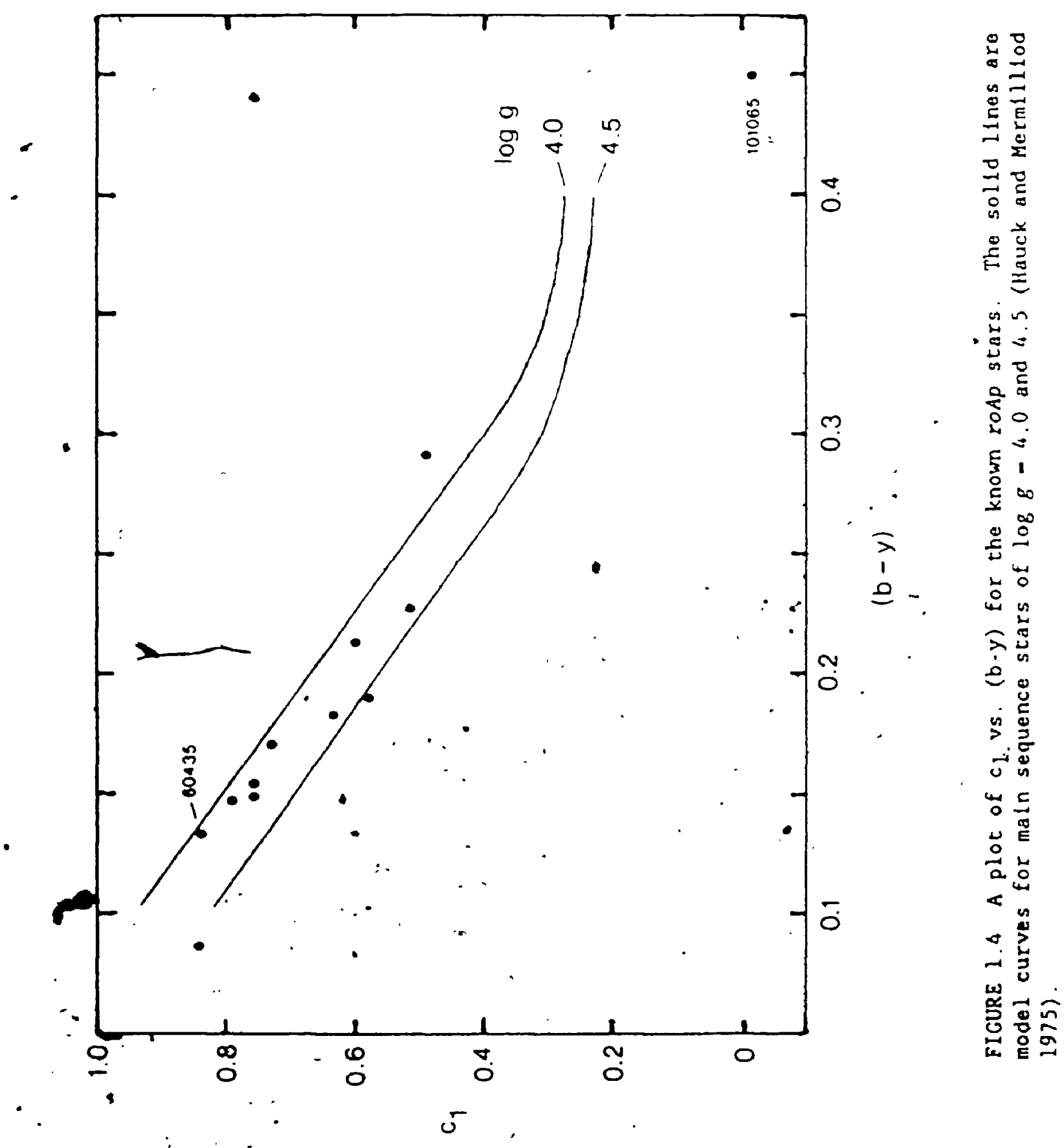


(Mathews and Wehlau 1985) There is clearly some aissing paramecer(s) which distinguishes an ratp star fron other apparently siallar - but constant - cool Ap stars

The classical Oblique Pulsator Model (Kurtz 1982)

The most successful model in explaining the long-cerm varlations observed in Ap stars has been the "obllque rotator". In whlch the axis of the stellar magnetic field (assuned to be dipolejor near-dipole) is Inclined to the rotation axis. As the star rotates, different aspects of the field are presented to the observer, along with abundance and surface brightness anomalies associated with the fleld geometry. This accounts for the equality of the magretic, spectroscopic, and (longterm) photometric perlods of an Ap star, plus features such as polarlty reversal of the magnetic field, often observed In these stars:

Kurtz's oblique pulsator model (OPM) extends this picture to the rapid óscillations by supposing that nonisdial pulsetions in an Ap atar may not be-aligned with the rotation axis - as ts-normally assumed. but rather with the magnetic axis. Hence, different aspects of the pulsation, are observed as the star rotates. This readily explains the observed modulation of the oscillation anplitude with the aagnetic (rotation) pertod of the star. And the obseirved phasing (maximus oscil. lation amplitude with agnetic extremua) arlses naturally if the pulsation pattern is zonal (1.e. - 0). The phase shifts come about tf the magnetic field undergoes polarity reversal; when the star passes chrough quadrature, different zones of the pulaztion pattern (varying In ant1-phase) alternately doalnate the vialble disc, and $180^{\circ}$ fupp in phase are observed. These effects are lllueirated schematically in 
Figure 1.5, wich represents the rotation of an $l-1$, a - o oblique - pulsator with moderate inclination and obliquity (such that polarity reversal of the fleld takes place).

The OPM can also be treated sonewhat wore quanticatively. Consider the noniadial pulsation partern as a simple sphertcal harmonic The luminosity varlations at tbe sub-solar point on the stellar disc may be represented by a Legendre polynomial $P_{2}, 0$. such that

$$
\left.\frac{\Delta L}{L}-T_{2} \operatorname{teg} s\right) \cos \left(\omega\left(t-t_{0}\right)+\phi\right]
$$

where a is the angle between the axis of symmetry of the pulsation and the line of sight, $w$ is the pulsation frequency, and $t_{0}$ and are an arbltrary epoch and phase. The angle a is related to the star's Inclination 1 and the obliquity $\beta$ of its pulsation axis by spherical trigononetry:

$$
\cos \alpha-\cos i \cos \beta+\sin i \sin \beta \cos A
$$

Here: A is the longttude of the pulsation pole on the stellar surface. nosured such that the longlfude of the sub-solar point is $0^{\circ}$. For an oblique pulsator. A - Ot, where $\Omega$ is the angular rotation frequency of the star. so cosa is a perlodic function of time. The angle $\beta$ in equa. tion (1.3) is now the obliquity of the magnetic field, and the epoch to In equation (1.2) is chosen to colnclde with maximun effective magnetic E1.1d.

If. we asume $t-1, P_{l}(\operatorname{cosa})$ - cosa. Equation $(t .2)$ can then be

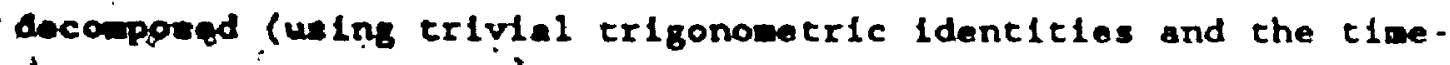
. dependent version of equetion (1.3)) into 

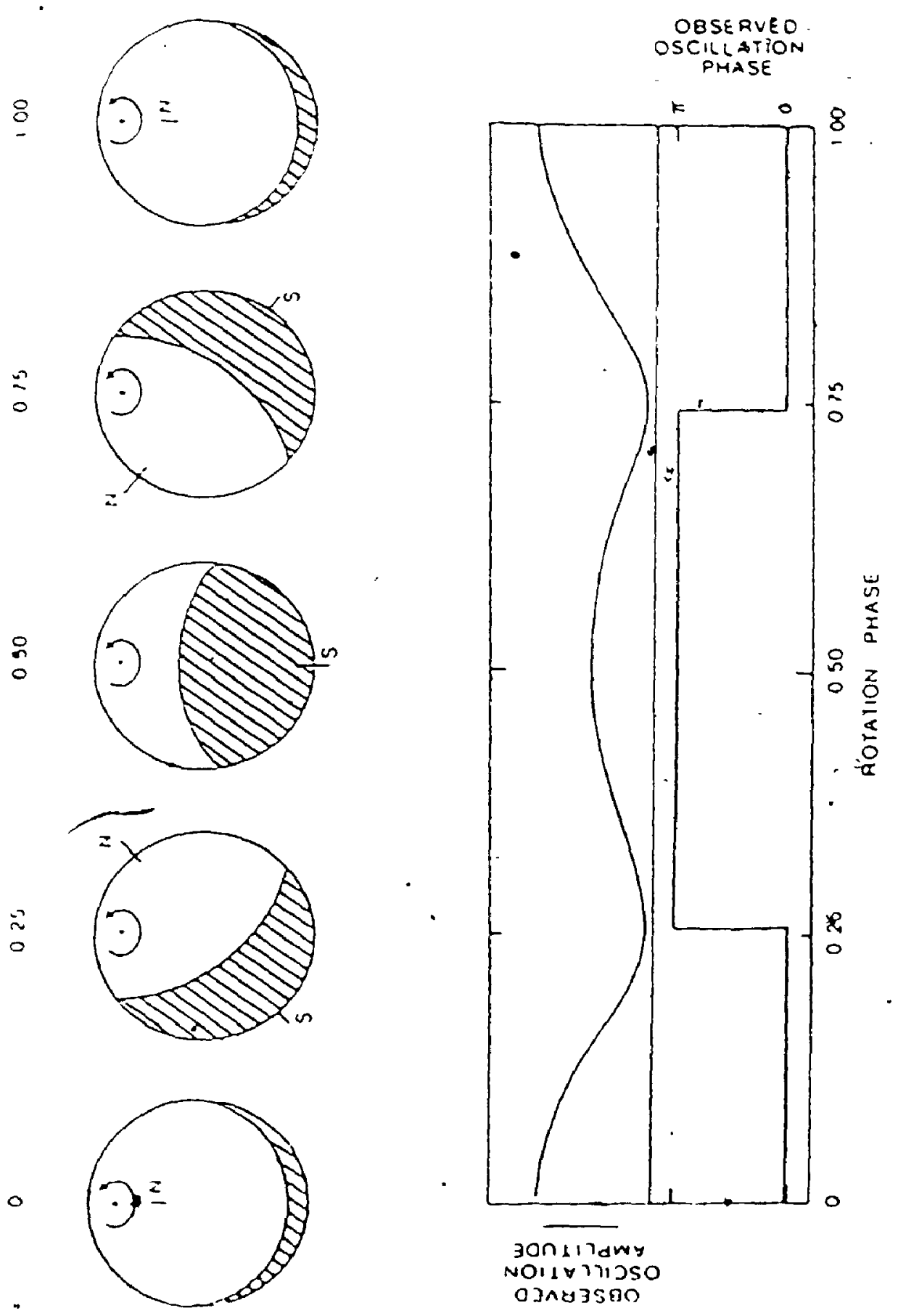

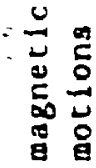

导品泀

5

온

s.
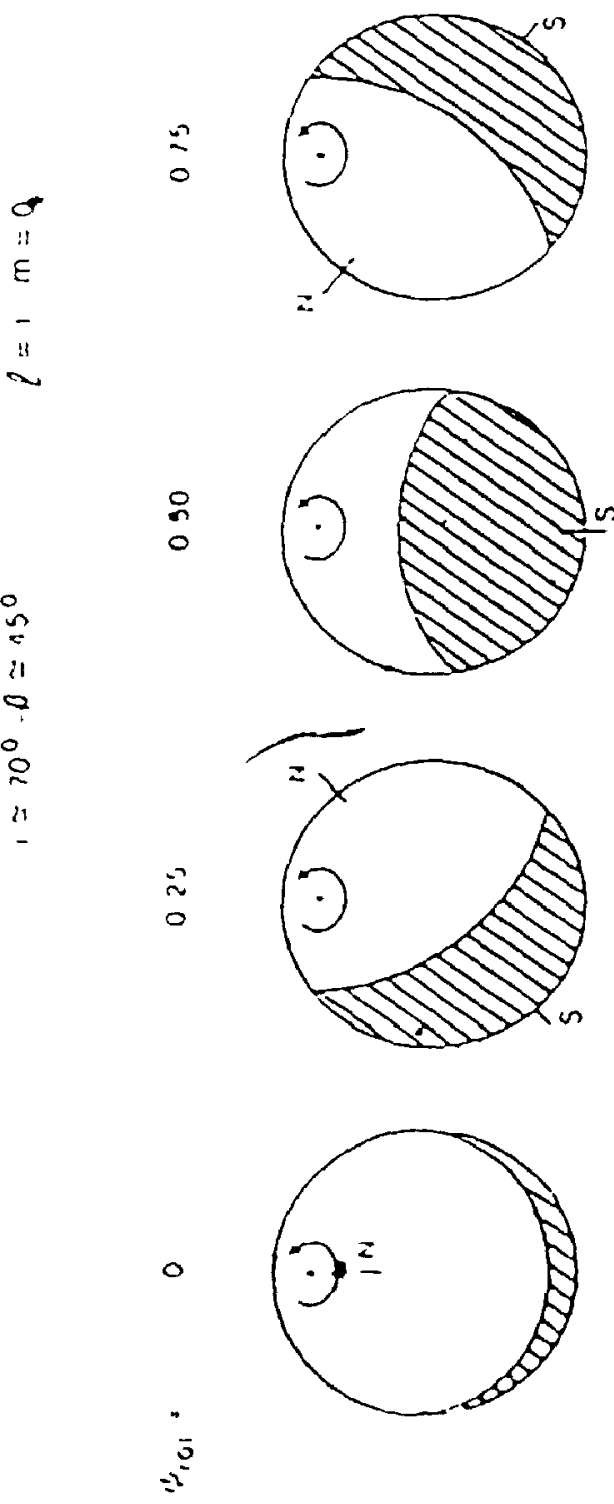

$\checkmark$.

芦豆

ज定

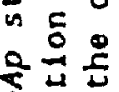

ㄴ.

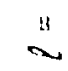

$\circ$
$\because 1$
0
0
0
$\vdots$

NOIL

ब

站卷

ธี

을

号宫

今ั

䓃苛

당 
$\frac{\Delta L}{L}-A_{0} \cos \left(\omega t^{\prime}+\phi\right)+A_{1}\left(\cos \left((\omega-\Omega) t^{\prime}+\phi\right)+\cos \left((\omega+\Omega) t^{\prime}+\phi\right)\right)$

where $t^{\prime}-t \cdot t_{0} \cdot A_{0}-\cos 1 \cos \beta$, and $A_{1}-2 \sin 1 \sin \beta$. In other words. the oscillation 1: split into a frequency triplet whose central couponent 1s at the osctilation frequency in the star's rest frane and whose sidelobes are spaced by thr star's rotation frequency. (Note that when cosa changes $s \mathrm{gn}$, then $-P_{1} \cos \left(\omega t^{\prime}+\infty\right)-P_{1} \cos \left(\omega t^{\prime}+\infty \pm x\right)$, which re produces the observed phase shifts at agnetic quadrature.)

A siallar expansion for $l-2$ shows that a frequency quintet is produced with the same spacing. In geveral, the opM predicts that a mode of degree $l$ wlll be split inta $(2 l+1)$ components, centred about the oscillation frequency in the star's rest frame and spaced by its rotation frequency. Thls type of frequency splitting has been observed in the Fourler spectra of several rosp stars (Kurtz 1982).

Kurtz's OPM 18 a purely phenomenological model; it does not attempt to explain the underlying mechanisa by which the aagnetic fleld controls the pulsation geonetry.

One difflculty with Kurtz's simple nodel is that Coriolfs forces on the obliquely rotating pulsation pattern should tend to make the pulsation axis precess with respect to the agnetic axis (1.e., advec. (ton). Therefore, the peaks in oscillation amplitude should not remain In phase with the angetic maxima. However, several years of abservation of roAp stars such as HR 1217 (Kurtz ot al. 1985) have shown that the phase equality holds to high precision.

To avold this apparent paradox, Dolez and Gough (1982) proposed that the angetic field alght selectively excite wodes which are alignied with it. They estimated the lifetimes of the exclted wodes to 
be shore (hours) compared to a typical rotation period (days). Thus, as the fleld is carried around by rotation, the modes which are no longer favourably oriented with that fleld die out quickly, while now modes áre in turn generated. Th picture is not without its problens. as well. It is difficule to ufderstand how individual pulsations can maintain phase coherence over long intervals of time (as is observed) if modes are being continually re-excited. Also, the rotation perlod of one of the roAp stars, HR 3831 - HD 83368, is under two days (Kurtz and Marang 1987); modes must have very short lifetides in this sta for the selective excitation process to be effective.

The "dynamical" Oblique Pulsator Model (Dziembowskl and Goode 1985)

The complexicyeof the Dolez and Gough scenarlo, and its Incomplete success in accounting for the observations, led Dzleabowski and Coode (1985) to return to Kurtz's "classical" OPM and show how the amplitude modulation is consistent with the perturbing effects of both a magnetic field and rotation.

Consider first a nrotating, nonmagnetic pulsating star. The eigenfunctions of its pulsation modes $(l, m)$ may be expressed in terms of the spherical harmonics $\xi_{\ell m} \propto Y_{l}(\theta, \phi)$, where the reference frane for $\theta$ and is completely arbitrary. If a dipole magnetic field is then Introduced. the Lorentz forces due. to the fleld lines can modify the equilibrium configuration of the star, causing an asymetry euch that the normal modes now satisfy $\xi_{\ell} \propto Y_{\ell}\left(\theta_{H}, \phi_{H}\right)$. where.the magnetic axis is defined as ${ }^{\circ}=0$.

The fleld also perturbs the elgenfrequencles of the oscillations:

$$
w_{l, m}-w(0)+w_{l,|g|^{\operatorname{mag}}}
$$




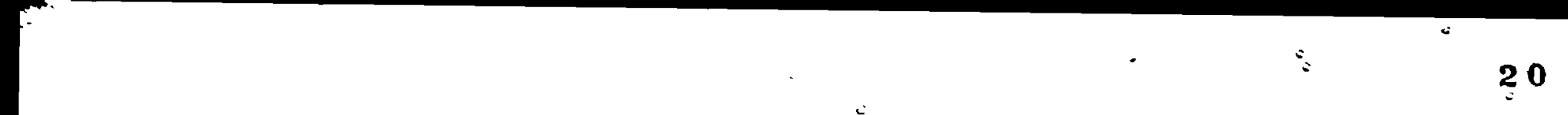

where $w(0)$ is the frequency in the absence of a agnetic field, and

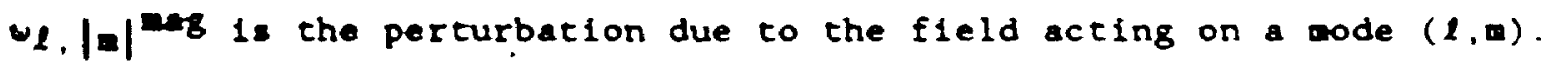
Therefore, the elgenfunction becones

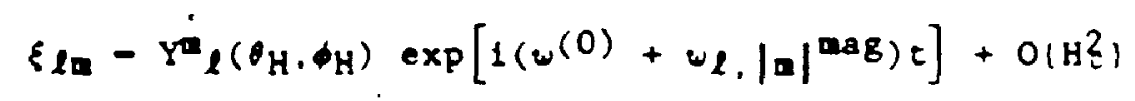

where $--l, \cdots, l ;$ and the last term represents the effect of the fleld on the. equilibriun state of the star (of order $H^{2}$ ).

Adding the effects of rotation about an axis inclined by an angle $\beta$ to the magnetic axis, and neglecting the equilibrium term of order $H^{2}$ :

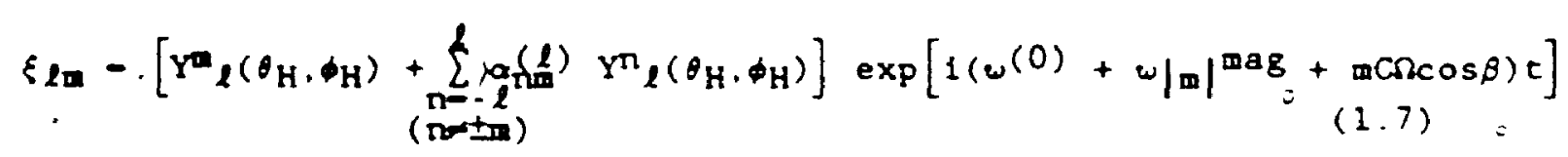

where the ters ancos $\beta$. Is the rotational splitting derived by Alzenman et a1. ( $\$ 984)$ : C is the Ledoux constant (see Appendix A), and $\cdots$

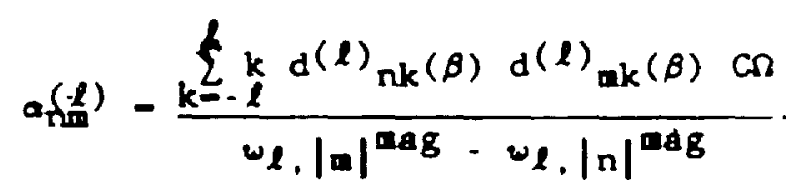

Th1s latter tern contains the transformation from the reference frame of the aegnetic field to that of the rotation axis, by applying the well-known Clebsch-Gordon coefficients $d^{(l)}{ }_{n k}(\beta)$ to the spherical. harwonics according to the following expansion.

$$
Y_{l}\left(\theta_{H}, \phi_{H}\right)-\sum_{n=-}^{l}(l) \operatorname{mn}(\beta) Y_{l}^{n}\left(\theta_{R}, \phi_{R}\right)
$$

where $\left(\rho_{R}, \phi_{R}\right)$ are measured relative to the rotation axis.

For the case of ade with $(l, a)-(1,0)$, then the appropriate attix of Clebsch-Gordon coefficients can be written as (Kurtz and Sh1bahash1 1986), 


$$
d(\beta)=\left(\begin{array}{ccc}
\frac{1}{2}(1+\cos \beta) & \sqrt{2} \sin \beta & \frac{1}{2}(1-\cos \beta) \\
\sqrt{2} \sin \beta & \cos \beta & \sqrt{2} \sin \beta \\
\frac{1}{2}(1-\cos \beta) & -\sqrt{2} \sin \beta & \frac{1}{2}(1+\cos \beta)
\end{array}\right)
$$

and equation (1.7) can be solved for the relative varlation in luminosity using the capproach of Dzlembowsiki (1977), giving...

$$
\frac{\Delta L}{L}-A_{0} \cos \left[\left(\omega(0)+\omega^{\operatorname{mag}}\right) t+\Phi\right]+A_{+1}\left(\cos \left[\left(\omega(0)+\omega_{0}^{\operatorname{mag}}+\Omega\right) t+\Phi\right]\right\}
$$

where $A_{0}-\cos i \cos \beta$, and

$$
A_{1}\left(\cos \left(\left(\omega(0)+\omega_{0} \operatorname{mag}^{\circ}-\Omega\right) t+\phi\right)\right)
$$

$$
A_{ \pm 1}-4 \operatorname{sinisin} \beta\left[1 \pm \frac{C \Omega}{w_{1}^{\text {mag }} \cdot w^{\text {mag }}}\right] \text {. }
$$

Note that this result is very similar to that of the classical opM(equation 1.4), in that the dynamical model also predicts that an $(2, m)$ - $(1,0)$ mode should be split into three components spaced by exactly the rotation frequency of the star. However, the amplitudes of the sidelobe components are now governed by the relative perturbations from the rotation $(-C \Omega)$ and the magnetic field (w mag - woma). The use of this in the interpretation of HD 60435 will be discussed in Chapter VI. $r$

\section{The Spotted Pulsator Model (Mathys 1985)}

Whereas Dzlembowski and Goode have argued that global magnetic field can force the pulṣation pattern to corotate with the fleld axis. Matbys (1985) has proposed an alternative model to explain the ampl1tude modulation which does not require the pulsation node to be ymetric about the angnetic axis. His spotted pulsator model can reproduce the observed nodulation by Invoking inhomogeneous distributions of surface brightness $F(\theta, \phi)$, as well as the amplitude ratio $f(\theta, \varphi)$ pd phase 
lag $\downarrow(\theta, \theta)$ of the flux and radius osclilations.

Unfortunately, a given arplitude modulation curve for an roAp star does not correspond to a unlque conbination of $F, f$ and $\phi$, so the nodel is very difficult to test against observation.

\section{Cause of the varlations}

The mechanfer which produces the oscillations in these variables has not yet been established. The two leading contenders are considered to be: an envelope lonization (or "kappa") mechanism, like that which governs the pulsatimg $\delta$ Scuti stars (Appendix A), and "overstable magnetic convection".

The forwer is attractive because the position of the roAp stars on the HR diagran appears to overlap a known region of pulsational instabllity, that of the $\delta$ Scuti variables. However, there are several unanswered questions associated with this interpretation. First, the perlods of the roAp stars (minutes) are much shorter than those of the $\delta$ Scut gtars (typlcally about two hours); the rapld oscillators are apparently pulsating in much higher overtones. Why? Does the magnetic fleld play a role in damping all but the higher overtones? Second, if diffusion is occurring in the acnospheres of Ap stars, then one would expect that nost - If not all - of the hellun w111 have setiled below the HeII Ionization zone (the aln source of the driving in $\delta$ Scut 1 acara). Surveys (e.8. Kreldl 1987) appear to Indicate that Ap stars and \& Scuti-timescale varlabllity are mutually-exclusive. Perhaps the reaton for this exclusion is not the complete remoyal of he from the Ionlzution zone in Ap stars, but again the possible selective excita. tion/daping of certaln overtones by the nagnetic field. 
An alteriative mechanisa for the excltation of rapid oscillations

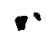

In Ap stars has been proposed by Shibahashi (1983): overstable aagnetle convection. (See also a more qualitative treatment by $\operatorname{Cox}\left(1984 \mathbf{a}^{\text {). }}\right.$ ) , This overstability arises from the resistance of the tension of the magnetic field lines to the convective motions in the atmosphere. If the convective motions occur in a superadiabatic region, that region would be convectively unstable if no field (or abundance gradient) is present. If a fleld is present, then the "restoring" force applied to a rising element of plasma will increase, and the result will be oscll. lations of increasing amplitude. Cox (1984), using reasonable values for the magnetic field and atmospheric parameters, derives oscillation perlods of several hundred seconds, in the same range as the observed values.

Currently, there is no definitive observational test to choose one of these mechanisms over the other. However, the discovery of a magnetic roAp star far outside the instabllity strip would constitute strong evidence in favour of overstable magnetic convection.

\section{$\underline{\text { HD } 60435}$}

This star is one of the more recent additions to the class of rodp varlables. It is the faintest $(V-9.00)$ of the known oscillators and the second most southerly ( 1950 coordinates: a $-07^{\text {h }} 30^{\text {s }} 018.8 ; \delta-57^{\circ}$ 53. 03:9). Kurtz (1984) flrst detected perlods near 12 and 6 minutes in this star in 1983. His 16 -night observing run adso revealed dramatic amplitude modulation of both oscillation. The "6-inute" oscilletion appeared to be transient, appearing only when the "12-atnute" oscillation was present at its largest amplitude. Unforturately, the 
data were insufficlent for a thorough study. of the frequencyl spectrum and any characteristic aplitude nodulation.

HD 60435 had not garnered much attention prior to the discovery of its rapld oscillations. Kurtz inclúded it in his rosp search programe at the South African Astrononical Observatory (SAAO) because of 1 ts classification by BIdelman and MacConnell (1973) and Houk and Cowley (1975) as Ap SrEu, and its relatively large (b-y) index of 0.132 .

This study of HD 60435 was undertaken with the Initial aims of

1) identifying the frequencies present in the star;

11) deteraining a modulation period/timescale and a long-term photometric perlod/tinescale as a test_of the OPM:

111) obtaining amplitude spectra. with sufficiently high resolution and suppressed cycle/day aliasing, to investigate the fine. splitting of frequencies in the context of the OPM; and

Iv) using these data to infer sone of the physical properties of the star.

Although the intial lack of supporting data on the star (e.g. rotation perlod, strength and variabllity of magnetic field (if any)) could be copsidered a handlcap to such a study, it also made HD 60435 an excellent proving ground for the role of oscillation observations and the oblique pulisator nodel in studying Ap stars. 


\section{Rapid photometry}

Studying the short-term light variations of a star like HD 60435 presents several problems to the observer, the most serfous of which are the high time resolution required and the spectral aliases inherent in the frequency analysis of astrononical time serles.

Reliable detection of stellar oscillations with periods of anly a few minutes demands monitoring of the star with a sampling interval of less than one minute ${ }^{+}$. One is left with two options: 1) differential measurements using a "multi-star" photometer (or potentially, a caltbrated imaging device such as a CCD detector), or i1) non-differential photometry with a conventional single-channel instrument.

In principle, the first alternative is ideal; the necessary time resolution is achieved with continuous compensation for extinction. changes through simultaneous readings of one or more nearby compertion stars: In practice, however, the fact that no major southern heml. sphere observatory (from which HD 60435 could be observed) is presently equipped with a multi-star photometer and the difflculties associated with bringing a visitor instrument to such an observatory, make this option less viable.

Fortunately, non-differential photometry can be used to decect oscillations with perlods as long as 12 alnutps from an observing site of suitable quality, as was. previously demonitrated by Kurtz (e.s.

+ It has been demonstrated theoretically (Beutler 1966) that a period $P$ can be extracted via Fourler techniques frod data containing a pertodic signal, even if the average sampling interval is as long" as $P / 2$. However, in practice, one ragely has a sufficlently large sample and the high ignal-to-nolse ratio necessary to ake this-possible. 
1982). The success of these observations hinges on the temporal incoherence and small amplitude of sky variations at short timescales on a good nighe.

Given atable photoneter system, the major sources of noise are these sky transparency (and background) fluctuations, and scintillation. Clarke (1980) has found that, even under the best conditions. the former can have auplitudes of order $0^{m 00}$ in a period range from anutes ${ }^{2}$ to tens of anutes. Scintillation noise, on the other hand, is primarily a function of telescope aperture. However, experiments by Kurtz (1985) using a 0.5 - and $9.9-0$ telescope indicace that, for perlods near ffue alnutes, and longer, scintillation is not the dowinant contributor to the liniting nolse in rapid photometry.) Therefore, the only constralnt on telescgpe aperture in this type of lobserving is that 1t be large enough to make the photon noise in a single integration (where the integration ilme must be less than half of the shortest period of interest) smaller than the scintillation noise. For relati. vely bright stars such as HD 60435 , this can be attained with a celescope in the 0.5 - to 1- class.

The other anjor dyfficulty is one comon ta any search for periodlcitles, in data with large gaps: spectral allasing. (This will be discussed in greater detall in the next chapter.) The topic is introduced here because aliasing is a product of the time sampling of the observations, and it is bost effectively dealt with at the observing stage, If permitted by scheduling constralnts. The most severe allases are those with spacings of 1 cycle/day, which arise fron the natural diurnal pattern of nightetive estrononical observations. The problem is exacerbated in the case of the rapldiy oscillating Ap stars by the pre- 
sence of many closely spaced and/or rotationally-split frequencles in several of these variables. Identification of each true frequency from its aliases (and those of other neighbouring frequencies) is not alvays a simple matter, particularly if the incrinsic frequency spacing is close to an integer multiple of l cycle/day.

By reducing or ellainating the large gaps between sets of obser. vations, one can in turn reduce or elininate the corresponding aliases in. the frequency spectrum. Strategies for continuous monteoring of a star from a single site involve the use of a near-polar station or a satelite in a sultable orbit. Suftable faclities for'rapid stellar photometry do not currently exist to reallze either of these options. A more practical approach is to make contiguous sets of observations

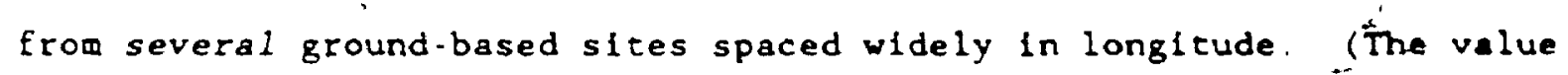
of an observing programe like this was aptly demonstrated by the history of the frequency analysis of the rapld oscillator HR 1217. Kurtz (1982), on the basis of his SAAO observations alone. identffled only two frequencies in this star. each finely-split into a triplet. Concemporaneous observations made later from both South Africa and Chile (Kurtz and Seeman 1983) showed that allasing in the earlier data set had masked. the true pattern of six equally spaced frequencles.) In principle, given clear weather and an appropriately-placed star, a minimum of only three observatorles located at 8-hour intervals in longltude could offer complete dally coverage of the star and the elinination of the cycle/day allases in the frequency analysis of the data. (Feastbility and site-testing studles carried out for proposed global monttoring of the Sun (e.g. Global Oscillation Network Group 1985) recomend a inimu of six station to achreve a -92 duty cycle.) 


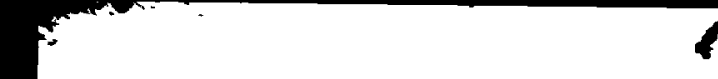

For this trvestigation of HD 60435, rapid photonetry was carried out in two capaigns from three locationst (observers are indicated in boldface) :

a) the Las Camanas Observatory (LCO), Chile, using the University of Toronto 0.6-n telescope and 1P21 (S-4) photoneter (the wthor):

b) the terro Tololo Inter-American Observatory (CTIO), also in Chile, using its oig-e telescope and photoweter, with an FH-130 (S-20) phototube (the autbor); and

- e) the sucherland secacioin

c) the Sucherland station sian, using its $0.5-\mathrm{m}$ telescope (and on three nights, the 0.75- telescope) and The People's Photoneter. 'with an S-20 tube (Dr. Donald Furtz and his assistant, Fred Marang).

The observing campaigns, conducted prinarily in the early wonths. of 1984 and 1985, resulted in a rgeal of 64 nights of data of which 11 vere contiguous or overlapping between SAMO and one of the Chilean sites. Since only two longltudes vere avallable, dafly gaps in the resultani date were unavoldable; the longest "continuous" run lasted arout 14 hours. However, the mere shortening of sone of the daily gaps In the record serves to reduce the amplitudes of the cycle/day sidelobes In the Fourler spectra and thus to clarifs the identification of. the trus frequincies.

The observing routines at all three observatories were essentially the sav. Meseurements conststed of continuous 20-second integrations of 600435 through a Johnson B fllter. (A broad bandpass was necessary op enoure sufficlently high photon count rates. White light mesurmants would givantee good rates, but would have ande extinction + An observer had bean recrulted to monitor the star from a fourth obearvatory In ker zealand during the 1985 cimpilgn, but no resalts wro obcaind from there. 
corrections and comparisons to the resules of other observers nore difficult. The Johnson systen had already been euplayed by previous

- observers in che fleld; the B filter was chosen since earlier bulticolour observations of roAp stars (e.8. Kurtz 1980) Indicated that oscillation amplitudes are much smaller in V.) A large (-30.40 arcsec) dlaphr̈aga was used to alninize edge effects and guiding errors. Star - observakians were occasionally interrupted for sky background aesurements and telescope guiding. (At CTIO, however, an offset gulder was employed.) Sky readings were made as often as once an hour when the moon was above the horlzon, but spaced.aperiodically to avold introducing additional allases to the data.

Typlcal stellar counting retes, at the LCO telescope werf -12000 counts $\mathbf{s}^{-1}$; at CTIO, -23000 couniks $s^{-1}$. The sky background varled between about 158 (during full woon and aty large zenith distances) down to 0.28 (during "dark time") of the perlar photon flux.

Numbers of counts and starting times of integration were automat 1 cally recorded by computer on varlous medla, depending on the observatory and year (e.g. LCO 1984 - thermal printer tape; LCO 1985 - floppy disk; CTIO - agnetic tape). The times were obtained from the conputers Internal clocks, synchronfzed at the beginning of each night with WrV standard time signals to within 0.5 second or better. (The drift of each of the clocks was less than 1 second $\ln 24$ hours.)

A complete 108 of observations is provided in Table 2.1 , 11sting calendar and Julian dace, observatory and observer, length (In hours) and number of integratione per night, and the ecendard deviation, 0 (in mag), of one 20-sec integration relative to the nlghtly wan. (The tern $\sigma$ conteine contributions from the palseon nolse of the nessure. 


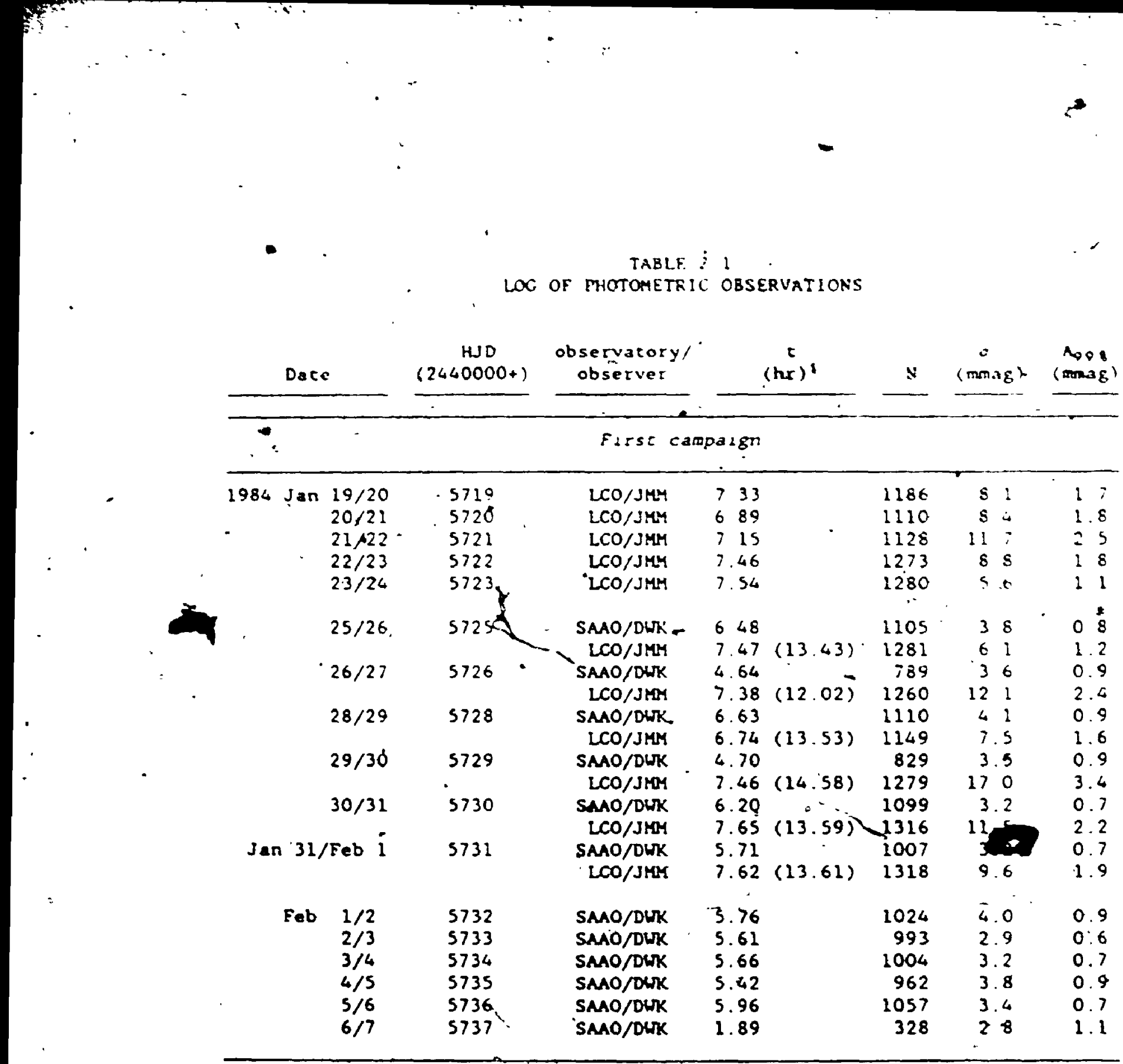

Second cenpeign

\begin{tabular}{rlllllll}
\hline 1984 Nov $13 / 14$ & 6019 & SMAO/DUK & 1.32 & & 217 & 4.5 & 2.0 \\
$15 / 16$ & 6021 & SMO/DUN & 1.20 & & 204 & 4.9 & 2.2 \\
$16 / 17$ & 6022 & SMO/DWN & 2.82 & & 477 & .4 .7 & 1.4 \\
$17 / 18$ & 6023 & SMO/OWN & 2.65 & & 452 & 4.8 & 1.5 \\
$18 / 19$ & 6024 & SMAO/DWN & 2.76 & & 485 & 8.3 & 2.5
\end{tabular}

(conclnued) 


$$
\begin{aligned}
& \text { TABLE,? } 1 \text { cont } d
\end{aligned}
$$

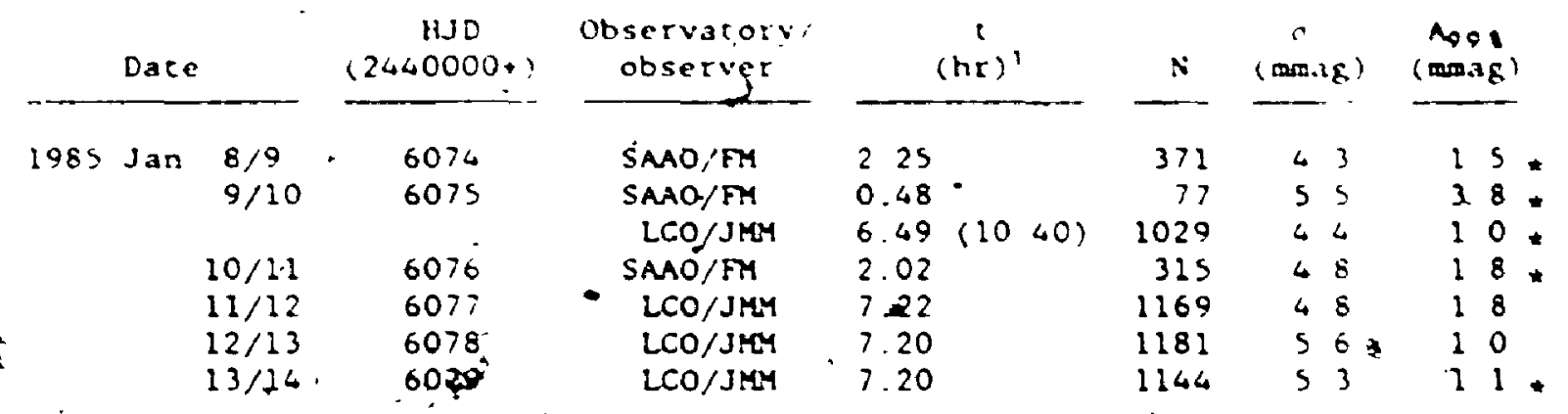

$$
\begin{aligned}
& \begin{array}{l}
16 / 17 \\
17 / 18
\end{array} \\
& 21 / 22 \\
& 26 / 27-6092 \\
& 27 / 28 \quad 6093 \\
& 28 / 29 \quad 6094 \\
& \text { - } 29,30 \quad 6095 \\
& 30 / 31 \quad 6096 \\
& \text { Jan 31/Feb 1 } 609 \\
& \text { Feb } 1 / 2 \quad 6098 \\
& 2 / 3 \quad 6099 \\
& 3 / 4 \quad 6100 \\
& 4 / 5 \quad 6101 \\
& 5 / 6 \quad 6102^{\prime} \\
& .6 / 7 \quad 6103 \\
& 7 / 8 \quad 6104 \\
& 8 / 9 \quad 6105 \\
& 9 / 10 \quad 6106 \\
& 10 / 11 \quad 6107 \\
& 11 / 12 \because 6108 \\
& 12 / 13 \quad 6109 \\
& 13 / 14 \quad 6110 \\
& 14 / 15 \quad 6111 \\
& 15 / 16-6112 \\
& \text { Mar } 19 / 20 \quad 6144 \\
& 6144 \text { SAMO/DEK } \\
& \text { SAAO/FM } 2.00 \\
& \text { SAAO/RH } 0.47 \\
& \text { SAAO/FM } 174 \\
& \text { SAAO/DWK } 2.93 \\
& \text { SAAO/DWK } \\
& \text { SAAO/DLK } \\
& 1.99 \text {. } \\
& 1.95 \\
& \text { LCO/JMY } 6.59(12.82) \quad 1027 \\
& \text { SAAO/DWK } \quad 5.63 \quad 947 \\
& \text { LCO/JMY } 4.85(10.81) \quad 775 \\
& \text { SAAO/DHK } \\
& 1.19=182 \\
& 4.56(7.54) \quad 722 \\
& 0.91 \\
& 4.88(6.51) \\
& 4.89 \\
& \text { LCO/JMA } \\
& \text { LCO/JMI } \\
& \text { SAAO/DWK } \\
& \text { 1. } 76 \\
& \text { 5. } 38 \\
& 5.67 \\
& 6.40(12.77) \quad 1051 \\
& \text { SAAO/DWK } \\
& 7.41 \quad 1235 \\
& 1.61 \\
& 7.51(13.36) \quad 1253 \\
& 7.47 \\
& 7.22 \\
& 6.70 \\
& 5.52 \\
& 6.48 \\
& 4.33 \\
& 6.31(12.54) \quad 1084 \\
& 6.61 \quad 1144 \\
& 5.22 \\
& 6.43 \\
& 6.61 \\
& 1265 \\
& 1211 \\
& 1139 \\
& \begin{array}{l}
60 \\
47
\end{array} \\
& 50 \\
& 8727 \\
& 1224: 4 \\
& 7125 \\
& 1393.0 \\
& 972.2 \\
& 591.5 \\
& 4722 \\
& 1112.8 \\
& 54 \quad 2.8 \\
& 83.21 \\
& 7.2 \quad 1.7 \\
& 7.2 \quad 2.8 \\
& 8.82 .0^{\circ} \\
& \text { 8. } 61.9 \\
& 490.9 \\
& 5.0 \quad 1.0 \\
& 6.6 \quad 2.8 \\
& 6.0 \quad 1.2 \\
& \text { 3. } 6 \\
& 4.4 \\
& \text { 3. } 7 \\
& 6.5 \\
& 4.1 \\
& 5.2 \\
& 3.2 \\
& \text { 3. } 1 \\
& \text { 2. } 5 \\
& \begin{array}{r}
894 \\
1091
\end{array} \\
& 1144 \\
& 3.3 \\
& \begin{array}{l}
97 \\
0.8
\end{array} \\
& \begin{array}{l}
0.8 \\
1.5
\end{array} \\
& 0.9 \\
& 1.4 \\
& 0.7 \\
& 0.6 \\
& 0.6 \text {. } \\
& 0.6 \\
& \text { CTIO/JHA } \\
& \text { CTIO/JPM } \\
& 1.29 \\
& 222 \\
& \text { ०5. } 2 \\
& 1.1
\end{aligned}
$$


ments, sky transparency variations during the night, and any intrinsic variability of the star itself).

The final colum of Table 2.1 offers an estinate of the ainimu amplitude, Ag9: (again in mag), of anj oscillation which showld be detectable with 99 confidence in a Fourier perlodogran of each night of data. This parameter is based on Scargle's (1982) "false alam probability" for properly ngralized spectra of unequally-spaced time serfes. (This is also discussed in greater detall in the next chapter.)

\section{Dete reduction}

The Tav LCO and CTIO photonetric neasurenents were reduced by the author at two. (The SAAO observations were provided by Dr. Kurtz in the for of instrumental magnitudes already normalized to a mean of zero.) The reduction procedure involved:

1) Linearly interpolated sky subtraction.

11) Coincident pulse (or "dead tinen") correction, by a simple comionly-used formula (b.g. Harris et al. 1981) valid for counting rates loss than $0.5 \mathrm{MHz}$ (Fernie 1976)

$$
N=n[1+r n] \text {. }
$$

where $N$ - actual photon arrival rate at the detector, $n$ - number of pulses generated, and $r$ - the "dead tipe" of the tube/predmplifier comblnation (1.e. the shortest time between two photon arrivals in which two distinguishable pulses will be produced). The quoted values of For the systams usad all fell noar $10^{-9}$ seconds. In any event, for the maxime countiog rates encountered in this programe, the coincidance corrietion la not very important. 
111) Correction for atrospheric extinction. For the infstal reduc. tions, a mean first-order extinction coefficlent, $k_{B}$, for each site was employed. (The coefficlent $k_{B}$ represents the aggint of light (in angnitudes) absorbed by one ait ass (1.e. the thickness of atrosphere in the direction of the zenith) as neasured through the B bandpass. It is usually estinated by neasuring the brightness of a star known to be intrinsically constant at several zenteh angles and plotting those argnitudes vs. Alr mass. On a stable night, and if the zentth angles are less than about $60-70^{\circ}$. the points should fall along a stralght line whose slope is $k_{B}$.)

When the rapid and long-tern photonetrlc behavlour of HD 60435 was betcer understood, $k_{B}$ was calculated using the programe star itself: The star's mean intrinsic varlability is considerably less than - 0 ofol In B over a 7-8 hour interval. Once this was recognized, observations of HD 60435 were averaged in bins of 20 -ainute duration to renove the effects of the rapid oscillations. These averages were then used to construct a plot of instrumental magnitude vs. alr mass. A least squares stralght-line fit to the polnts ylelded an estiaate of $\dot{k}_{B}$. The extinction coefficlents so derived are recorded in Table 2.2.

iv) Conversion of recorded times to hellocentrlc Julian dates, centred on the actual intervals of integration.

An example of : 11 ght curve of HD 60435, In which the -12-ainute" oscillations first found by Kurtz (1984) are easlly seen above the nolse, is presented in Figure 2.1 .

\section{Mean photometry}

A rapldry oscillating Ap etar also any be expected to exhibit the 


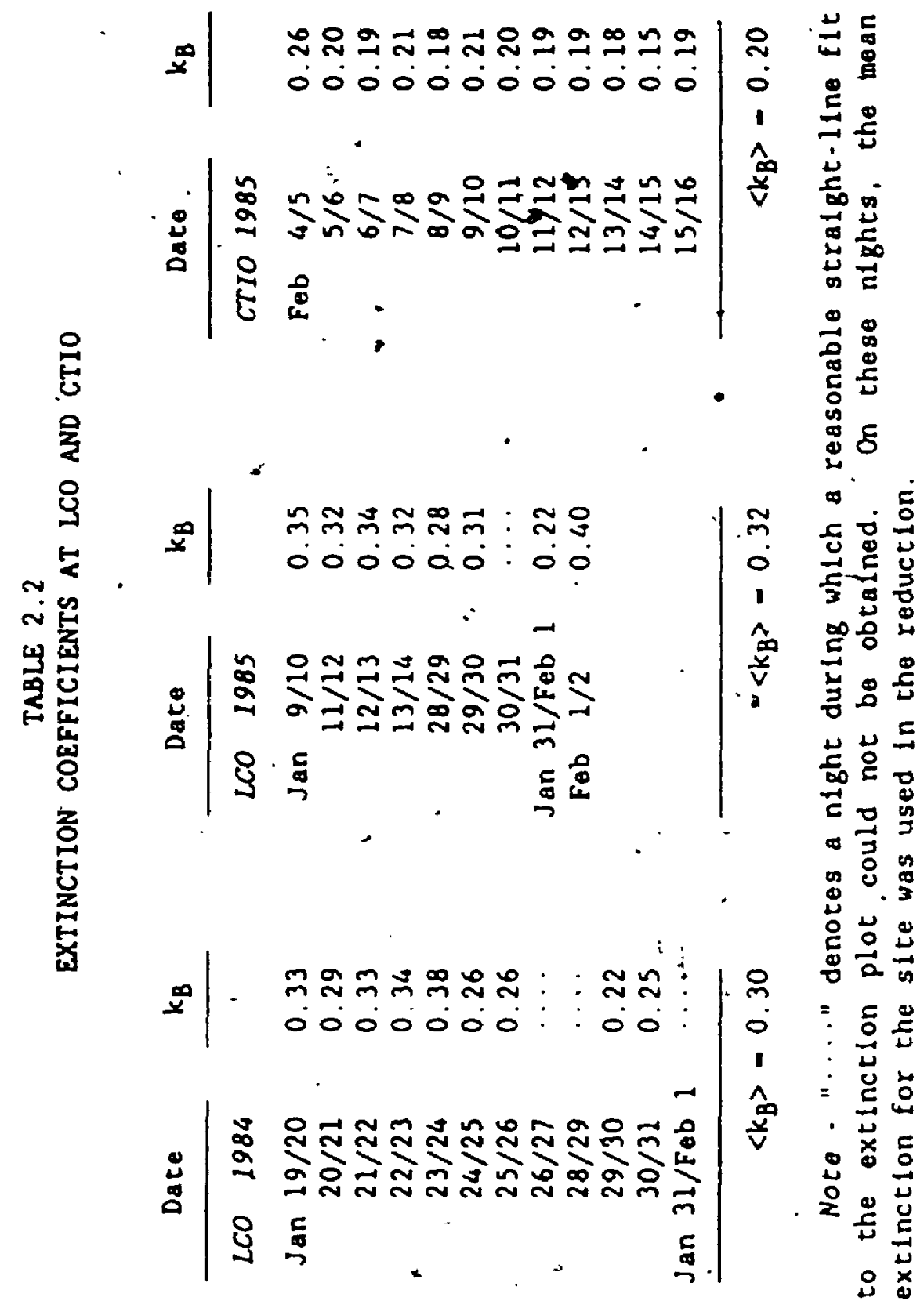




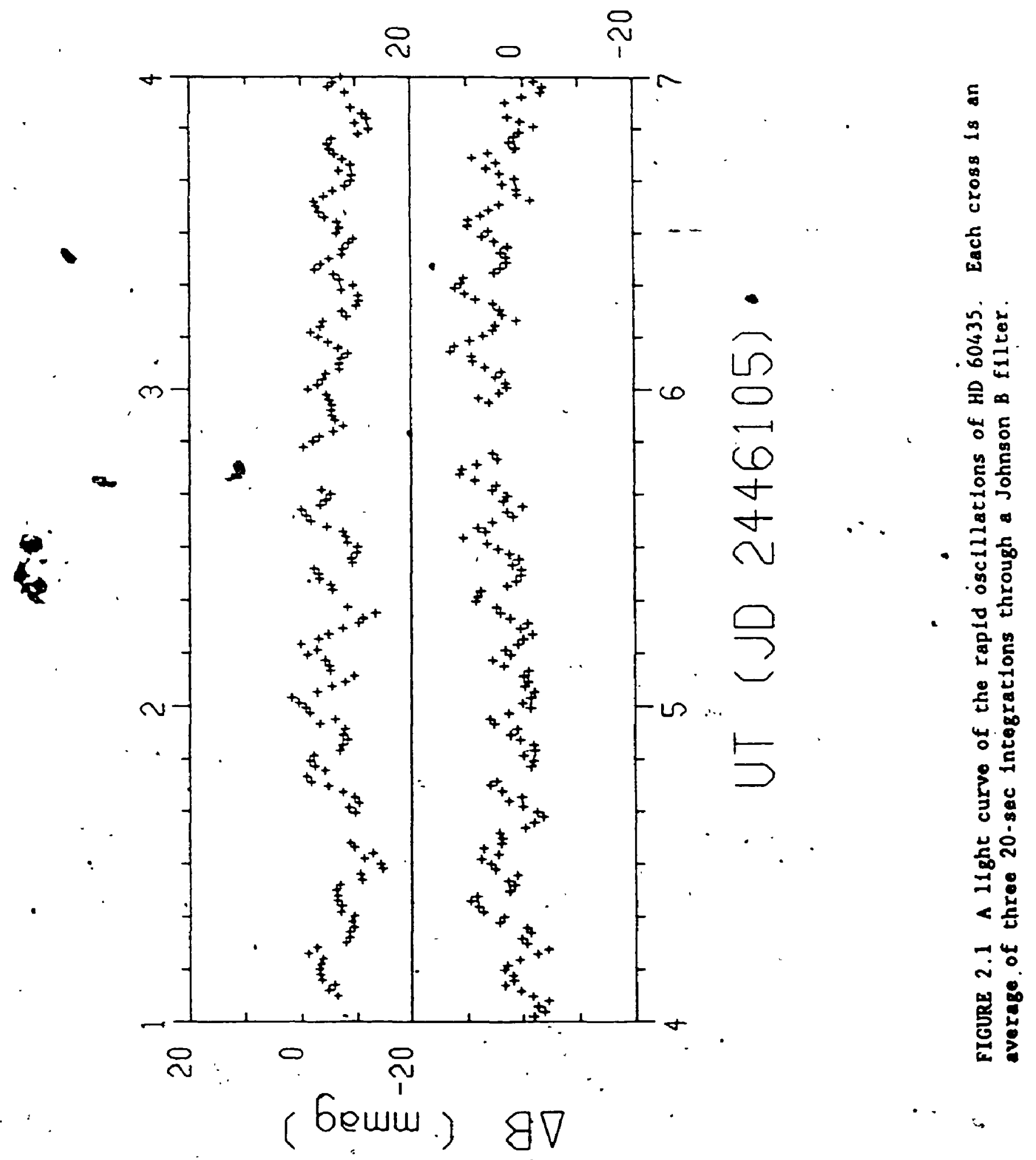


longer-term photometric variations, assoclated with rotation, found in any eagnetic peculiar stars. Such variations typlcally have periods of a fer days".

In order to deternine if this type of varlability.exists in $\mathrm{HD}$ 60435, comarison star was observed at the beginning and end of inst n1,ghts. The measurements of the programe star (HD 60435) at the start and and of eech run were later averaged over the longest period of osclilation detected. The difference between the respective programe and comparison values, corrected for mean extinction, provided instruwental magnitudes twice each night per site.

The comparison star used was HD $59994 \mathrm{AB}$, which has a visual magnitade of 8.5 and spectral classifications by several authors of A2m, A5. and A7 (Houk and Cowley 1975). Its (1950) coordinates are: a $-7^{\text {h }} 2^{\text {m }}$. $26 \$ 2, \delta-,-55^{\circ} 12^{\circ} 0: 2$, placting the star about $2^{\circ} 40^{\prime}$ from HD 60435 . It was selected by Kurtz (1984) for his first observations of HD 60435 , as thie closest star of conparable spectral type and suftable brightness which showed no evidence of variability.

In general, these comparison measurenents were ade on each night that rapid photonetry took place. On some nights, though, neasurenents were alsed for a varlety of reasons (e.g. power fallure near the end of the night). Those nights are Indicated In Tabłe 2.1 by an asterisk.

The actual differential wasurements are presented in Table 2.3.

\section{Spectroscopy}

Iary Ap etars show spectroscoplc variabllity, as vell, with the sam perlod as the wan photometric variations. Changes in the line etrongth of HD 60435 may be correlated with 1ts rapid osc1llations. $+\cdots$ 
TABLE ? 3

MEAN PHOTOMETRY OF HD 60435

LUD (2440000+)
$\Delta B$

Observacosy
HUD $(2440000+)$ $\Delta \mathrm{B}$

Observatory

Flfse campaign

5385.299
5385.499
5386.286
5387.285
5387.495
5409.260
5409.425
5410.260
5410.460
5412.261
5412.425
5413.260
5413.450
5415.258
5415.426
5423.251
5426.249
5427.249
5427.326
5428.247
5429.372
5719.545
5719.847
5720.568
5720.852
5721.567
5721.861
5722.550
5722.857
5723.532
5723.863

0.528

0.527

0.523

0.535

0.531

0.526

0.526

0.535

0.537

0.525

0.520

0.534

0.535

0.540

0.536

0.525

0.518

0.525

0. 523

0. 530

0.531

0. 521

0.513

0.528

0.543

0.539

. $0^{3} 533$

0.522

0.514

0.514
SAAO

SAAO

SAAO

SAAO :

SAAO

SAAO

SAAO

SAAO

SAAO

SAAO

SAAO

SAAO

SAAO

SAAO

SAAO

SAAO

SAAO

SAAO

SAAO

SAAO

SAAO

LCO

LCO

LCO

LCO

LCO

LCO

LCO

LCO

Lco

LCO

$$
\begin{aligned}
& 5726 \\
& 572 \\
& 572 \\
& 572 \\
& 5726 \\
& 5726 \\
& 5726 \\
& 5728 \\
& 5728
\end{aligned}
$$


6

TABLE 2.3 (core'd)

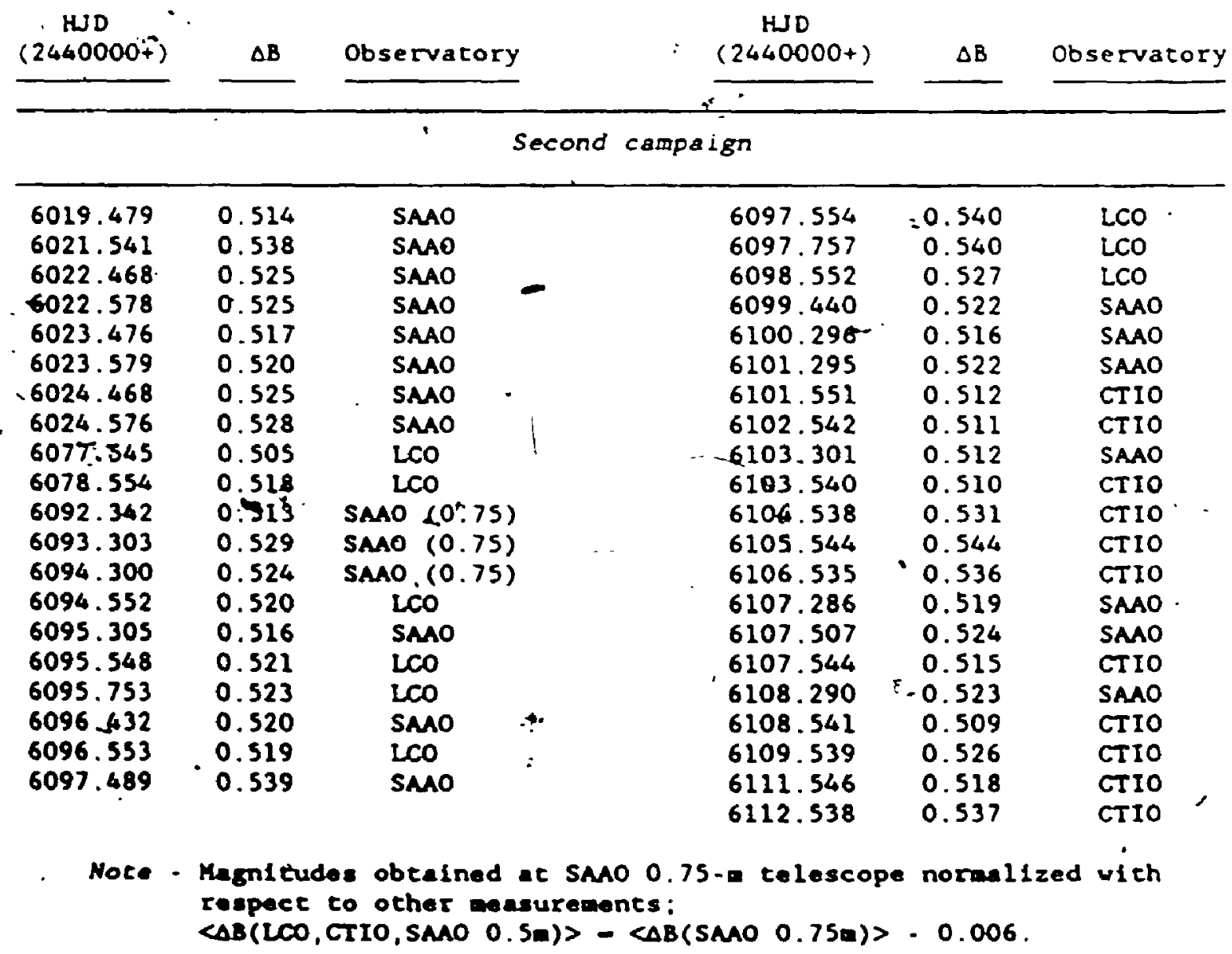


During the second observing campaign (January/Fobruary 1985), a dozen photographic spectra of HD 60435 were obtained by the author and Robert slawson, using the Garrison spectrograph of the $U$ of I telescope at LCO. (Rapld photonetrlc observations vere also collected on the sane nights, elther simultaneously or contiguously.) The spectra vere recorded on IIa-O plates (both baked and unbaked) at a dispersion of 67 $\mathrm{A} / \mathrm{me}$. Wavelength coverage was -3800 - $4900 \mathrm{~A}$, with $\mathrm{S} / \mathrm{N}$ ratios of -30 40. Exposure tines were generally under two hours for the baked plates. A spectrum of a neon-argon comparison lamp was oxposed for about 40-60 seconds before and after each stellar expowre and adjacent to 1 on the place. Table 2.4 is a log of the spectral exposifes.

The photographic. spectra were later digitized using the PDS microdensitometer of the David Dunlap Observatory for quantitative analysis of apy line strength varlations. Continum flattening, wavelength calibration (using the Ne-Ar comparison spectra), and-noralization of the scans wete performed at the same tine. 


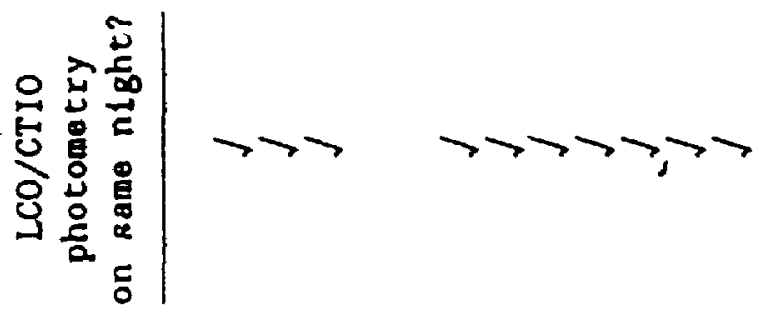

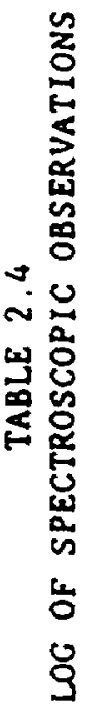

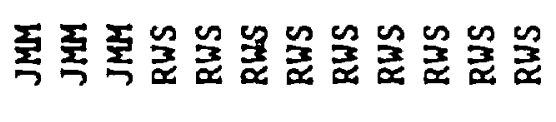

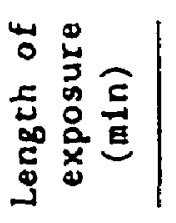

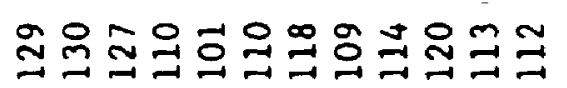

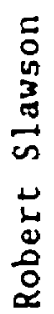

$5 \underset{\sim}{\stackrel{5}{*}}$

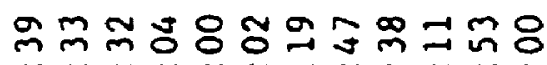

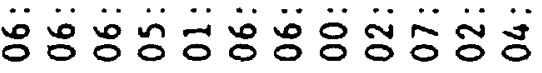

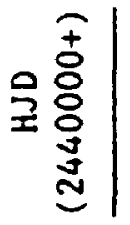

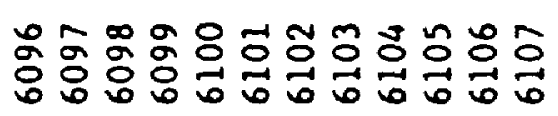

$\stackrel{\infty}{\approx}$

竞

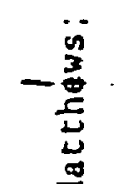

帘

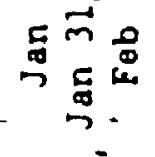




\title{
III. FREQUENCY ANALYSIS
}

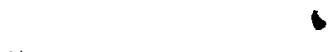

Many techniques exist.for the detection of periodicities in daca.

Those applied to the analysis of astrononical photonetry includa:

$\nabla$ Methods which seek to minimize some perlod-dependent quantity, such as the' 'string length' of a set of phase-ordered points (Lafler and Kinman 1965); or the magnitude dispersion in pre-selected phase bins (Stellingwerf 1978), for a set of trial periods.

7 Maximum Entropy Spectra Analys!̣s (MESA), which attempts to "optimize" the information about the original cime series contained in its power spectrum (e.g. Burg 1975).

$=\nabla$ Least squares fitting to a small number of sinusolds whose periods, amplitudes, and phases are treated as free paramerers (e.g. Bevington .1969).

$-\nabla$ Fourier perlodogran analysis (e.g. Wehlau and Leung 1964).

The first two types of analysis, and their kin, wake no assumptlons aboiut the form of the periodicity in the data; the remalnder ${ }^{+}$ attempt to represent the light curve by one or more sine waves. If the actual periodicity is markedly nonsinusoidal, then these techniques introduce harmonic terms (at integer multiples of the true frequency) into the solution.

St111, of these approaches, the Fourler perlodogran has several advantages. It does not suffer from allasing in gapped deta quite as severely as the flrst two methods. (Fahlanen and Ulrych (1982) have trled to "fill the gapa" in trial data sets by applying a predictive

+ Scargle (1982) showed that Fourler perlodogran anlysis and least-aquares fitfing of sine waves are essentlally equigalent- 


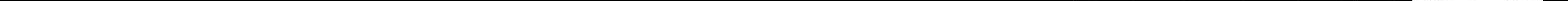



widespread use in the astronoulcal applications of Fourler analysis. Scargle (1982) later modifled that classical periodogran to recover the smple satistical behaviour of the equally-spaced case. He developed en expression for the "false alarm probabllity". Since power at a given frequency is exponentially distributed about that frequency, the probabllity $\eta$ that a peak of helght $z$ ( $1 \pi$ power) occurs in a periodo-. gran of a sample of pure white nolse is

3

$$
7-1-\left(1-e^{-2}\right)^{N}
$$

where $\mathrm{N}$ is the number of independent frequencies which are searched and the power 2 has bef normallyed with respect to the standard deviation of the sample. (Horne and Baflunas (1986) provide an empirical formula for the number of independent frequencles which are avallable from a given number of data, based for the most part on samples of even spacing.) One can then set soue liafting probabllity.-say $\eta-0.01$, to calculate a animum peak helght above which there is only a is probability of observing a peak arising solely due to noise.

- 10 apply the scargle criterion to an amplitude rather than a power spectrua, 2 (actually a power "signal-to-nolse" ratio) is expressed as

$$
z-N_{0}\left[\frac{x}{2 \sigma}\right]^{2}
$$

where $N_{0}$ - the number of polnts in the tine serles, $X$ - the amplitude of the peak, and $a$ - the standard deviation of the data.

Values of the erplitudes corresponding to $\eta-0.01$ (1.e. 99 confidance) and $N \leq 2000^{\circ}$ for the nightly data samples of HD 60435 were Inkluded in Table 2.1. These liniting aplicudes. Iepresent fairly conservative estinates for the 99 confidence level. The Scargle criterion is etrletly valid for a data set which conteins only a single

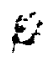


frequency and white noise. The results contained in this work demonstrate that HD 60435 can undergo multiple osclilations at one tive. The presence of two or iore oscillations simultaneously will raise the calculated value of 0 . which in turn results in an overestinate of Apg. Also, the nolse spectrun for non-differential photonetry is not white; there is a significant frequency dependence in that the sky noise is greater at low frequencies (see figure 4.1). Since only a single value of $\sigma$ is calculated for each night of data, 0 (and again. $A_{9}$, ) is likely overestimated for the frequency range of interest.

\section{Aliasing and the Fourier spectral window}

The sampling rate of observations, $1 / \Delta t$, during a nlghtly run is fairly easy to control. It is selected to ensure that the Nyquist frequency for the sample is greater than the highest frequency of tnterest. Therefore, Nyquist allasing does not present problen in - the analysis of these data. However, with observations from only two longitudes, daily gaps in the data record - and the resultant $1 \mathrm{~d}^{-1}$ allasing in the Fourler spectrum - cannot be entirely eliminated. Fortunately, the alias signature or spectral window can be deteralned for any given time serier.

The observing, record alght be thought of as an infinite sequence of discrete equally-spaced daca muleiplied by a series of "box" functions of unit height, whose separations and widths reproduce the segments of tive during which data vere ectually collected. Lat us refer to this as the observing window, which has anlque transform in the Fourler reglee.

Figure 3.1 outlines how a siplified version of a eyplcal estro- 


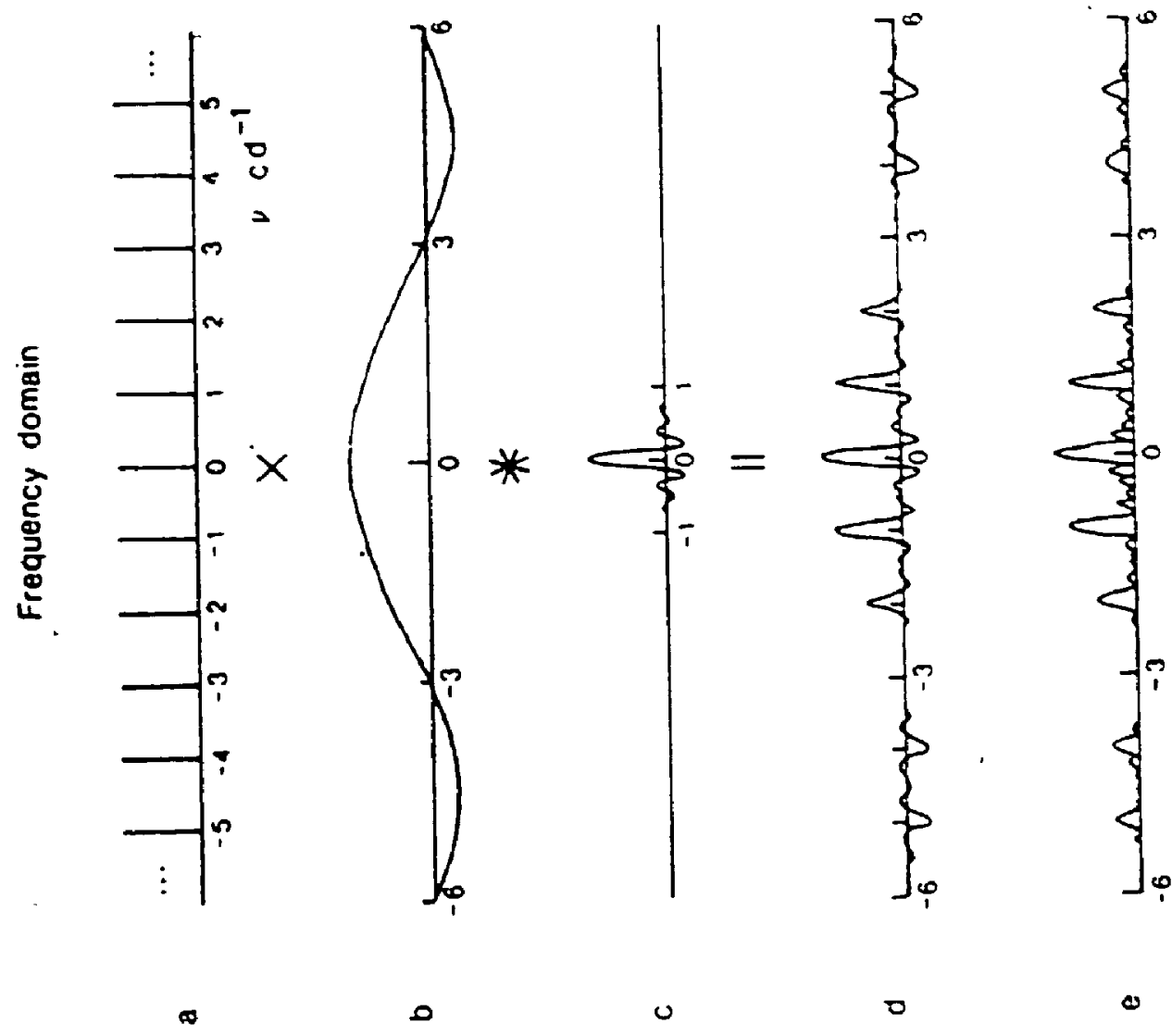

$\stackrel{9}{\check{L}}$

5

$\frac{3}{2}$

ఏ

?

ํํㅇ

홍

용

ㅇํㅇ

\&

-

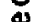

$\underset{-1}{0}$

르을

空

$n=$

4

$=$
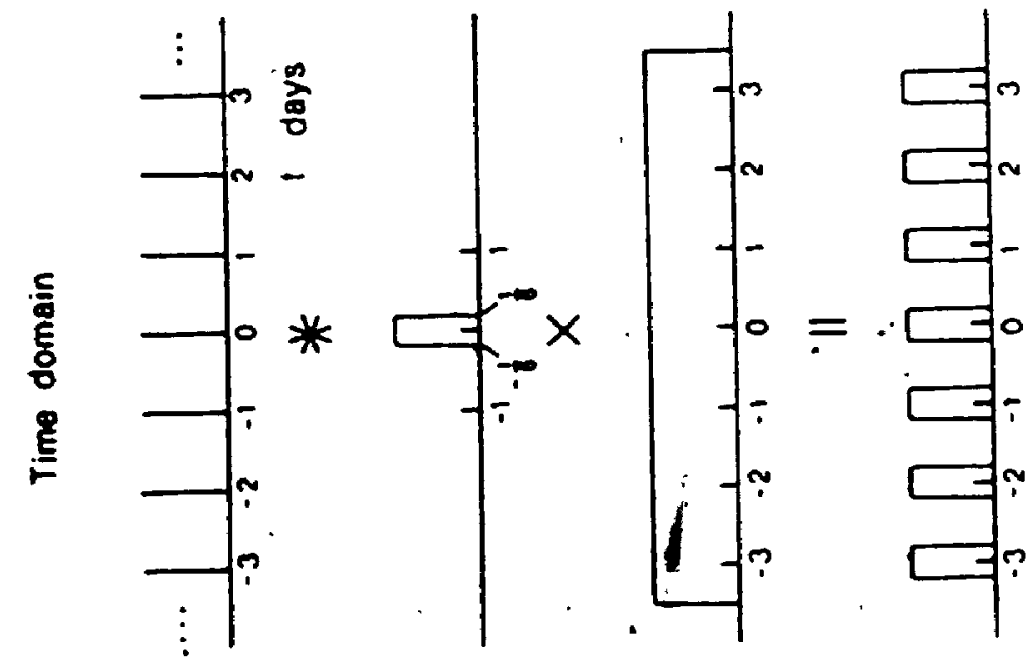

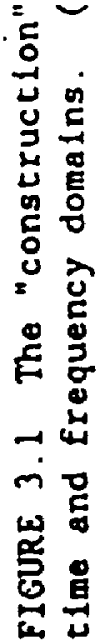

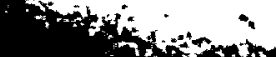


nonical observing window may be represented in both the time and fre. quency domains. We assune that, whlle observations are being ade. the sampling rate is high enough so that wyq is wuch greater than $6 \mathrm{c}$ $d^{-1}$ (the highese frequency represented in the transforms in Figure 3.1).- On the left, a Shah comb of delta functions [a] spaced by 1 day (the nightly observing cycle) is convolved with a box (b) of width $8^{\circ}$ houtrs - 1/3 day (the length of each night's run), and then wultiplied by another box $[c]$ of width 7 days (the span of the entire run) to produce the completed window [d].

The Fourier transforw of each contributor to the observing window is shown on the right of Figure 3.1. Note that convolution (multipl1cation) in the time domain corresponds to multiplication (convolution) in the frequency domain. To the left in panel (d) is the tranform of the final window. The actual spectral window (In terms of absolute amplitude) for the sample is given in panel [e] of the figure. It. shows how a single sinusoid sampled in this way spaws a number of 1 . $d^{-1}$,allases of non-negligible amplitude.

For comparison, Figure $3.2 a$ is the actual distribution of the HD 60435 observations during the first campaign, and Figure $3.2 b$ is the amplitude window for that sample. The partial "fiming-in" of sone of the dafly gaps has reduced the anplitudes of the allac sidelobes. Inequalities in the lengths and spacings of the nightly observing "boxes" account for the asymetry of the spectral window.

The regular pattern of the spectral window helpe to plck out true oscillations in a spectrum from randon nolse peaks. It can also be used to Identify, the frequencles 'present in the dete by succeselvely rewoving the power assoclated with candidate frequencles. Rather than 

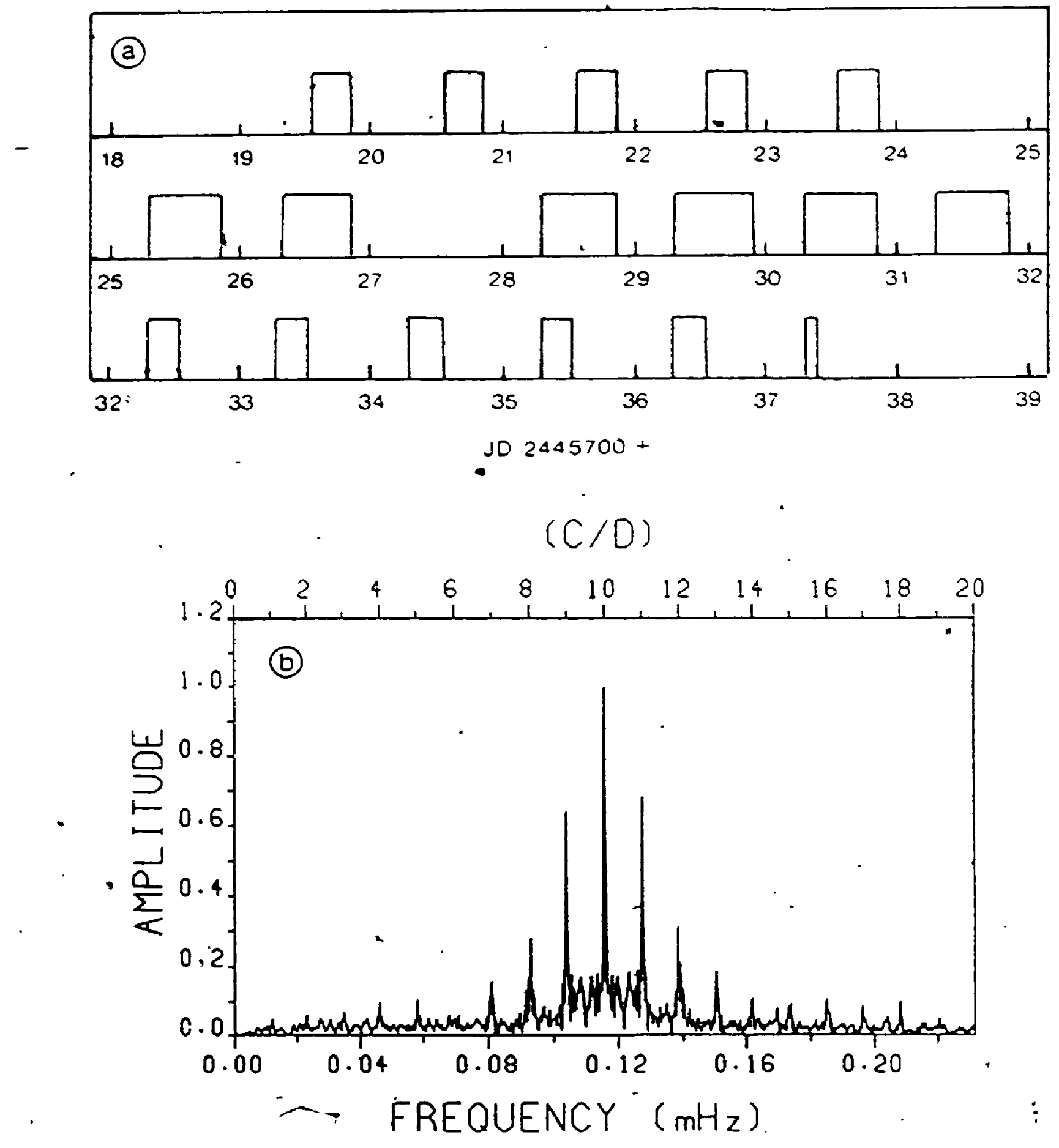

FIGURE 3.2 (a) The actual.tine-doanin window for the 1984 observations of HD 60435. (b) The spectral (aiplitude) window corresponding to (a). 
doing this in the tine donain by prowhitoning the data (1.e. subtrac. ting froa the light curve a sinusoid of the selected frequency, amplitude, and phase), the removal can be carried out in the fourler domain using the technique of Gray and Desikachary (1973). The spectral

window pattern is centred on the chosen.frequency in the perlodogram, scaled to the amplitude of the peak there, and subtracted from $1 t$. The process is repeated until no further allas patterns can be recognized above the noise level of the spectrum.

Analysis of the HD 60435 observations

All of the rapid photometric data of HD 60435 , including the SMAO observations provided by Kurtz, was analysed by the author at UwO. A routine similar to that of Deening (1975) was eaployed. The FORTRAN programe was originally written by Dr. Wllliam Wehlau and later nodlElde by the author. (See Appendix B for a complete ilsting.) There are two major differences between this programe" and the Deeming approach:

1) Since the periodograms are always generated with a grid of constant frequency spacing, the number of explicit sine and cosine calculations required are reduced through the use of recursion relatlons which explolt the simple trigonometric identities

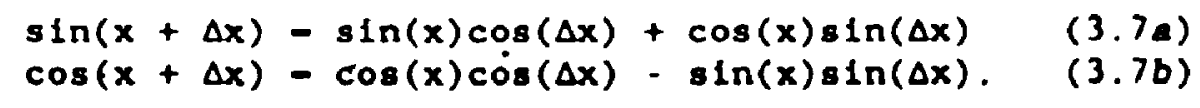

These are substituted into equation (3.4), where $x=2 \pi t_{1} \nu_{j}, \Delta x=$ $2 \pi t_{1} \Delta \nu ;$ and $\Delta v-\nu_{j}-\nu_{j}-i$.

11) Given a set of observations collected over many nighte, there are advantages" to treating the date in different segents. A perlodo- 
gram of the ontire set will provide the best frequency repolution. wile one beged on a angle night's data will be free of cyclefay allases. If the data contain a modulated oscillation, then a subset of those data selected at tines around maximum amplitude will enhance the signal and minivize the effects of strong beat frequencies.

Therefore, the Fourier perlodogran programe is divided into two parts. In the first part, the suns of the sine and cosine teras enclosed in square brackets in equation (3.4) are calculated and stored as Intermediate files. In the second, the sur files can be coadded wth sinflar files from other nights of data and normalized to produce perlodograms for various combinations of data without expensive recalculation. New data acquired later can also be patroduced with relatively little effort.

Tests of this prograne by the author using real and simulated data sets (and independent tests by Kurtz (private communication) with - Inilar perlodogran poutineTdemonstrate that it yields the'sane reaulta as the scargle algortthe.

For every night of data, a perlodogram was generated over a range of frequencles fron zero to the Nyquist frequency ( $\mathrm{Nyq}^{\mathrm{N}}-25 \mathrm{mHz}$ ). At this stage, amplitudes and phases for 2500 frequencles in this range were calculated. The constant frequency spacing of $10 \mu \mathrm{Hz}$ represented - typical oversampling factor of about $3-4 x$, simply to ensure adequate resolution of any spectral features.

Each aplitude spectrun was; exanined for algniflcant peaks above the nolse level. Signiflcance criterla ware twofold: 1) The mplitude of the peak wist axceed A99s, the minimu above which a peak has a false alere probability lese then 18, ind 11) the peak anst occur at a 
frequency uncontaninated by sky varlations. In general, the latter requirement set a lower frequency linit of approxinacely 0.5 :Hz: (perlod $\approx$ hour). In none of the spectra wera:słgnificant peaks detected at frequencies above $4.5 \mathrm{mHz}$. Therefore, to more clearly display the frequency region of interest for HD 60435 , the perlodograms in this worklare plotted only to a maximum of $4.5 \mathrm{mHz}$.

The data provided by Kurtz had already been filtered ta remove much of the low-frequency power due to transparency/background var1ations. This was done by successively subtracting sine waves at frequencies corresponding to the low-frequency peaks.

Such filtering was avoided if possible in the author's data. In those cases where long-terw variations might introduce harmonic power in the frequency range of interest for this study, the trends were removed by a cublc spline filter fit (see Appendix C) to averages of points separated by no less than 45 minutes. "Before" and "after" spectra were examined to ensure that the filter added no spurlous power in the relevant frequency range. The Fourier spectrum of each spline filter, such as the example in Figure 3.3, was also checked for any undesired peaks.

After potential oscillation peaks were singled out, highresolution ( $\Delta u-0.1 \mu \mathrm{Hz}$ ) amplitude spectra were generated fron many nights of data, In order to deteruine frequency values to greater precision and to study any fine structure present. These perfodograsis suffer from $1 \mathrm{~d}^{-1}$ allases; In some cases, the spectral window filtering technique described above was used to dietingulsh individual frequen. cles where several allasing patterns overlapped. 


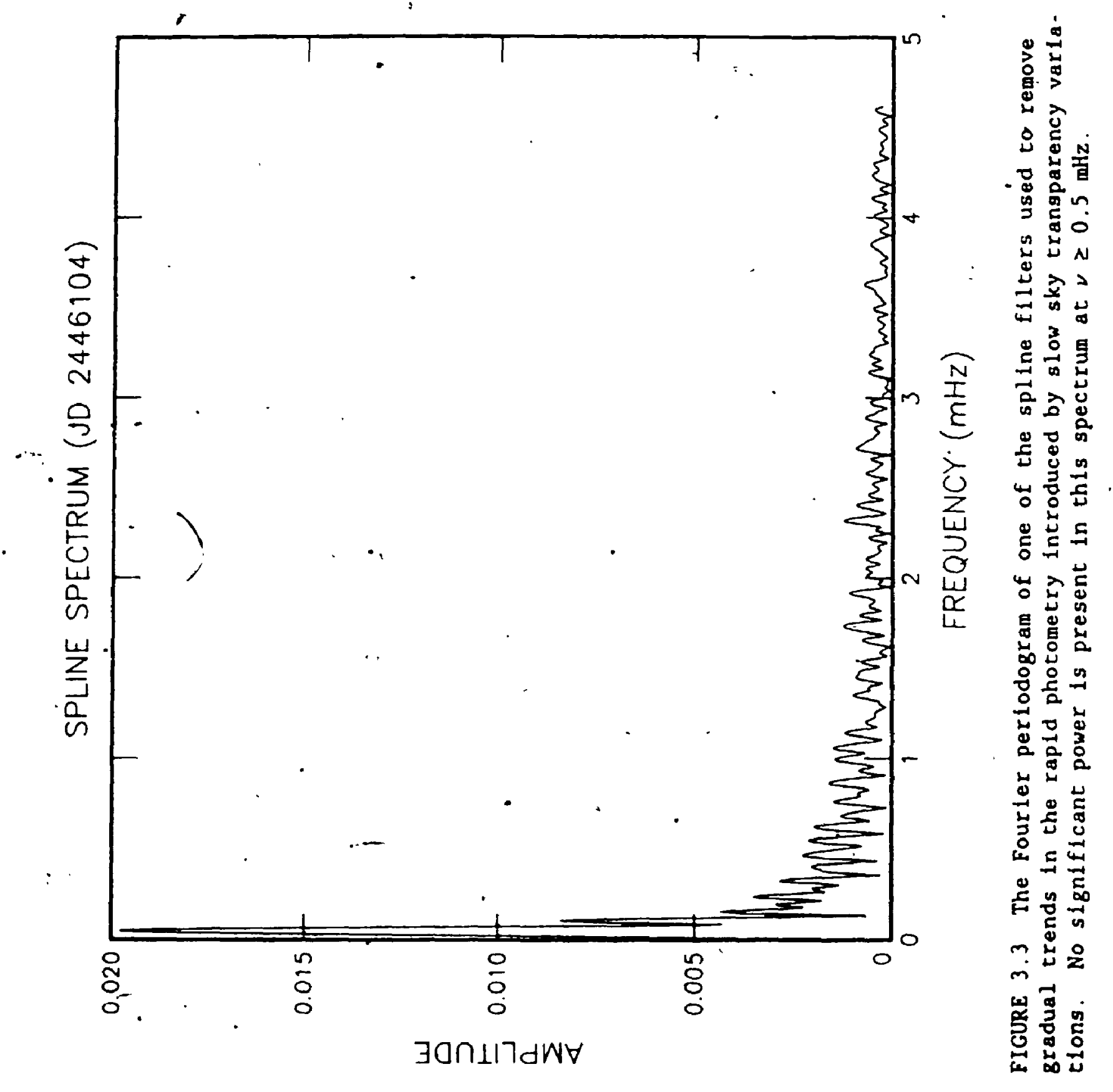


IV. THE OSCILLATIONS OF HD 60435

The oscillation spectrum of this star is the nost complicated yet studied amiong the roAp stars. Even after two extensive joint observing campaigns, the frequency behaviour of HD 60435 is not completely understood. The findings of the two campaigns are outlined separately below to establish for the reader how the frequency identificasions were arrived upon.

Results of the first campaign

The amplitude spectrum of the data from the entire joint run (JD. 2445719 - 737), covering frequencles from 0.5 to $4.5 \mathrm{mHz}$ (1.e. perlods'. from just over half an hour to less than four minutes), is shown in Figure 4.1. (At frequencies less than $0.5 \mathrm{mHz}$, the spectrum is dominated by residual sky variations. The upper limit of $4.5 \mathrm{mHz}$ is close to the "generalized" Nyquist frequency for the complete sample.) Peaks are evident at frequencies near $1.1,1.4$, and 4.2 mHz (periods near 15. 12. and 4 minutes, respectively). Note the trend of higher nolse with decreasing frequency. Also note that there is no evidence in the com. bined data of a $2.8 \mathrm{mHz}$ ("6-minute") variation, as seen by Kurtz (1984)" in his discovery observations.

a) Frequencles near $1.4 \mathrm{mHz}(P=11.9 \mathrm{~min})$.

Although the 1.1-nHz peak is the largest in Figure 4.1 , the ones near $1.4 \mathrm{mHz}$ - also defretéd by Kurtz In hls earlier observations. appear wore often in the spectra of individual nights. Two such spectra are shown in Figure 4.2. The presence of multiple osclilations here is revealed by the width and pronounced asmatry of the peak in 
8

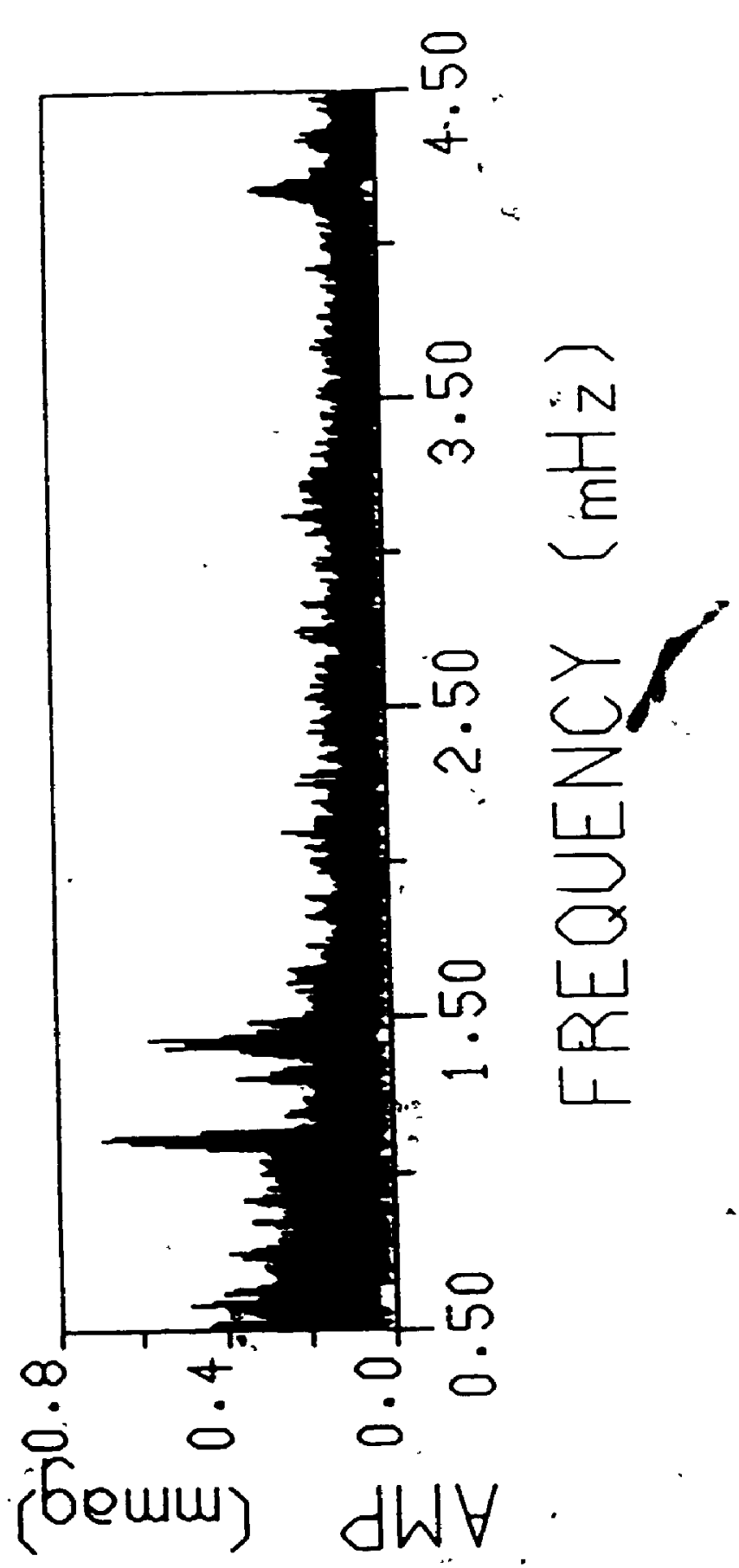

ถู่์ $\leftarrow$ क 爻嵒先 的 ह : 요

古迨岳 일 는 m ปั่ 오욤 w 3 ? - 어 ڤ \& 秃 足 造资 世

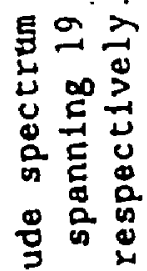
$\pm E$ 오 엉 运冬 - U

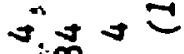
엉 엉 కُ Ð 


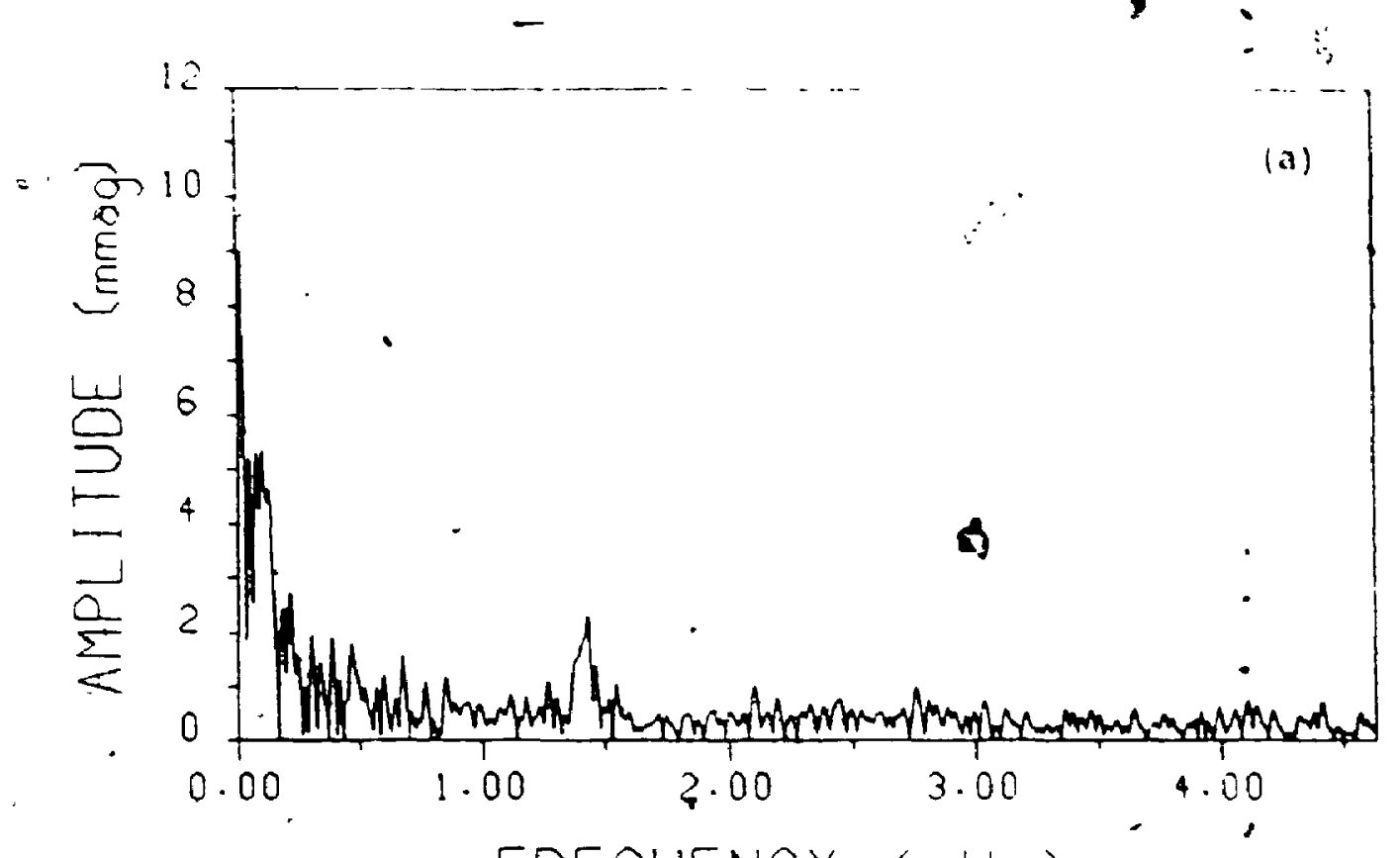

FREQUENCY $(\mathrm{mHz})$

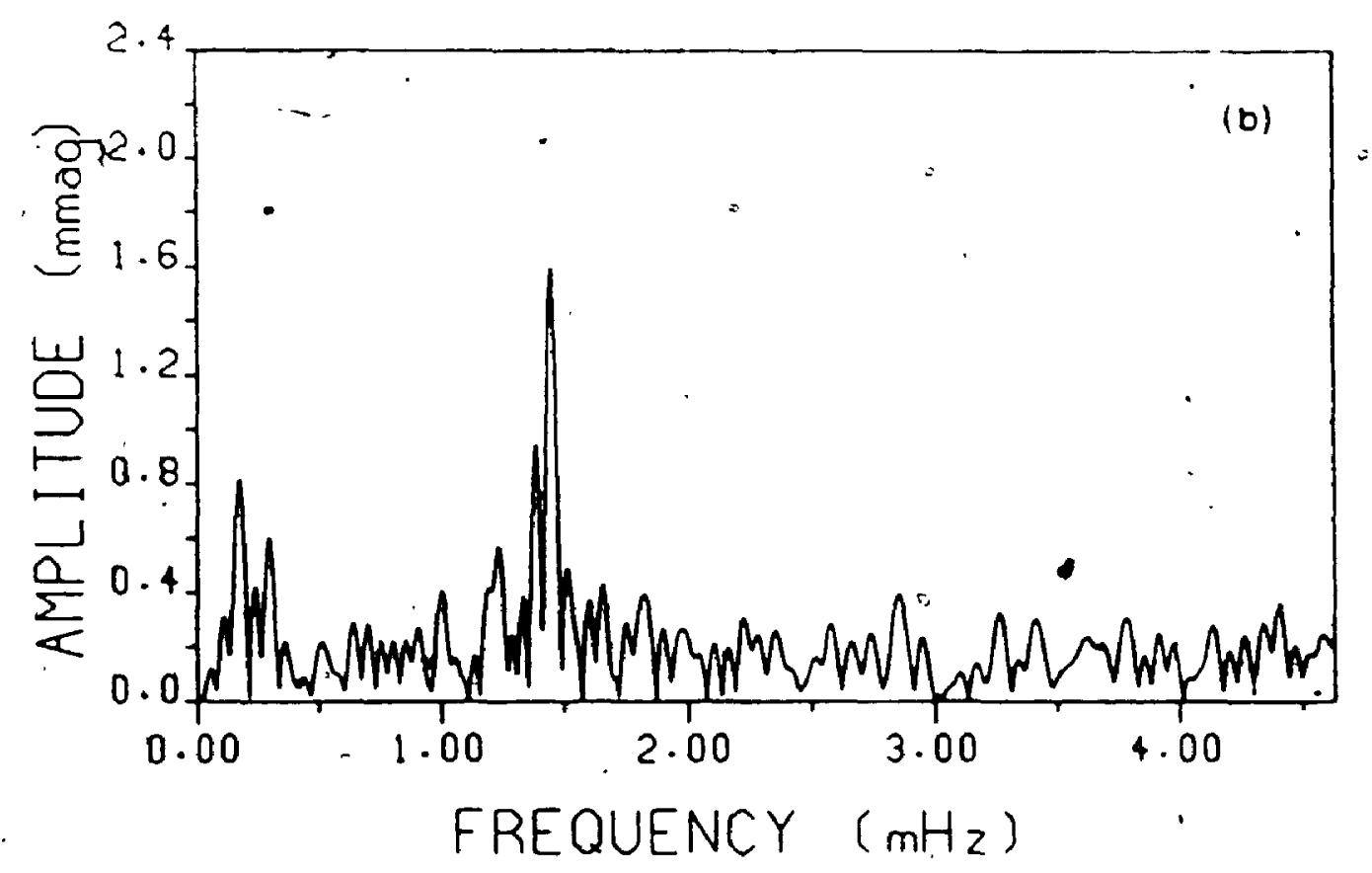

FIGURE 4.2 Amplitude spectra fhe 1 ight curves of HD 60435 obtalned (a) frow LCO on.JD 2445728, showing the peak near $1.4 \mathrm{mHz}(P-12 \mathrm{~min}$ ). and (b) from SMO on JD 2445736. (Note the different amplicude scales. The peake at low frequencles in (a) ar ateributed to slow changes in. sky cranaparancy which haye not been removed fi ja the observacions.). 
Figure 4.2a, and by that appeare to be enother resolved peak juct shortward of the largeist one in Figure $4.2 b$.

Hodulation of the aplitude of the -12-ninute" oscillations over the 18 alghts of the joint run 18 quite obvious in the varlation of the 1.4-diz peak in the nightly power spectra (Figure 4.3). Although no dafinitive period can be assigned to the modulation fron the se data alone, Its timescale appears to be around eight days. On.two nights (JD 2445728 and -729), the LCO and SAAO amplitudes seem discrepant.

Thls way be an indleation of wore rapld modulation occurring over several houra.

Figure 4.4 is an aplitude spectran of the entire'joint.run, this tiwe sapling only frequencles between 1.24 and 1.54 ahz. This shows the fine structure suggested by Figure.4.2, but the situation is conpliceted by the allasing. An aplicude spectrun of the contiguous ilght curve of SAMO and iLCO data fron JD 2445728, with higher resolution than the apectrin ôf.Figure 4.2a but stili no 1-d-1 allases, Is reproduced in Figure 4.5. At least three neariy equalily spaced peaks are partially reoolved:- the spacing is approxinately $26.3 \mu \mathrm{Hz}$. (The resolution of thls perticular spectrum is $\Delta \mathrm{y}-1 / 13.53 \mathrm{hr}-1=20.5$ mis. It 1s unlikely, that the equal spacing of the three peaks is rwerly an artifact of the resolution l1nit for the data sample. The other sinller pdake In Figure 4.5 are separated frọn thelr nelghbours o by vartow magih intervala ranging fron bout 21 - $36 \mathrm{mth}$ )

The two hicheze sets of poaks in Figure-4.4, which covere roughly

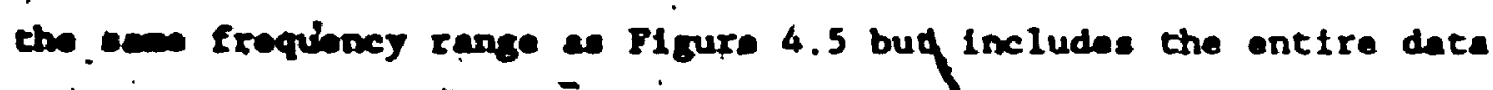
edt. colocide with two of the proniriont packe dascribed above. A third eot of paste antehes the raneining frequoticy. The other paake are pra: 


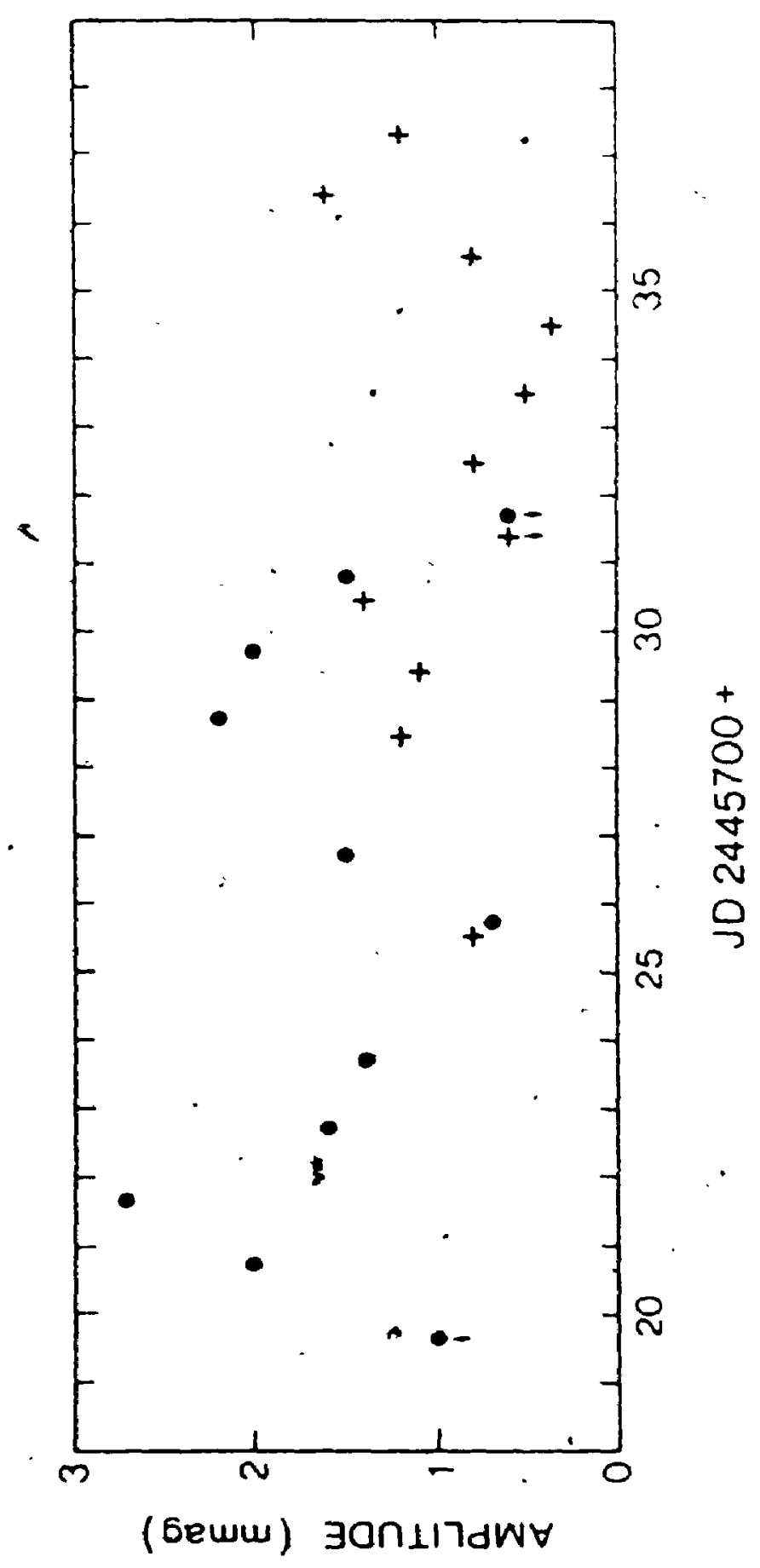

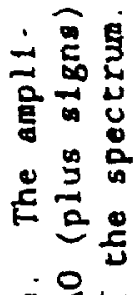

운

0 밈

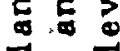

寻合。

- 릉

$>$

옥

ㅇํㅇ

-

of

핸

出

ᄃ

求家

क

$\exists$ 보을

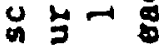

- R 돈은 岁 내요요

马 08

出

$\exists$ 요

量志的

궁

$\because$ 눈

눈 웅

䒓

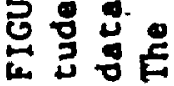

NOIเซาוכSO 


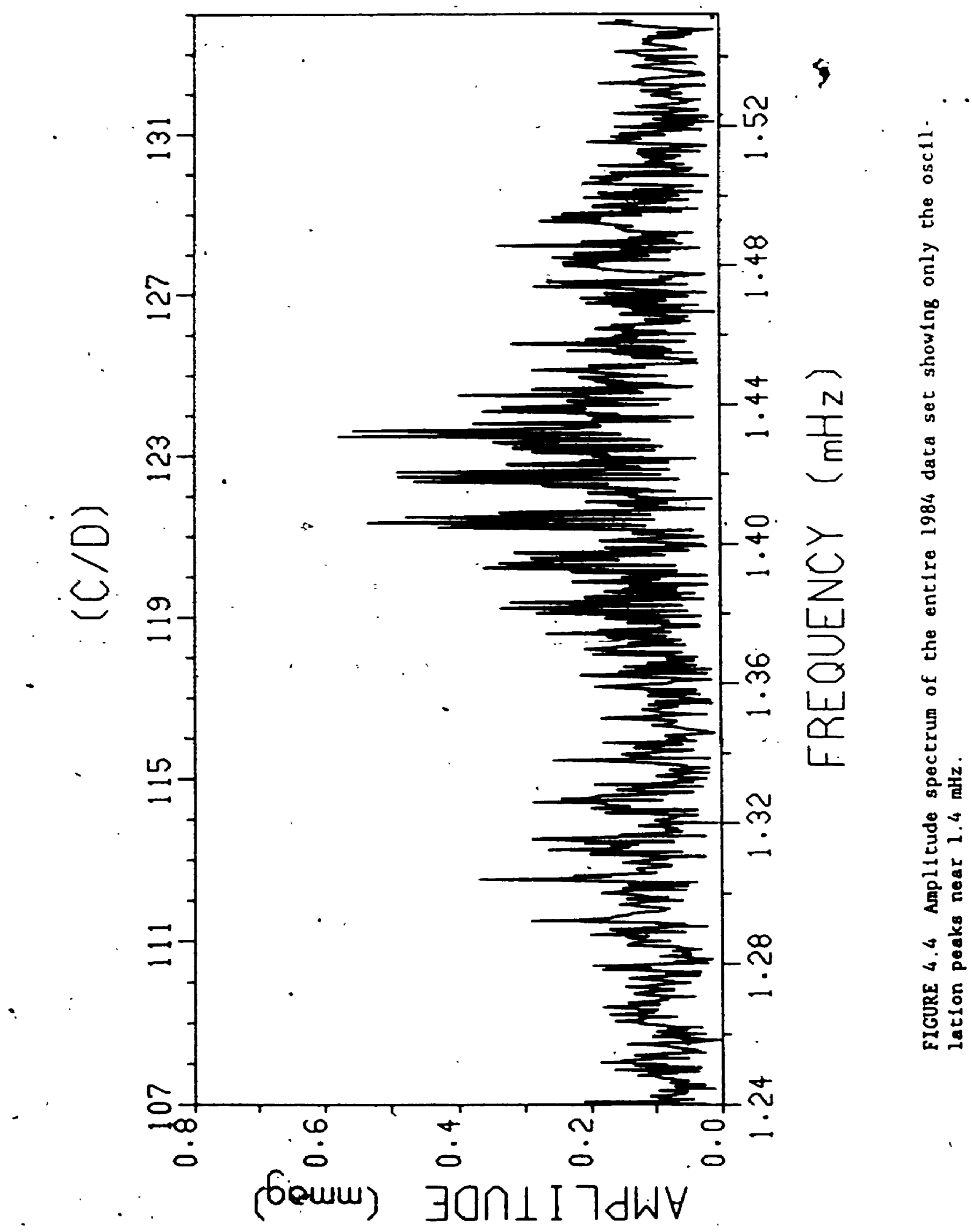




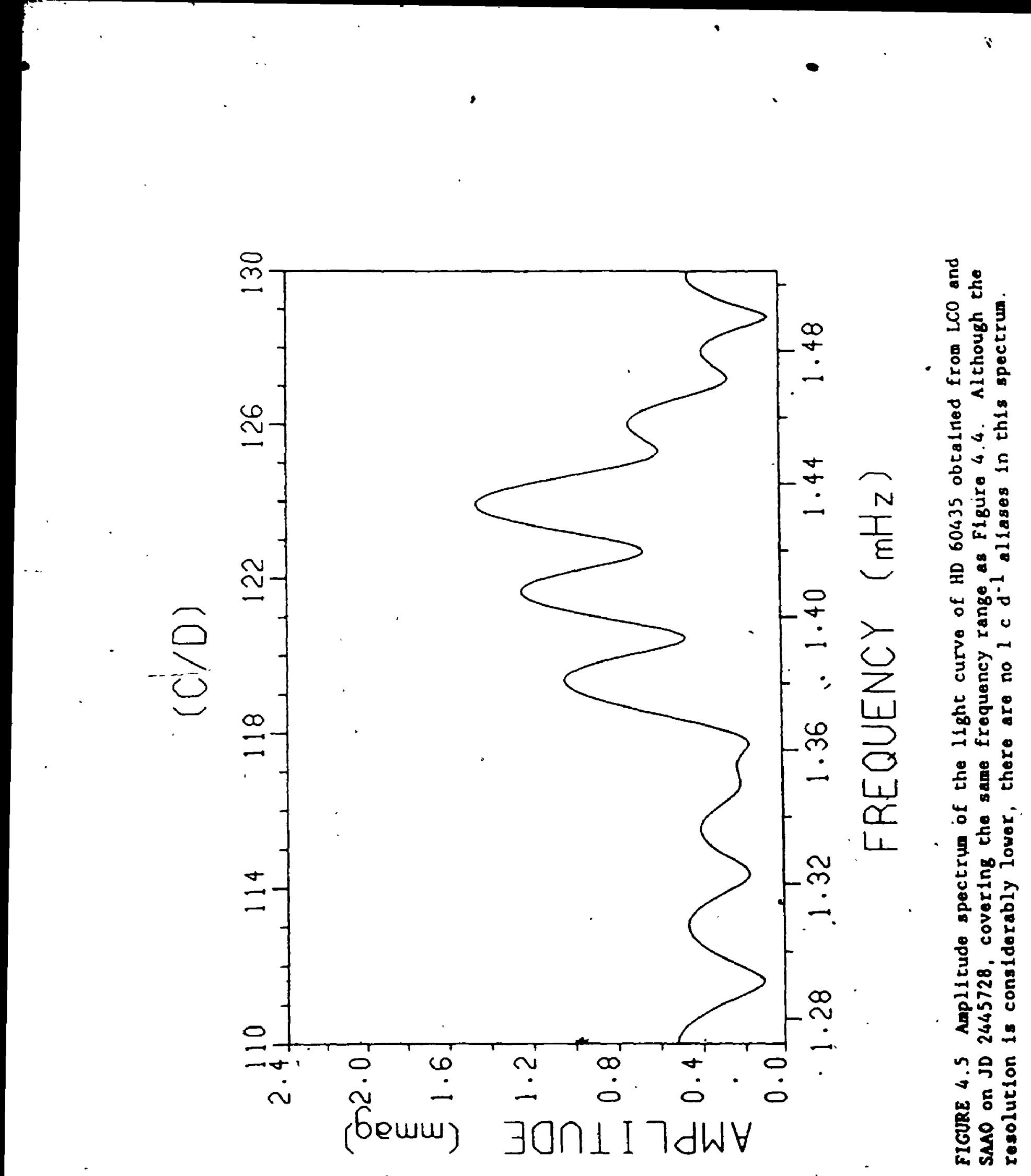


awed to be the results of Individual and co-added al ases

There is a eingle frequency at $1.30371 \mathrm{mz}$ in Figure 4.4 which roughly fits into the spacing pattern recognized in Figure 4.5.

Furcherwore, In another part of Kurtz's earlier photometry of HD 60435 (JD 2445383-387), one observes a frequency at 1.35210 whz which also falle Into this pattern. However, this latter frequency is notably absent from the daca set of the first campaign

The entire set of frequencies detected near $1.4 \mathrm{mHz}$ in the first campalgn (and including the additlonal frequency from Kurtz's dáta) is shown achenatically in Flgure 4.6 .

The fine structure evident in Figure 4.4 has a charactertstic equal spacing of $1.4 \pm 0.2 \mu \mathrm{Hz}$. There appears to be at least one tri: plet present, although the nost obvious candidate near 1.42 atiz is a byproduct of the aliases of the components of frequencles at 1.4075 and $1.4336 \mathrm{mHz}$.

\section{b) Other frequencies}

In the first six nights of LCO photopetry, osclilations with pertods near 15.2 and 4 alnutes bere observed. These osclilations" declined in amplttude unt11, by the time oonicorfng had begun at SAAR choy had dlsapperared into the noise. Both frequency peaks are ofsible In tho petiodogran ahow in F1gire 4.7.

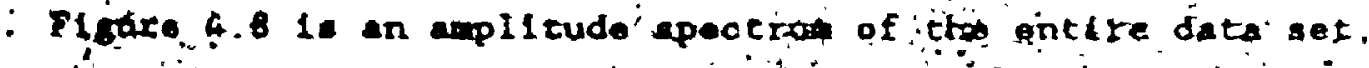

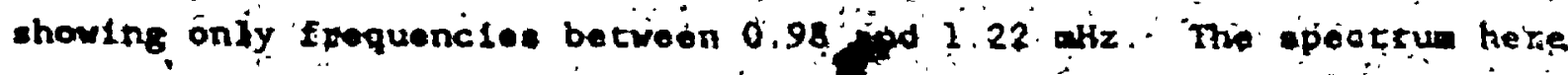

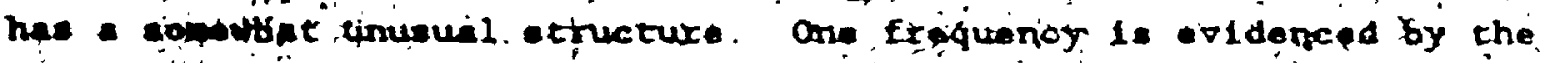

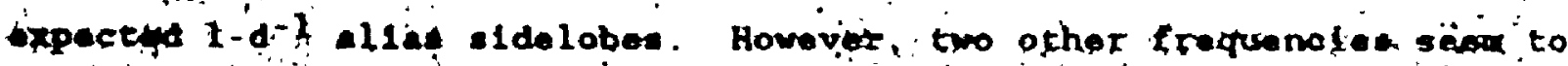

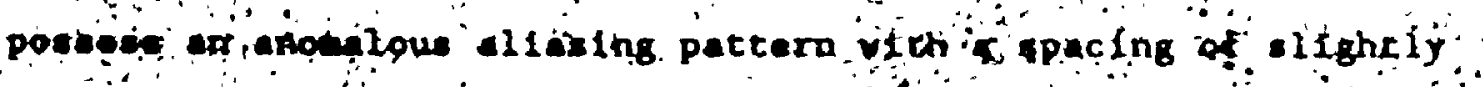

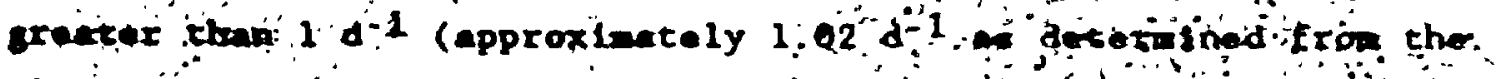



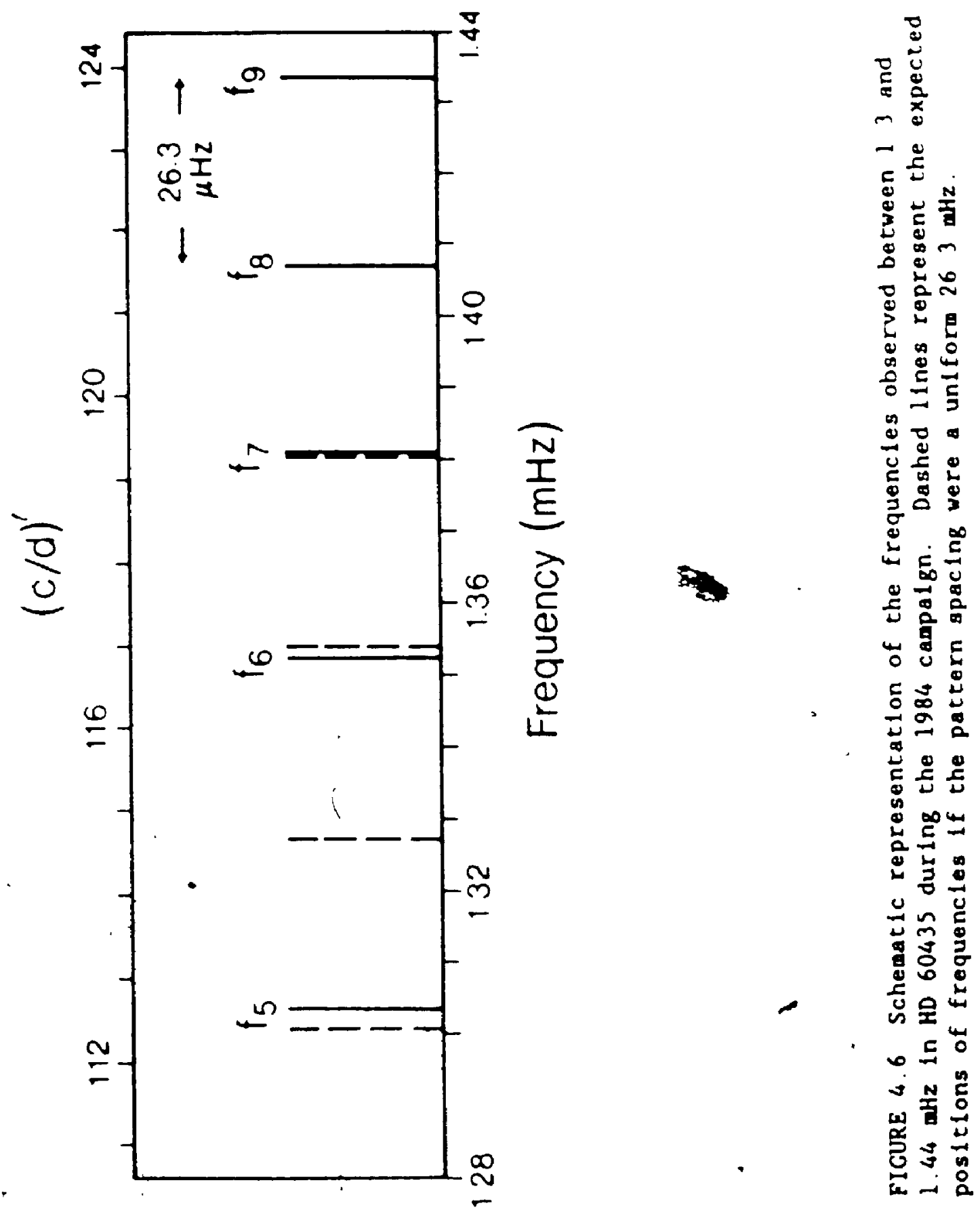


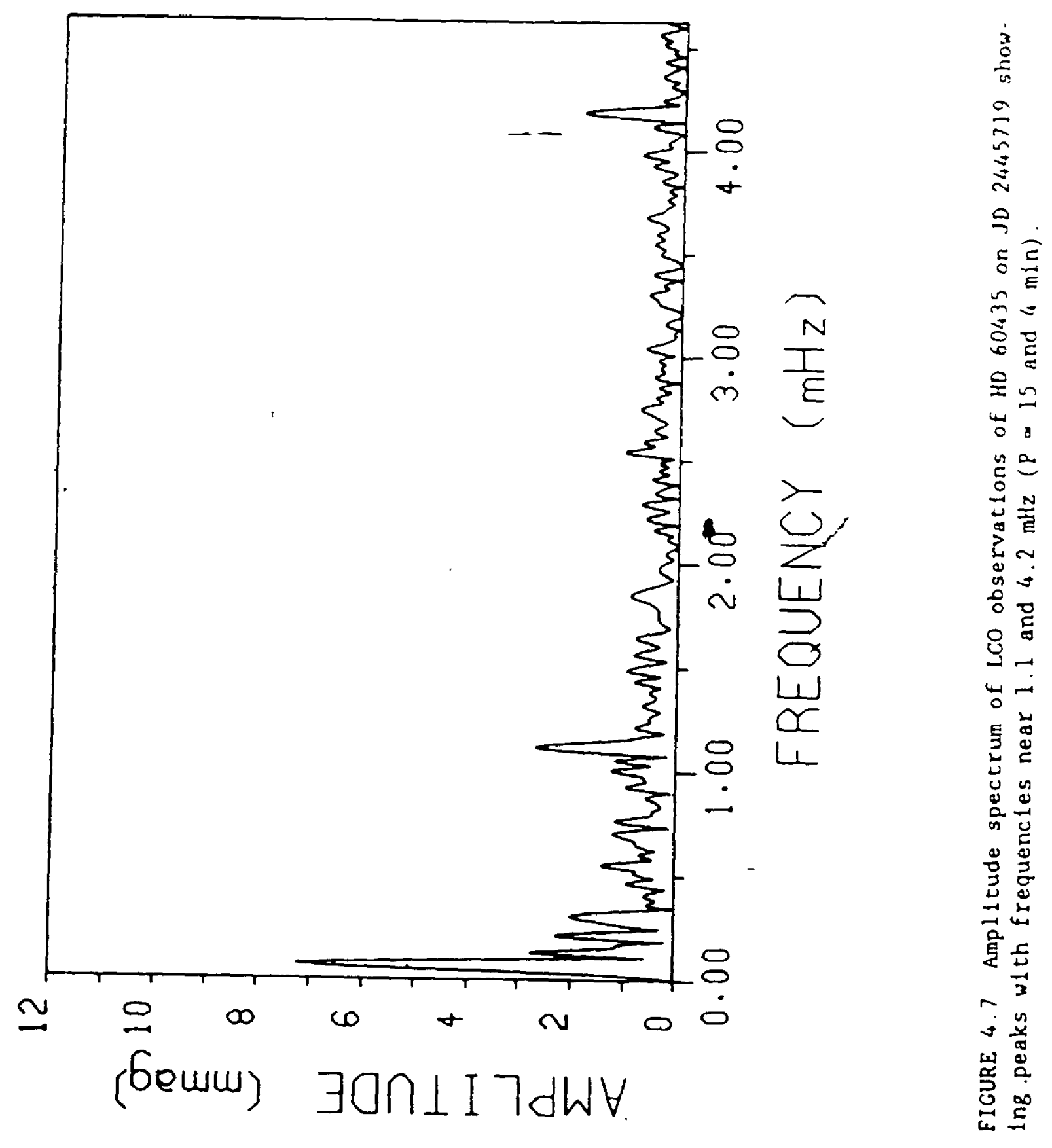




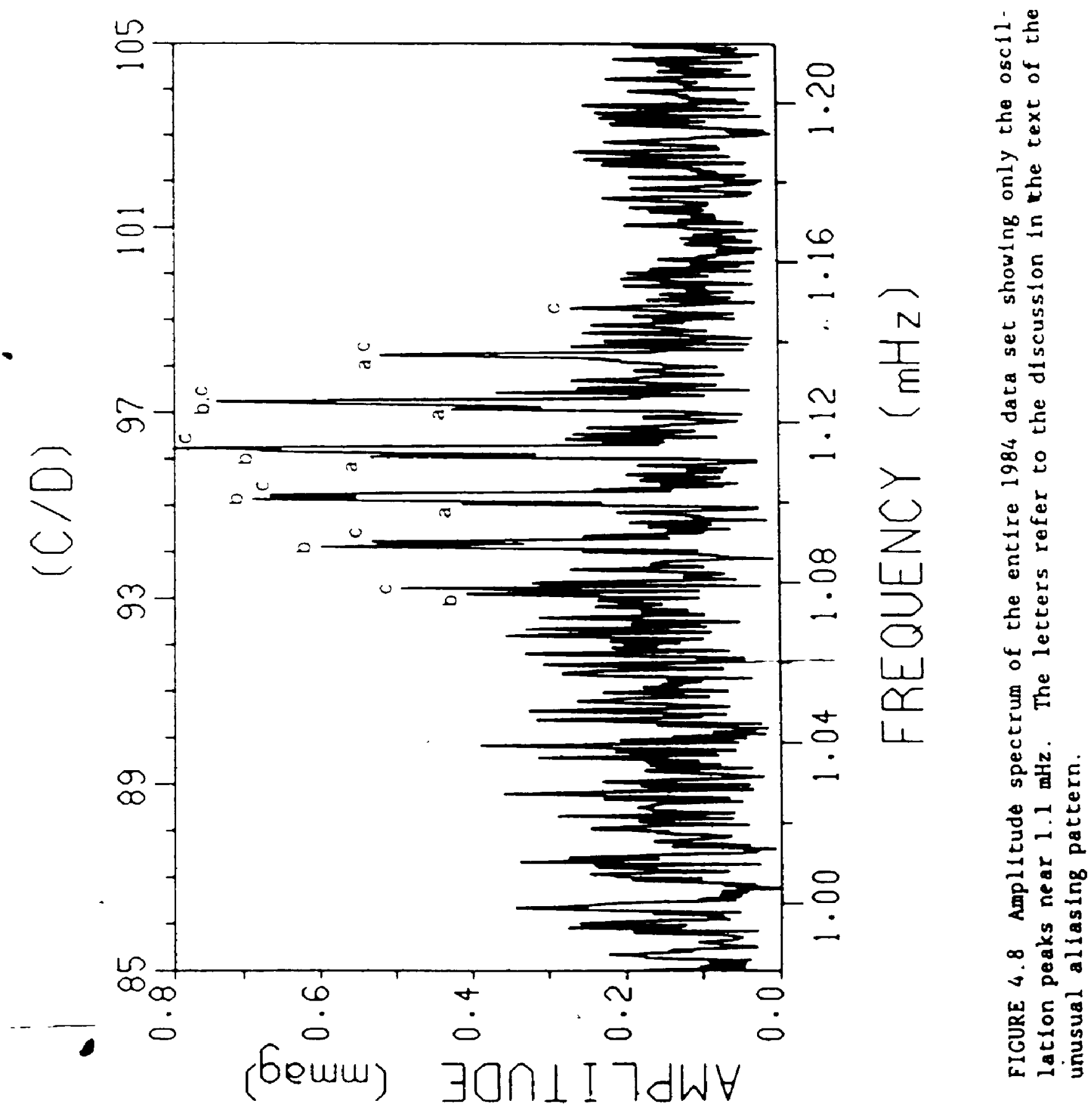


maxim of the peaks). The two patterns can be seen to nerge into the peaks of the first with increasing frequency. (The three allasing patterns can be nost easily distingilshed using the composite peak near $1.10 \mathrm{mHz}$ in Figure 4.8. The Ifght-hand peak (c) belongs to the 1-d-1 allasing pattern; the renaining two $[a, b]$ are part of patterns with $1.02 \mathrm{~d}^{-1}$ spacings. In the peak near $1.125 \mathrm{mHz}$, for example, two of the peaks have nerged completely.)

Such an effect can be produced by the addltion of two unresolved alising patterns with central peaks of different amplitudes spaced by slightly more than $1 d^{-1}$, but the frequency shift would be much smallet than that observed, given the resolution of this spectrum.

Frequency nodulation of the oscillations (e.g. an Inctease in Erequency by $0.02 d^{-2}$ ) could reproduce such an anomalous patcern. However, It is difficult to understand how only two of the many frequencles present - all thought to arlse from global varlations in the etar - would be independently modulated. Moreover, the only known mechanisa for frequency modulation of pulsation is stellar evolution, certainly neither a rapid nor a selective process. (This argument assures that the observed varlations in HD 60435 are due to pulsation.) It seens most likely that the funusual aliasing pattern arises from the Interference of more than three normal al wsing patterns. auperlmposed upon one another.

Using the window flitering technique described in Chapter 3 , it is poesible to select a frequency triplet centred at 1.10077 arz with a epacing of $1.39 \pm 0.24 \mu \mathrm{Hz}$ (the same as the spacing observed in the epectrum of FIgure 3.4, within the uncertainties) and a fourth single frequency et $1.11327 \mathrm{mz}$ to reproduce the observed spectrul. (The 
fourth frequency is offset by $1.08 \mathrm{~d}^{-1}$ frod the central frequency of the triplet: Its proximity to a spacing of exactly $1 d^{-1}$ aay account for the apparently" anogalous" allasing pattern.) Even so, the reality of this identification is unceltain, since the data sample clearly does not span a single modulation perlod (If there is one) for these oscll. lations.

Note: A significant feature of the spectrum in Figure 4.8 is the resolution of any fine structure at all If the osclllations near 1.1 mhz were only present in the first six nights of these LCo data, then additional structure (beyond what is contained in a spectrun of the first six nights) should not be resolvable. But there is indeed noge fine structure present. Clearly, some power must be present at these frequencies in subsequent data - albelt at very low amplitudes - to account for this.

The region of the spectrum near $4.2 \mathrm{mHz}(P=4 \mathrm{mIn})$, shown in Figure 4.9, provides little information about fine structure, given the low anplitudes of the peaks relative to the nolse. Whereas the nolse "continua" in the amplitude spectra of figures 4.4 and 4.8 are relatively flat. the nolse level in Figure 4.9 appears raised between the peaks of the one definite allasing pattern. There may be so many interwoven allasing patterns that the "contlnuus: nolse level of the spectrun is artificlally raised by the co-addition of the basea of the peaks.

Only one frequency is readily Identflable: $4.17307 \pm 0.00012$ mz. In light of the ailasing and. low amplitudes, It ls. pramature to attempt any other analysis based on this spectrun by itself.

There is litele, if any, evidence for the presence of the isix- 


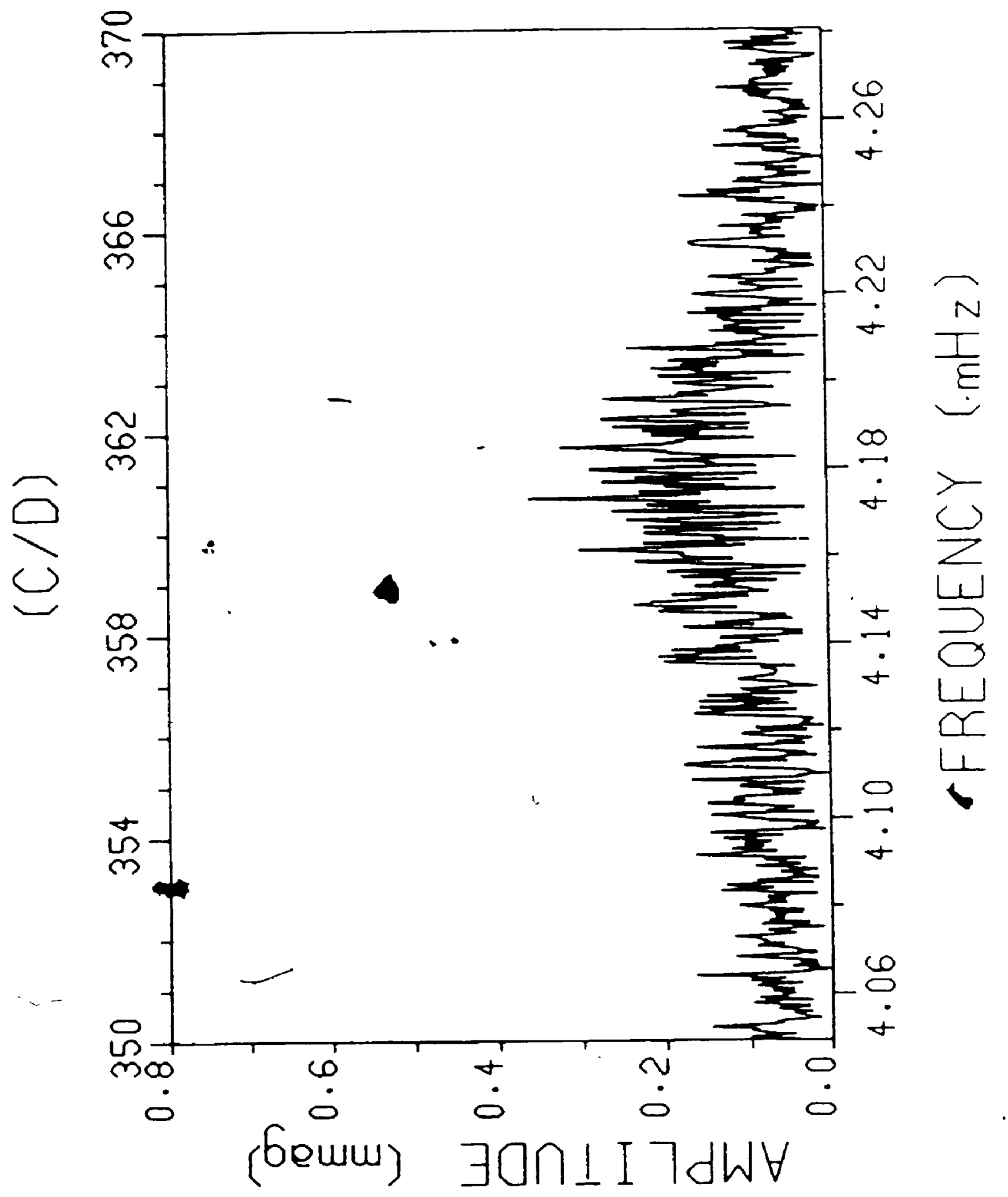

a $N$ 
minute" oscillacion raported by Kurtz (1984) in any of tho data from this inftial campaign.

\section{Results of the second campalgn}

Figure 4.10 is a sample of ten perlodograms selected frow the set of 35 nights in this campaign. Across each is a dashed ine which represents the value of $A_{9} g$ for that night, as given in Table 2.1.

The peaks evident at frequencies less than about 0.5 mbz reflect residual power which remalns after the flltering process described in Chapter III. Peaks which rise above Ago are tagged with letters; these have been keyd to the list of frequencles in Table 4.1.

The differences in frequency resolution and nolse level in the spectra come about primarily from the respective differences in nightly coverage and observing condltions for the corresponding data sets. The CTIO observations, for example, consist of runs of roughly equal $(6.7 \mathrm{hr})$ on nights of exceptional sky quality. Therefore the resolur tid and the values of $A_{9} g_{8}$ are comparable from spectrun to spectrum over these nights.

The periodograms of Figure 4.10 were chosen to lliustrate a few of the noteworthy features of HD 60435's oscillations which came to light during the second campalgn:

1. Frequencles near $1.4 \mathrm{mHz}$ continue to doninate; these osc111ations are the most persistent and reach the largest amplitudes.

2. The modulation timescale of $7-8$ days for those oscillations is evident. JD 2446022, $-082,-098,-105$, and -142 are nights during which the "12-min" osctilationg reached $\max 1$ mum - or near waxlmun anpl 1 tude. 

<smiles>[3H]CCCI</smiles>
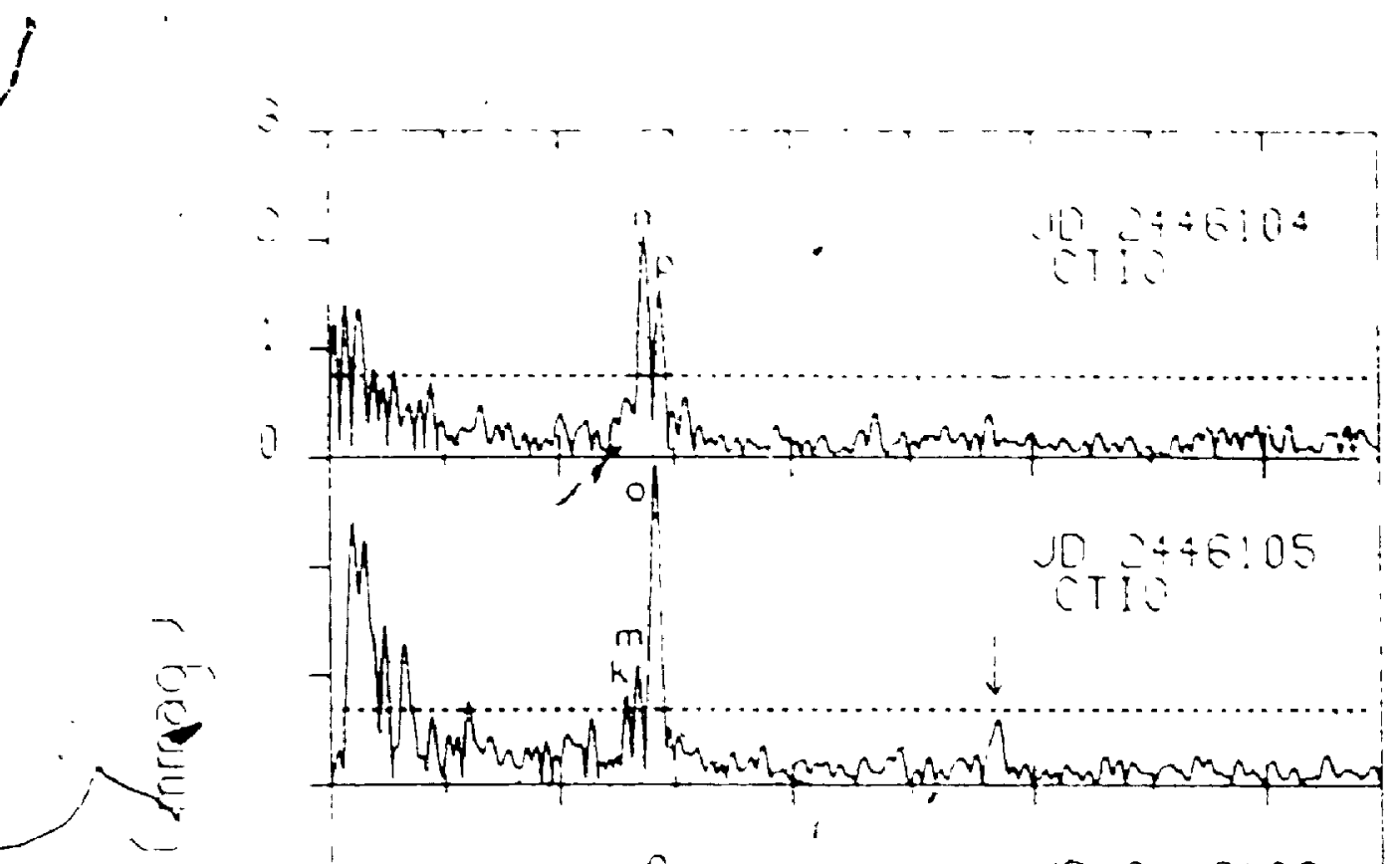

68

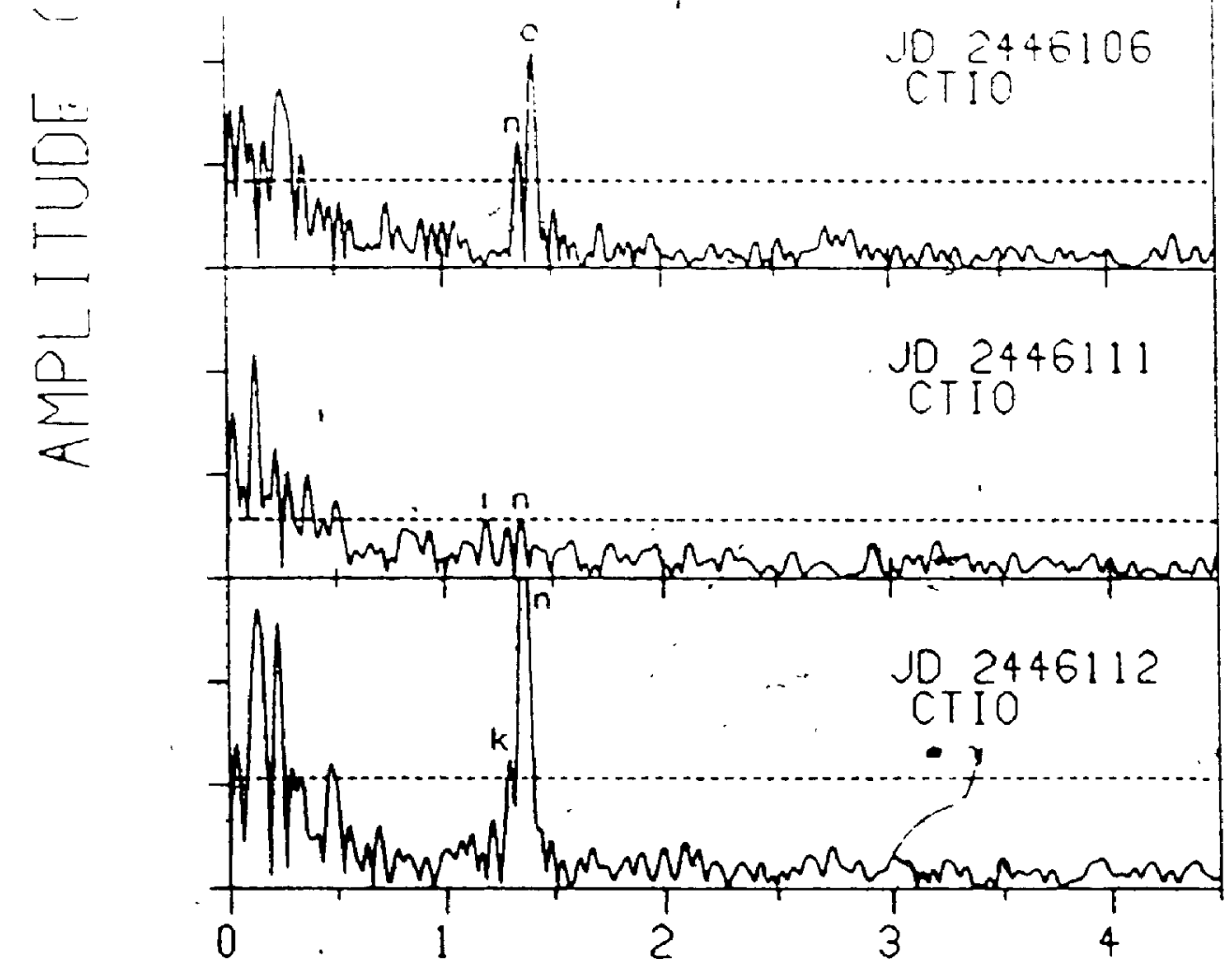

- FREQUENCY $(\mathrm{m} H z)$

which peaks are considered statistically significant at the 990 level (see discussion in Chapter III). The letters above the peaks are keyed to the list of frequencies in Table 4.1. (Figures 4.20 end 4.11 ere taken from Matthews, Kurtz and Wehleu (1987).) 
TABLE \& 1

FREQUENCIES OBSERUED IN HD 60435

Frequencies in ltalies are values derived from the farst campaign

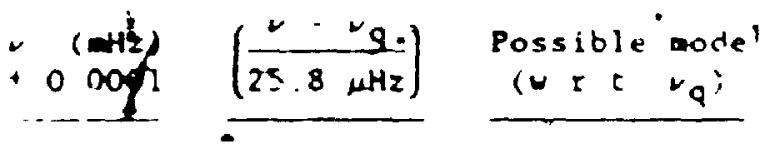

$07090 \quad 2900=29$

01614

08428

$23.81-24$

09397

$200 \hat{-20}$

09906

$1809-18$

10433

$\ldots$ $-\frac{-}{8}$

10990

11008

6 $^{\circ} 1133$

$\pitchfork \quad 1.1482$

$1198-i 2$

$11.00-11$

12848

$1.303 ?$

1.3281

1

1.

1. 3525

1. $3521^{4}$

n $\quad 1.3110$

1. 3009

1.6073

1: 1075

1.4334

i. 4336

- $1 . \$ \$ 572$
$2691=2 ?$

$n-6 \cdot 2$

$\left[\begin{array}{l}n \cdot 6 \\ n \cdot 5\end{array}\right] \cdot 2 \pm 1$

$9.00-9$

$\left[\begin{array}{l}n-5 \\ n-4\end{array}\right] \cdot 2 \pm 1$

$6.68^{2}$

$5.95-6$

$5.00-5$

$4.06-4$

$2.95-3$.

$\left[\begin{array}{l}n-15 \\ n-14\end{array}\right], \quad l \pm 1$

$\left[\begin{array}{ll}n-1 & 4 \\ n-1 & 3\end{array}\right] \cdot l \pm 1$

$n \cdot 12, l$

$n-10,1$

$n \cdot 9,2$

$n-8 \cdot 2$

$n \cdot 7.1$

.

$\left[\begin{array}{l}n-4 \\ n-3\end{array}\right], 2$

$\left[\begin{array}{l}n-3 \\ n-2\end{array}\right] \cdot 2 \pm 1$

$n-2 \cdot 2$

$\left[\begin{array}{l}n=2 \\ n-1\end{array}\right], 2 \pm 1$

$1.93 \div 2$

$n+1$ - 1

$0.92 \cdot-1$

$\left[\begin{array}{c}n-1 \\ n\end{array}\right] \cdot 1 \pm 1$

n $\cdot$
Tentative

Mantrfication

$\ln 14.1$

(n.13,

$\left(n-12.2 i^{\circ}\right.$

(n-11,0).

$[n \cdot 10.2]$

$[n \cdot 9.2)$

$(\pi-8.2)$

$\mid n \cdot 7.2]$

$[n \cdot 6,2]$

$[n \cdot s, 1]$

$\{n-4.1\}$

$[n-3.2]$

$[n-2.1]$

1

$\{n: 2,2\}$

$\{n-1,1\}$

$[n \cdot 1,2]$

$(n .1)$

$[n .2]$
Dates detected I JD $2445000+$ ?

1077,1097

$100^{\circ}$

1008

1082

1101

1078

1022. 1078

719.723

1077,1079

1101

1022

1105. 1112

1984 Combined $^{3}$

1102,1105

1019, $1021 \cdot 23$

1079, 1095.96

1105, 1107

1099, 1104

1106, 1111-12

$1074,1105-06$

1075,1082

$.1097-98,1106$

1985 comblnops 
1 According to equation (4 1), such that $(n-1),(l-j) \geq 0$

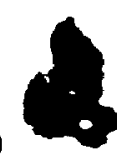

$$
2 \nu_{k}=((7 \times 25.8) \cdot 82\} \mu \mathrm{Hz}
$$

3 Detected in the amplitude spectra of several nights conbined. 
3. There exists a serles of peaks across'a range frov about 0.7 to $1.5 \mathrm{mz}$ ( 1.0 . periods from about 20 to $12 \mathrm{~min}$ ). The low-frequency lint of this range is rather 111 -defined, since resl oscillations below 0.7 ahz are nore likely to be masked by sky nolse, or conversely, peaks due to sky nolse at these lower frequencies can masquerade as stellar osclilations. In any event, the filter applied to the data Invaldates an analysis at frequencies less than about 0.5 ahz.

4. On two of the nights 11 sted in point 2 (JD 2446022 and - 105). peaks - Indlcated by arrows in Figure 4.10 - occur near a frequency of $2.8 \mathrm{mbz}(P-6 \mathrm{~min})$. In these spectra, they have amplitudes fust below the 99. confidence level; hovever. this level has been calculated for. the detection of a peak at any frequency in the spectrun. The Scargle false-alara probability of finding a randon nolse peak at a particular frequency.(In this case, at a $2: 1$ ratio with one of the $1.4 \mathrm{nhz}$ peaks) is different. The values of App for a specific frequency in each of the two data ete are approximately 0.9 and 0.5 mag, respectively. The peaks observed near 2.8 aHz are above these revised confidence 1191ts:

5. Certaln peaks can grow to (or decay from) observable anpll. tudes in less than a day; e.g. the development of peak ' $n$ ' In Figure 4.10 between JD 2446111 and -112 .

On the besis of epactra like those in Figure 4.10, from both camplgos, a list of observed fraquencles in ho 60435 was compled in Table 4.1. The frequencles vere Hermined to the quoted accurecy ulng higher resolution apectra of many nights of data (e.g. Figure 4.11b).

An exantmation of the frequancies of Table 4.1 revealed that 


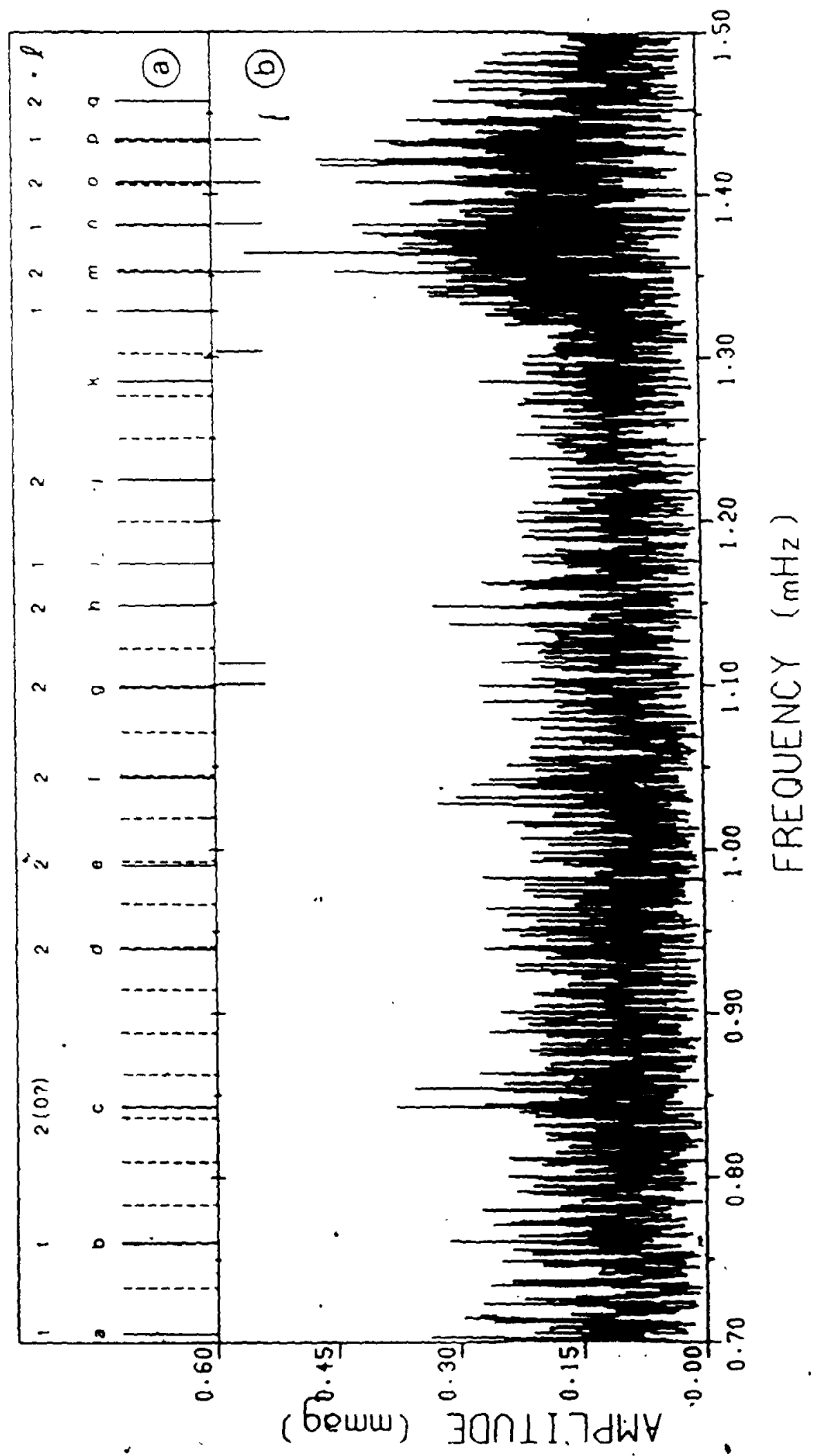

ำ

-

용요

- 1 車

구

- वे है

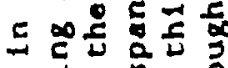

ड

본

$\alpha 0$

on

$\exists-5.5$

S0 0

잉

\&

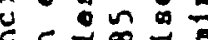

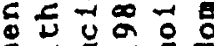

ये $\overrightarrow{3}=$

光

W E :

원

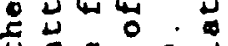

ป

4 可

- $\rightarrow$ 5

$5 \subseteq$

궁

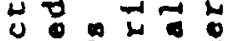

영

응 용

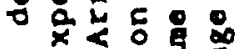

0 잔

L:

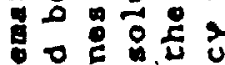

도웅

군용

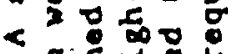

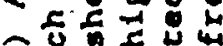

可出

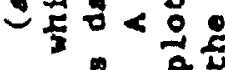

$=0$

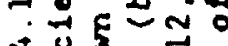

$\checkmark$ c

幽

苟要

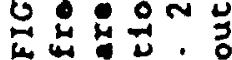





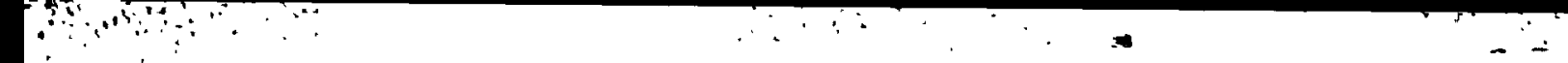

spacing will again be $v_{0}^{\circ}$; but if bodes of both even and add degree ( $l$. $\ell+1, \ell+2, \ldots)$ are present, then the frequency epacing vill be only $t_{0} / 2$. The observed spacing in HO 60435 is approxtately 26 uliz; this, for this star. $\nu_{0}$ should be exther -26 or 52 whz.

Evolutionasy status of KD 60435

Gabriel et al (1985) have calculated the elgenfrequency spectra of ain sequence wodels betreen 1.5 and $2 \mathrm{k}$. Combining their results with observations af the solar oscliletion spectrun. they conclude that for MS stars between 1 and 2 "

$$
\nu_{0}=(0205 \pm 0.11)\left(\frac{G M}{R^{3}}\right)^{h}
$$

where Is the star's ass and $G$ is the gravitational constant. It is relatively easy to show that, based on the above equation, I Ines of constant $\nu_{0}$ are approxtarely stralght fines in a $\log (\operatorname{lun} \operatorname{lnos} 1 t y)$. $\log$ (effective temperature) diagram. Given that a star's luninosity $L$ is reiated to its temperature $I_{\text {eff }}$ and radius $R$ by

$$
L-\sigma T_{e f E}^{4} \times 4 \pi R^{2}
$$

and to Its ass by an emplrical ass-luminosicy relation for ain. sequence starz only a few tlaes brlghter than the Sun (Harrle et al. 1963)

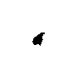

$$
4 \div m^{4} \text {. }
$$

then it follows that $\nu_{0}^{2} \propto T_{e f}^{6} / L^{5 / 4}$, or

$$
\log L=\frac{24}{5} \log T_{e f f}-2 \log \nu_{0}+\text { constant. }
$$


Shlbahash1 and Salo (1985) have calculated these $*_{0}$ contours analytically based on the interfor sound speeds of stellar models with masses near 2 . track for several wodels in the sane inftal mass range? are plotted In Figure 4.12. The lower ends of the tracks nark the zero-age main sequence (ZAMS).

It can be seen fron this figure that a value of $\nu_{0}=26 \mu \mathrm{Hz}$ (contour D in Figure 4.12) would place HD 60435 well above the ZAMS (close to contour $A$ ), beyond the polnt at which core hydrogen exhaus. tion occurs in the model stars. It is unlikely that any observed Ap stars have evolved this far off of the main sequence. For example. peculiar atars aro found in the young assoclatlons of Scorplo-Centaurus (H111 1986) and Orton (Joncas and Borra 1981), whose ages are Incon- 1stent with having nembers whlch are highly-ovolved A stars. Therefore, value of $\nu_{0} \Rightarrow 52 \mu \mathrm{Hz}$ (contour C) is more likely, suggesting thet RD 60435 is sonewhat evolved but still close to the ZaMS band. (The only other roAp star for which a simllar pattern of near-equal frequency spacing has been discovered 1s HR 1217 (Kurtz and Seeman 1983). For this star, the observed epacing is $-38.5 \mu \mathrm{Hz}$; by a inflar ergument.to that used above, the inferred value of $\nu_{0}$ is about $67 \mathrm{\mu Hz}$. Therefore, examining the contours of Flgure 4.12, HD 60435 appears -11ghtly sore evolved than KR 1217.)

Uaing equation (4.4A) and the $\nu_{0}-52 \mu \mathrm{Hz}$ contour in Figure 4.12. and asouning that this rodp star falls aoswhere within the $\delta$ Scuti inetabllify atrip, the radius of $\mathrm{HD} 60435$ can be estinated:

$$
R=2.2 \pm 0.3 R_{O} \text {. }
$$




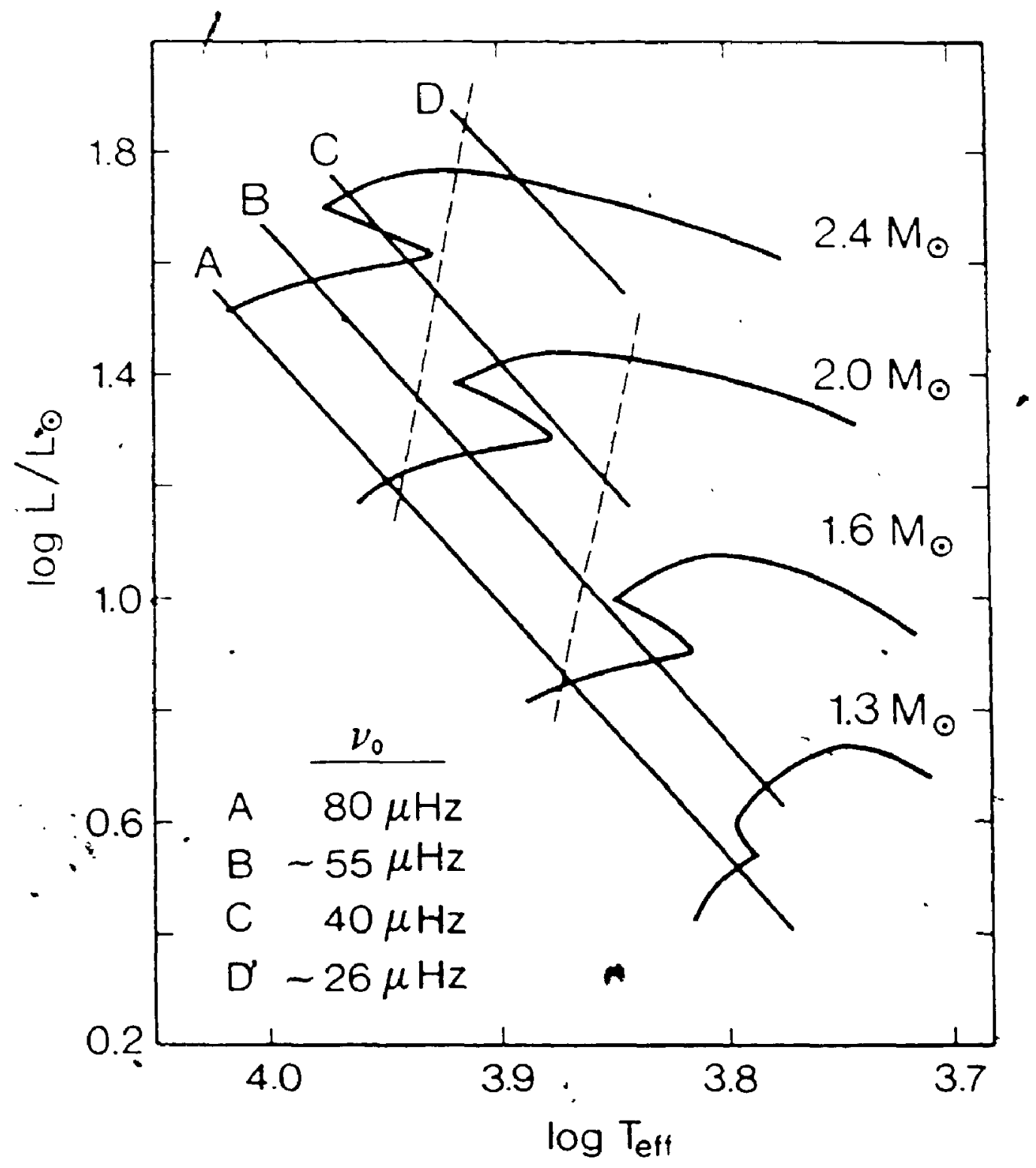

FIGURE 4.12 A theoretical H.R diagram of -the evolutionary tracks of starsnear 2 Mo with chemical composition $\left(X_{0}, Z_{0}\right)-(0.70,0.03)$ and a $T-$ r rela. tion from Kurucz's (1979) standard model atmosphere (Shibahashi and Salo 1985). The solid straight lines labolled A-D are contours of constant vo. The dashed lines are the boundaries of the observed $\delta$ Scuti instablilty strip (Breger 1979) converted to $\log \mathrm{L}$ vs. $\log \mathrm{Teff}$. 
which is roughly $1.4 \times$ the radius of a main sequence star in the spectral range AS - FO which 18 wost likely to encoupass an roAp star.

The portrayal of HD 60435 as a star which has evolved further off of the an sequence than sone of the other cool Ap stars is bolatered by the Interpretation of its Strongren indices (Chapter I). HD 60435 is the only one of the roAp stars which falls at the upper bound of Golay' (1974a) $[u-b], \beta$ aain-sequence zone. It Also has the only positive value of $\delta c_{1}$. placing it above Crawford's (1979) $c_{1} \cdot(b-y)$ main sequence curve. Although some scater in $c_{1}$ is to be expected due to differences in ataospheric abundarice, this is still highly suggestive that HD 6043518 the most luminous of the roAp stars.

Mode Identiflcation

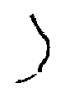

A value of $\nu_{0} \approx 52 \mu \mathrm{Hz}$ in turn cignifles that adjacent frequencies In the pattern depicted in Figure 4.11 represent overtones of alternatIng even and odd degree. The third colum of Table 4.1 shows the combination allowed by a llatted number of degrees $l_{1}$, where the frequency $\nu_{q}$ has been arbitrarlly designated as $(n, l)$.

When examined in detall, the frequency spacing between adjacent modes is not expected to be precisely uniform, and the observed Inequalities can further restrict the possiblities for specific node Identifications. ShIbahasht and Salo' (1985) calculations of theoret. Icel elgenfrequencles for their A star models Indicate that these in-. equalities will be systematic, such that

$$
\begin{aligned}
& \nu(n, 1)-\nu(n, 0)<\nu(n+1,0)-\nu(n, 1) \\
& \nu(n, 1)-\nu(n-1,2)>\nu(n, 2)-\nu(n, 1)
\end{aligned}
$$


in agreement with the findings of Shibahashi et al. (1983) for the solar case.

For HD 60435, frequencles $\nu_{k}$ ' to $\nu_{q}$ represent a part of the overall pattern in which there are no gaps. These frequencles can be used to test the above relations by equating the observed values, with a self-consistent set of $(n, l)$ and substituting them into equations (4.6) where approprlate. One finds that equation (4.68) cannot be satisfled by the observed frequencies, and that equation $(4.6 b)$ is satisfied only If $\nu_{q}$ is a mode with $l-2, \nu_{p}$ a mode with $l-1$, and so on. This added constraint restricts the mode identifications to those provided in the fourth colum of Table 4.1 and at the top of Flgure 4.11a.

The frequency $\nu_{k}$ presents something of a probled in this scheme. It clearly does not fit the pattern of $i-1$ and 2 nodes that $i s$ proposed for the other frequenckes. By combining Shibahashi and Salo's numerical results for $l-0,1$, and 2 nodes, it can be shown that no mode with $l \leq 3$ should occur at frequencles betweer: a given $l$ - 1 mode and the next higher $l-2$ mode. I offer no explanation for thls frequency at present. although it does not seem to be spurtous. (Note: One of the frequencles observed in the first' campalgn, ${ }^{\prime}{ }^{\prime}$, also does not flt the pattern of Figure $4.11 \mathrm{a}$. However, it is compatible with either an $l$ - 0 or 3 mode in the Shibahashi and Salo elgenfrequency set. In addition, that particular peak in the anplitude spectrum appears to have no sidelobes, which is expected of an $l-0$ sode in an oblique pulsator.)

The overtones $n_{1}$ of the modes in Table 4.1 cannot be detereined with precision, but equation (4.1) can be used to estimate thelr range. The frequency ratio of consecutive overtones of like degree may 

V. THE SPECTRUM OF HD 60435

The spectroscopic observations described in Chapter II were obtained in conjunction with simultaneous or contiguous rapid photometry to refine the spectral classification, and to deternine:

1) If the star is indeed a spectrum variable, and if so, to what degree :

and, in the event of sufficiently strong variations..

i1) a rough estimate of the variation period (or timescale) for comparison with values derived from the oscillation dats and the mean photometry; and

111) any correlations between the line strength varlations and the modulation of the oscillation amplitude (1.e phase of maximum/ainlmum line strength relative to the modulation cycle).

A tracing of the average of the twelve exposures, covering wavelengths from $3800-4600 \AA$, is shown in Figure 5.1 . few of the strongest lines have been labelled. Many lines which are apparent upon )

- visual inspection of the photographic plates appear as "nolse" in the continuwe of the tracing.

\section{Spectral classiflcation}

The strengths of the Sr and Cr lines are consistent with late Ap or FOp (SYCr) classification for HD 60435. The equivalent width of the $\mathrm{Hy}$ line, $W(\mathrm{H} \gamma) \propto 7.5 \pm 0.5 \AA$, Is noral for an FO $v$ or III star, basied on the correlation between Sinnerstad's (1961, cf. Golay 19746) neasured width and spectral type. The equivdlent width of HP deteralned from these epectre is approximately $11 \pm 0.5 \dot{A}$, which watches, a clase of A7 III according to the sinnerstad relation. (Cravford's (1958) 



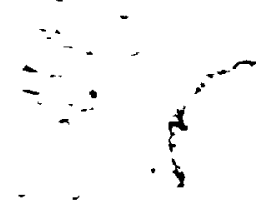

calibration of $W(H B)$ and the photonetric index leads to the value of $\beta=2.79$ given in Table 1.2. The resultant position of HD 60435 in a [u-b].B diagran (see Chapter I) yields a rough spectral class of $A 8 \mathrm{~V}$ or III.)

The Ca II lines also seen to indicate a somewhat earlier spectral type. There are sone concerns about the linearlty of the plate at the short vavelength end, but they are not serious enough to disqualify the $\mathrm{Ca}$ II lines as classifying parameters. In an FO $\mathrm{V}$ star, $\mathrm{Ca} \mathrm{K}$ and $\mathrm{Ca} \mathrm{H}$ + He) should have roughly equal equivalent widths, but $C a k$ is clearly weaker in this spectrum. The Ca K equivalent width israughly $S \pm 0 . S$ A, witch matches A6-A8 (III-V) on Floquet's (1981) plot of W(Ca K) Vs. spectral type for normal stars between BS and FO. However. Adelman (1985) cautions that the Ca II K I ine noy not be a rellable cemperature indicator for the Ap stars, citing differences between the temperatures he derives fron the UV energy distributions of peculiar stars and the resules of floquet. Also, Ca is variable in some Ap stars; for example, 53 Can appears to have an Inhomogeneous distribution of Ca on 1ts: surface (Landstreet, prlvate comunlcation).

\section{Spectroscopic variability}

To display variations in line strengths, each individual spectrum was divided by the averaged spectrun of Flgure 5.1. In the divided (or "ratloed") spectra, lines weaker than average will appear as bump in the continuun, while stronger lines are seen as depressions. Changes in line width will result in "double-humped" features. The divided spectra, showing only the range 4050 - $4550 \mathrm{~A}$, are plotted in Figure ? 5.2. On ef laset one exposure ( 3 Feb), there are 1 gns that the photosetric properties of the plate are non-unlfora, and hence, line infor- 


$$
2 \text { oflde } 2
$$




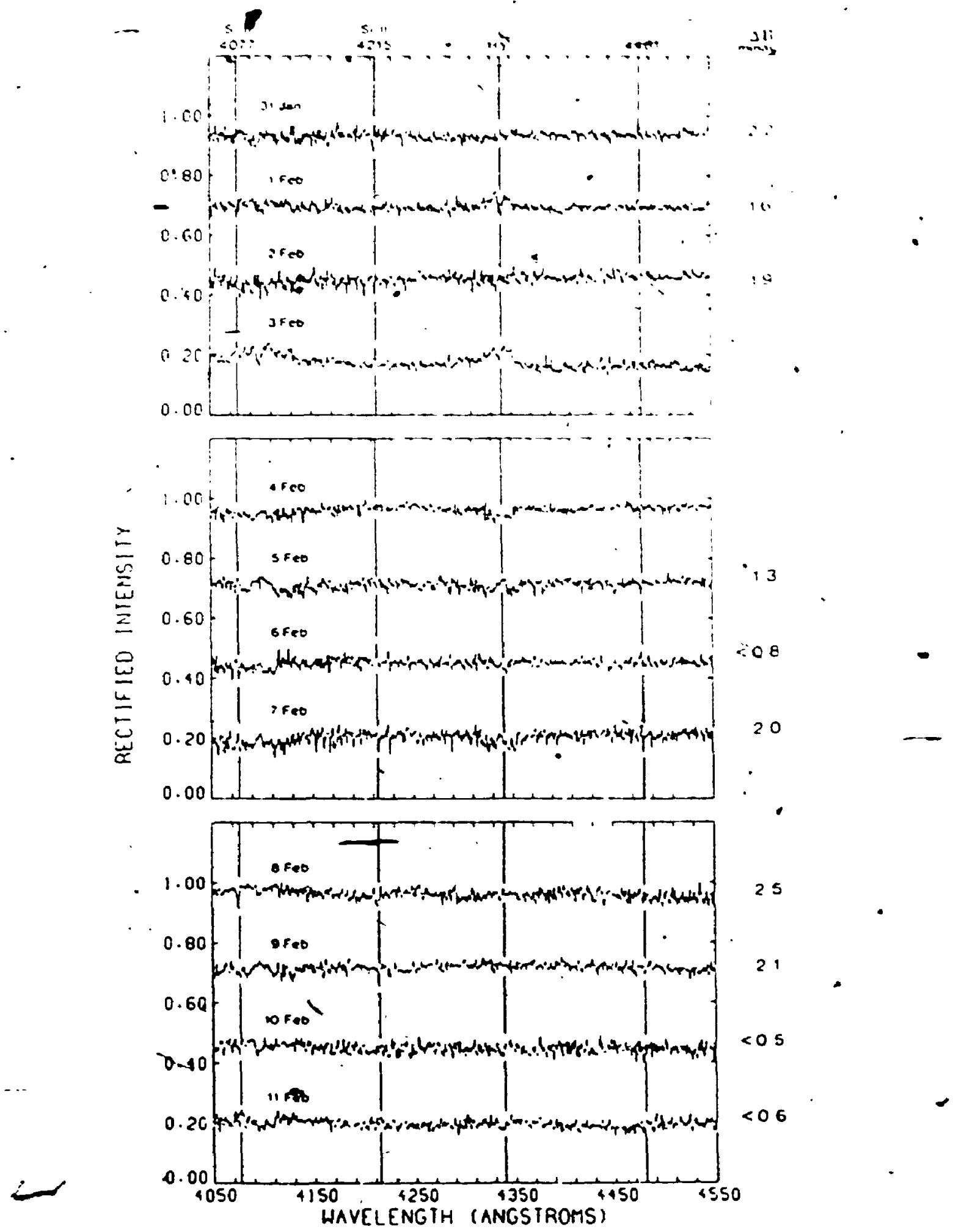

FIGURE 5.2 The twelve individual spectra of HD 60435, divided by the ave-. rage spactrum of Figure 5.1. On the right are the corresponding $B$ anplitudes of the 1.4-miz oscillation measured on those nights. 
during the 1985 campaign (also tabulated in Table 2.3). The 11ght curves show clear evidence of a secondary minimum in brightness. Both sets of data have been plotted according to the ephenerts

$$
J D\left(B_{\min }\right)-2445729.791+(7.6662 \pm 0.0001) E .
$$

The period was determined by a "string length minimum" analysis of all of the data, similar to the technique of Lafler and Rinman (1965). (See Appendix B for a listing of the actual programme used and a brief description of the algorithm.) If the oblique rotator model applies to. HD 60435 , then 7.6662 d represents the rotation period of the star. The apparent double-wave shape of the light curve suggests that, if this star possesses a measureable dipole magnetic field, the observed effective field will undergo polarity reversal. This argument assumes that a dark photospheric patch is associated with each magnetic pole: hence, magnetíc extrema would colncide with light minima.

A survey of magnetic and light curves of Ap stars avallable in the literature (Table 6.1) shows thls to be a reasonable assumption. Of the sample of 19 stars, $17^{\circ}$ reach minimum B magnitude during an extremum In magnetic fleld strength, and 13, of those at the absolute maximur in the magnetic curve. Furthermore, note that 11 ght minimum in HD 60435 coincides with oscillation amplitude maximum (Figures 6.1 and 6.2 ). $\because "$ Recall from Chapter $v$ that the spectroscopic observations of this star suggest that peak Sr II line strength also occurs at the sase phase. Another literature survey - this time of the nagnetic and spectroscoplc variations of 18 Ap stars - by Floquet (1979) Indicates that the SrEuCr stars always have their rare earths, and elewents such as Sr, concentrated at the longltudes of the magnetic poles. Thls tends to corrobo- 


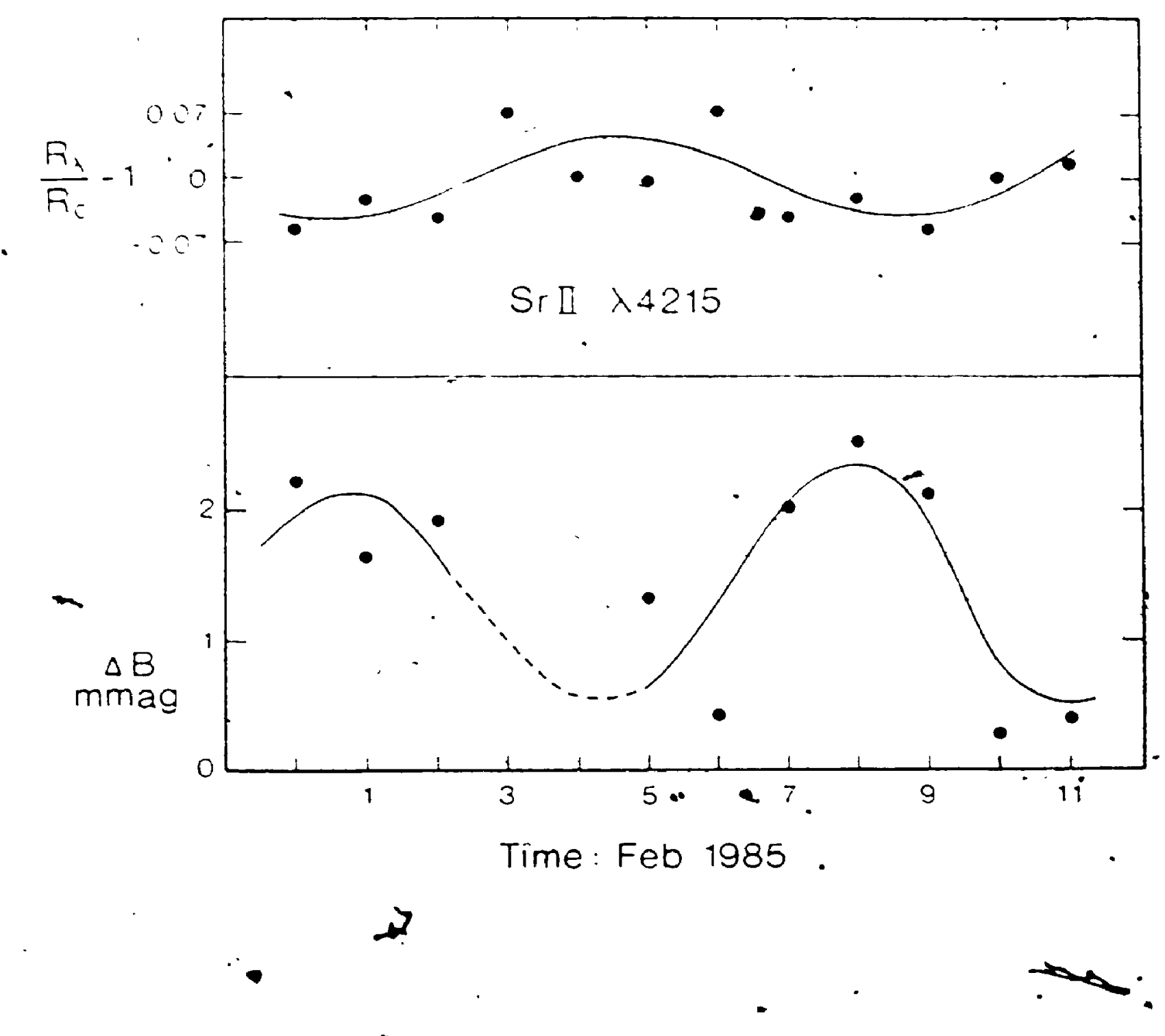
FIgURE 5.3 the variations of the Sr II 74215 line strength and of $\Delta B(t)$
amplitude of the light variability) plotted against time. The curves tre fits by eye to both sets of data. $\because$ 
line shows no arked deviations from average on any other night.

1v) Varlations of the $\lambda 4481$ ine reveal no obvious correlation with the photometric noduletion, nor any indications of perlodicity during:

the span of observation. 


$$
-3
$$

VI. HD 60435 AND THE OBLIQUE FULSATOR KODEL

The oblique pulsator nodel (OPM) makes several specific predictions about the observed behaviour of an roAp star:

i) Amplitude modulation of the oscillations implites the presence of a dipole or near-dipole magnetic field whose axis is inclined to the star's rotation axis. The overall fleld strength must be sufficiently intense to override - at least in part - the influence of rotation on the star's pulsations. (See also (v) below.)

ii) The period of that modulation is identical to the magnetic/ rotation period.

iị) Maximum oscillation amplitude occurs at the phase of primary magnetic extreouin.

iv) If the modulation curve shows a "double wave" (1.e. a primary and secondary maximum during each cycle). Then the star must possess a polarity reversing magnetic fleld. In this case, tha oscillations. should also undergo $180^{\circ}$ phase shifts twice per cycle, coinciding with phases of minimum amplitude of the oscfllations and zero crossover in the magnetic fleld.

$v$ ) In the Fourier spectrum, a pulsation mode- of degree $l$ wlll be split into $(2 l+1)$ components. For $l-1$, the relative amplitudes of the central and sidelobe components supply constraines on the geonetry and intensity of the stax's magnetic fleld (based on the Dzlembowski." and Goode (1985) treatment; cf. Chapter I). Fron equation (1.11): .

$$
\begin{aligned}
& \frac{A_{1}+A_{-1}}{A_{0}}-\tan 1 \tan \beta \\
& \frac{A+1-A-1}{A+1+A-1}-\frac{\dot{C}}{w_{1}-w_{0}+8}
\end{aligned}
$$


where $1_{0}$ - the applitude of the central peak in the frequency triplet. $A_{1}$, A.1 - the aplitudes of the respective components longward and shortward in frequency.

1 - the Inclination of the stellar potation axis,

- $\beta$ - the obliquity of the magnetic field.

C - the Ledọu rotational splitting constant.

worg - the angnetic perturbation of the frequency of an

$\therefore(l, 1)-(1,0)$ mode, and

$\vartheta$

$w_{1} \mathrm{mag}$ - the corresponding perturbation for $(l, m)-(1, \pm 1)$.

- (Note: If $A_{+1}-A_{-1}$. these equations reduce to Kurte's "classi.

cal" oblique pulsator model, where the magnetic field totally doninates advection')

$\therefore$

. Let us exanine how well these predictions atch the observations of HD 60435, and wat in turn they may teil us about this star.

Extstence of an obllque magnet's fleld (1)

Rotation period of HD 60435

All avaltable evidence for the presence of an ordered magnetic fleld in HD 60435 is indirect. Its spectrun (see Chapter V) is. fairly typical of a magnetic Ap(SrCrEu) star, and that spectrum shows line strength varlations sinllar to those seen in other stats known to have strong dfpole-1ike flelds. The star also exhibits long-term photo-

- Dotric varlablity wose amplitude and perlod is consistent with that abserved in almot all agnetic Ap stars. A phase diagram of the mean johnion B measureants of (HD 60435 - HD 59994) frod Table 2.3. spanming the 18.nighes of the first camplgng Is presented in Figure 6.1. Flgure 6.2a is a phase diagran of comparable photometry collected 


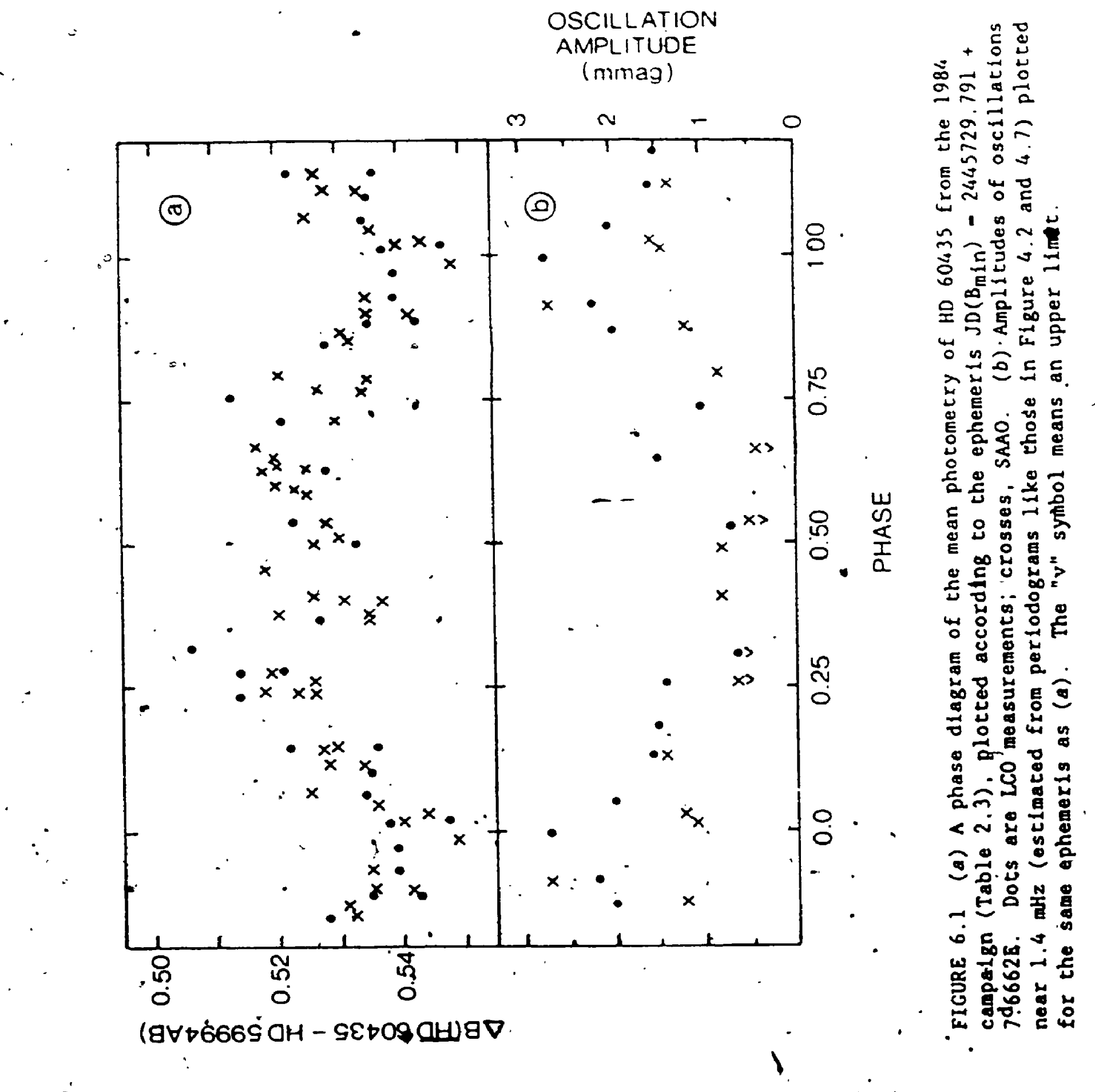


OSCILLATION

AMPLITUDE

(mmag)

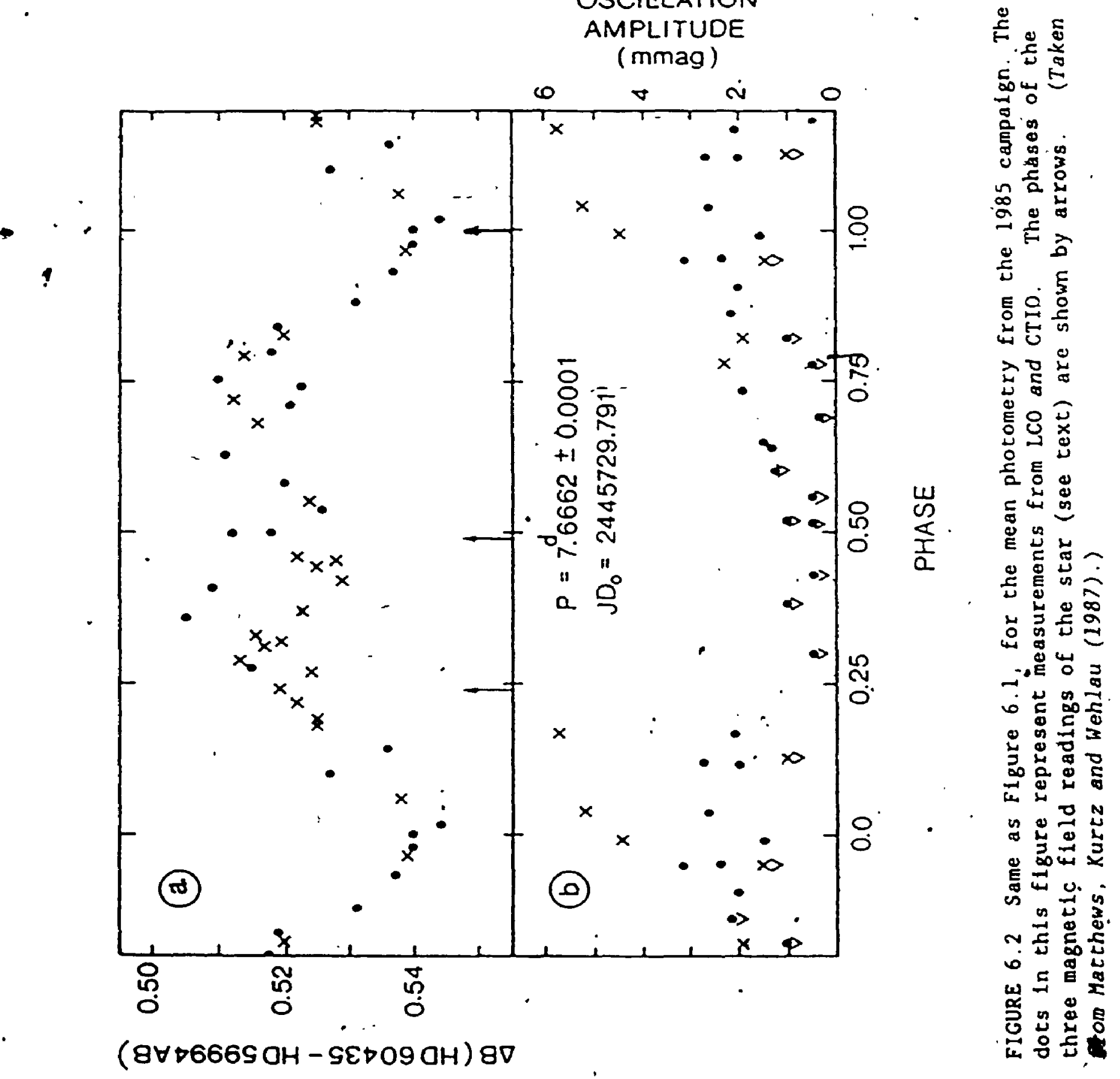

$(8 \forall \nabla 6669 \mathrm{OH}-\mathrm{S} \triangleright \triangleright 09 \mathrm{OH}) 80$ 
during the 1985 campaign (also tabulated in Table 2.3). The IIght curves show clear evidence of a secondary minimun in brightness. Both sets of data have been plotted according to the epheneris

$$
J D\left(B_{\min }\right)-2445729.791+(7.6662 \pm 0.0001) E .
$$

The period was determined by a "string length minimum" analysis of all of the data, similar to the technique of Lafler and Kinman (1965). (See Appendix B for a listing of the actual programe used and a brief description of the algorithm.) If the oblique rotator model applles to. HD 60435, then 7.6662 d represents the rotation period of the star.

The apparent double-wave shape of the light curve suggests that, If this star possesses a measureable dipole magnetic field, the observed effective field wil undergo polarity reversal. This argument assumes that a dark photospheric patch is associated with each magnetic pole; hence, magnetic extrema would colnctde with light ainima.

A survey of magnetic and light curves of Ap stars avallable in the literature (Table 6.1) shows this to be a reasonable assumption. Of the sample of 19 stars, $17^{\prime}$ reach minimum B magnitude during an extremum In magnetic field strength, and 13 of those at the absolute maximuin in the magnetic curve. Furthermore, note that 11 ght minlmum in HD 60435 colncides with oscillation amplitude maximun (Figures 6.1 and 6.2). $\because$ Recall fron Chapter $v$ that the spectroscopic observations of this atar suggest that peak Sr II line strength also occurs at the same phase. Another 1iterature survey - this time of the magnetic and spectroscopic variations of 18 Ap stars - by Flaquet (1979) Indlcates that the SrEuCr stars always have their rare eartha, and elements such as $\mathrm{Sr}$, concentrated at the longltudes of the magnetic poles. This tends to corrobo- 
TABLE 6.1

PHASE RELATIONS BÉTHEEN MAGNETIC AND IIGHT CURVES OF AP STARS

-

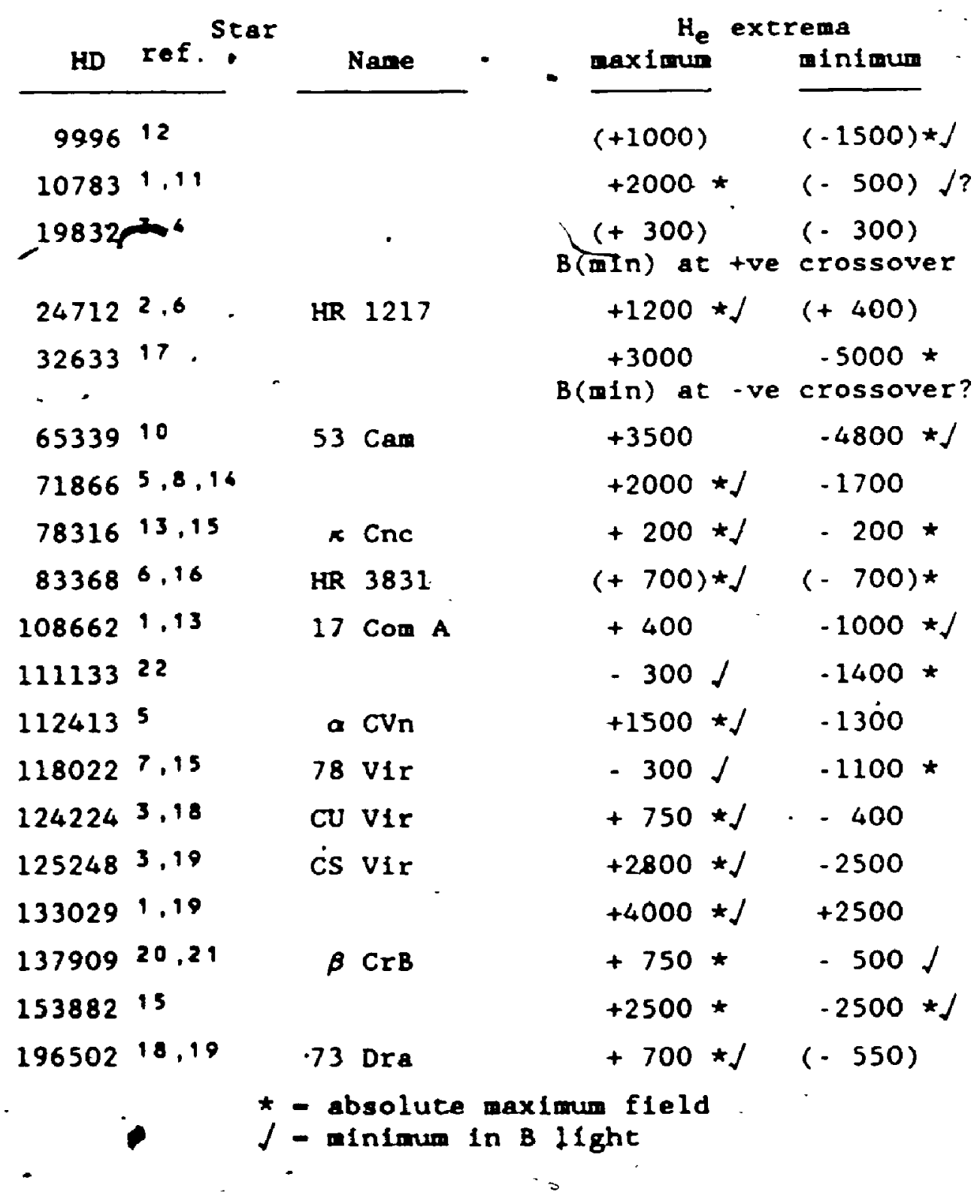

1. Babcock (1958)

2. Boneack (1979)

3. Borra and Landetreet (1980)

4. Hardie and Schroeder (1963)

5. Jarzabowsk1 (1960)

6. Kurtz (1982)

7. Preston (1969)

8. Preston and Pyper (1965)

9. Prazton and Stapion (1968a)

10. Preston and Stepien (1968b)

11. Praston and Stepien (1968c)
12. Preston and Wolff (1970)

13. Preston et al: (1969)

14. Rakos (1962)

15. Stepien (1968)

16. Thompson (1983)

17. Trasco (1972)

18. Winzer (1974)

19. Wolff and Bonsack (1972)

20. Wolff and Wolff (1970)

21. Wolff and Wolff (1971)

22. Wolff and Wolff (1972) 
rate the assertion that $B$ light ainimun and agnetic extremum in HD 60435 colnctde.

If times of minimum.brightnes5, are also times of maxlmun effective field strength, then the secondary minimum in the to. 60435 light curve would correspond to a secondary magnetic extremun. Any magnetic var1ation detected should also match the 7.6662 d period.

Nevertheless, thesę are only alrcumstantial slgns of a dipole field associated with the star. At the author's request, J.D.

Landstreet and D.A. Bohlender (private communication) obtained two field measurements of HD 60435 in 1986 March using the uwo photoelectric Pockel's cell polarimeter, attached to the 2.5-m telescope of the Las Campanas Observatory. Their results were: .

$$
\text { HJD } \begin{array}{rr}
2446513.582(1.8 \mathrm{hr}) & \mathrm{H}_{\mathrm{e}}--250 \pm 560 \text { Gauss } \\
15.522(1.6 \mathrm{hr}) & -70 \pm 680
\end{array}
$$

where the values in parentheses indicate the exposure times. The observations were made at phases relative to the ephemeris of equation (6.3) of $0.240 \pm 0.001$ and $0.493 \pm 0.001$, respectively. In 1987

February, Landstreet and B. Ventrudo (private communication) provided a, third measurement using the same telescope and instrument:

$$
\text { HJD } 2446833.669(2.0 \mathrm{hr}), \mathrm{He}_{\mathrm{e}}--770^{\circ} \pm 570 \text { Gauss }
$$

at a phase of $0.990 \pm 0.001$ on the above ephemer1s. These three part1cular phases are marked in Figure 6.2 a wh arrows.

Given the estimated observational errors, the measurements are compatible with elther a near-zero magnetfc field, or, with fleld as intense as $-1300 \mathrm{G}$. If one continues to assune that prinary 11 ght minimum occurs during primary magnetto extremum, then the phases of the flrst two nagnetic observations (spaced by alnost exactiy cycle) fall. very close to zero crossover and secondery extramm in a polarlty 
reversing field. The shallow secondary dip in the wean ifigt curve suggesta only a veak secondary extremun in the field. This is consistent with the relatively low upper linits to the field strengths at those phases, 'established by Landstreet and Bohlender's measurements. The nost reicent masurenent should have sampled the strongest apparent fleld in the magnetic cycle of $\mathrm{HD} 60435$. This is the only reading which differs from zero by more than the observational uncertainty: however, like the previous two neisures, it is also consistent with a null fleld (at the 20 level).

Despite the inconclusive results of direct observation in this case, there are still a few indirect methods we may use to infer some useful information about the magnetic field of HD 60435. For example. Cramer and Maeder (1980) have developed a photometric paraneter, $\mathrm{H}_{S}$. which appears to be influenced by the mean surface fleld in Ap stars: "0

$$
H_{s}--0.15+(0.02 Z-0.0042) Z \times T_{e f f}(X) \text { Gauss }(6.4)
$$

where $\log T_{\text {eff }}(X)-4.496-0.453 X+0.086 X^{2}$, and $X$ and $Z$ are 1 inear comblnations (defined by Cramer and Maeder (1979)) of the Geneva colours $U, B_{1}, B_{2}, V_{1}$, and $G$. Cramer and Maeder suggest that $H_{s}$ is approximately equal to the surface field of the star, and that this dependence 1 s an effect of the $5200 \AA$ depletion found in the energy distributions of Ap and Bp stars.

The Geneva colours of HD 60435 (Hauck and North 1982), and the resulting values of $X$ and $z$, are provided in Table 6.2. Substituting these Into equation (6.4) gives. $H_{s}=1.9 \mathrm{kG}$. This implies - at first glance - that HD 60435 possesses a nean surface field near two kG. However, Thompson of $A 1$. (1986) have argued that $\mathrm{H}_{\mathrm{s}}$ 'Is influenced by 
TABLE 6.2

GENEVA PHOTOMETRY OF HD 60435

$$
\begin{array}{ll}
U=1.542 & B_{2}=1.402 \\
V=0.670 & V_{1}=1.381 \\
B_{1}=0.985 & G=1.800
\end{array}
$$

$x-1,4182$

$2--0.0394$

$T_{\text {eff }}(X)=-10,630 \mathrm{~K}$.

$\mathrm{H}_{\mathrm{s}}-1.9 \mathrm{kG}$ 
both the anetic field of a star and its abundance peculiarities. When they apply the $H_{s}$ criterion to a homogeneous sample of stars (whose effective flelds have been measured at least three times ustng a Balser line zeenan analyser), they find that there is no siaple relationship between observed $h_{\text {eff }}$ and photowetrically-derived $H_{S}$. The few stars in the saple with an observed Heff greacer than $-2-3 \mathrm{kG}$ do indeed also have large values of $\mathrm{H}_{s}$. On the other hand, a smaller value of $\mathrm{H}_{\mathrm{s}}$ does not sees to be so correlated; many stars predicted on the bas 18 of thelr Geneva photometry to have flelds as large as 2 kG are observid to have much weaker or undetected ones. Also, the calibration of the Geneva deterainations appears to be in orrect. A predicted $\mathrm{H}_{\mathbf{S}}$ of $2 \mathrm{kG}$ corresponds to a measured yalue of the effective fleld $B_{e} \leq 2$ kG. Thus, the $H_{s}$ paraneter is useful for identifying candidates likely to be strongly magnetic Ap stars, but it is of limited effectiveness (If any) In plcking out stars with flelds of about $2-3$ kG or less. Consequently, the $H_{s}$ value for $\mathrm{HD} 60435$ probably represents a rough upper linte to that star's effective agnetic field; $1 . e$. HD 60435 1s unlikely to have a field above about $2-3 \mathrm{kG}$, but little more can be gleaned fros the Geneva photonetry. Of course, given an appropriate Inclination 1 for the star, and obliquity $\beta$ of the field axis, $a$ surface fleld strength of 2 kG or more could result in a measured effective field of only $1300 \mathrm{G}$ or less.

\section{Aplitude codulation and phase shifts (21, 111, iv)}

All of the oscilletions in HD 60435 appear to be modulated. Many are aufficiently tranelent (appearing on only ona or a few nights) thit no ecdulation perlod is spparent. Only the osclilations near $1.4 \mathrm{wHz}$ 
are persistent enough to exhiblt a clear nodulation cycle.

A 7-8 day Eycle was recognized in the 1984 data and was seen again in the 1985 observations. This characteristic tiaescale is evident in Figure 4.3 and in the sample of anplitude spectra shown in Figure 4.10: those nights when the peaks near $1.4 \mathrm{nHz}$ are highest are separated by 6-8 days, or some integer multiple thereof. In fact, if the amplitudes of oscillations near $1.4 \mathrm{mHz}$ (estimated from spectra like those if that figure) are plotted in phase according to the 7.6662 d period derlved from the photometry, there is a clear correlation (Figures 6.10 and 6.2b). Maximum oscillation amplitude occurs during or close to primary. B minimum, which may also coinclde with primary magnetic extremum. $\nabla$

This is in accord with the prediction of the OPM. However, there is no hint of a second 5 ise in amplitude at the phase of secondary $B$ minimum (secondary magnetic extremum?), as is also predicted by the aodel. If such a rise is indeed presert, it may be so small as to be nasked by the noise.

The OPM also predicts that a $180^{\circ}$ shift in oscillation phase should occur at phases of 0.25 and 0.75 cycles in the mean 11 ght curve (1.e. times of magnetic quadrature using the magnetic phasing adopted above). Figure 6.3 is a plot of oscillation phase for the $1.4-\mathrm{aHz}$ oscillations vs. the phase of mean light. The oscillation phases vere deterwined by measuring the times of maxima of the dowinant oscillation in the nightly 11 ght curves, relative to an arbltrary epoch. Only those nights when the oscillation is easily distinguished above the nolse in the 11 ght curve have been used to construct this figure.

Unfortunately, on any individual night, the oselliation phase covers a wide range, probably because of beating anong the several fre- 


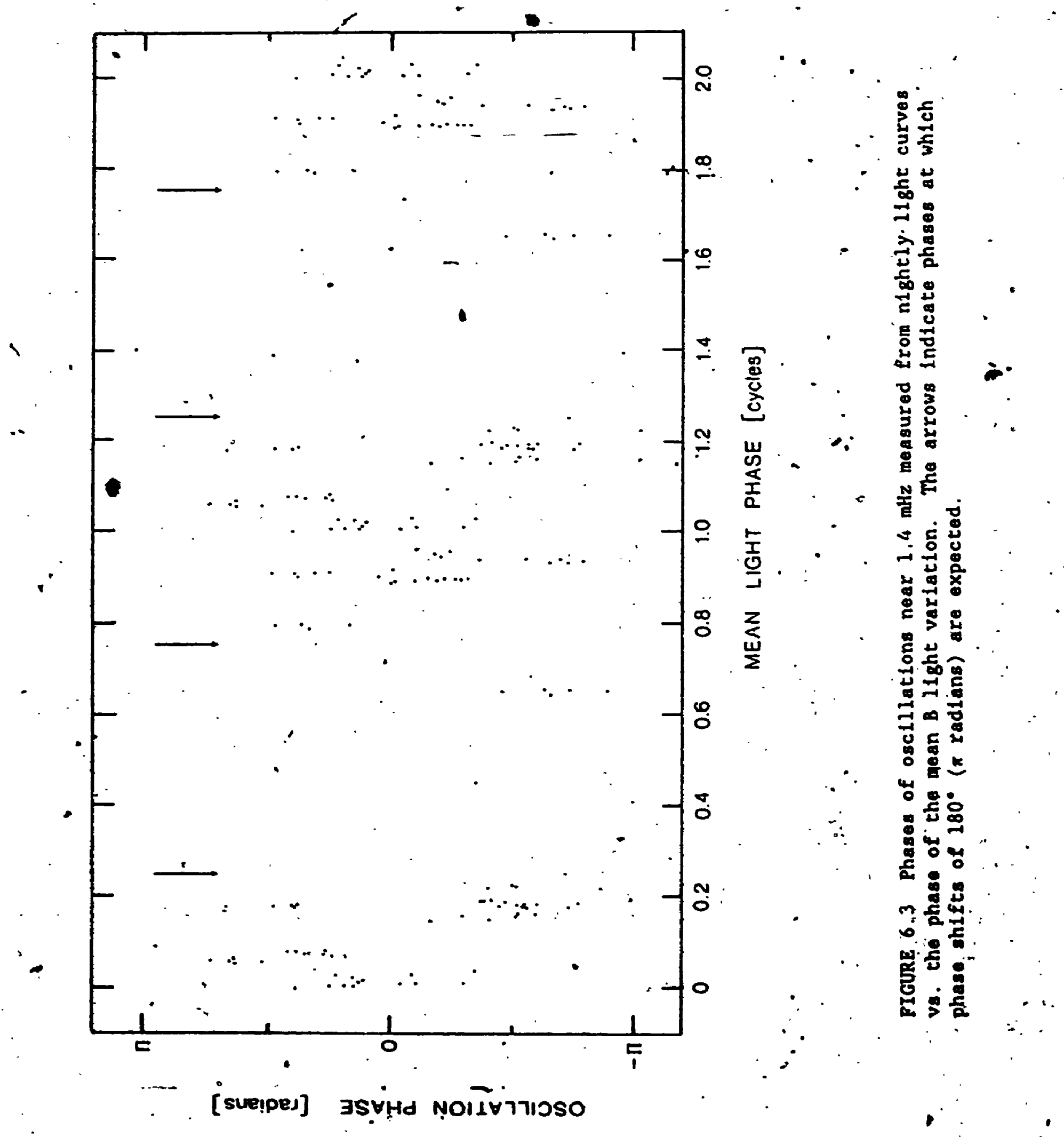


quencles present in the star at one tine (see belov). The resultant scatter in Figure 6.4, and the paucity of oscillations of sufficiently large amplitude between wean ilght phases 0.25 and 0.75 , obscures any phase shifts which aay be taking place due to oblique pulsator effects. Observe in Figure $6.2 b$ that the amplitudes of oscillation at zero phase are not constant; the "naximun" anplitude ranges between almost 6 . down to Iy mag. This secular variation is not predicted by the OPM. It is symptomatic of still another modulation, yet one which preserves the 7.7-day modulation period. Beating between adjacent and/or nearby Erequencils may be partly responsible for chis effect.

There are many obvious signs of amplitude modulation which occurs over timescales less than a day. Since the separation of adjacent frequencies in the overall pattern of HD $60435(-26 \mu \mathrm{Hz})$ corresponds to a beat period of about 11 hours, this is not surprising. In fact. the nightly varlations in phase shown in Figure 6.4 have a characterlistic timescale near 11 hours.

One of the most dramatic examples of rapld modulation is found in the observations of JD 2446111 and 112 (the last two panels of Flgure 4.10b). Figure 6.4 is a set of anplitude spectra of those two consecutive nights of rapid photometry, each divided into three equal segments. (The first third of JD 2446111 is onitied since 1t is little different from the two segments of that night shown.) The osclilation amplitude rises fron a level below the nolse on the first night to almost 6 imag in less than a day. The modulation observed on che night of JD 2446112 alone can be explatned by the beating of frequenc1es spacted by $26 \mu \mathrm{Hz}$. However, the beat period should be approxinately 11 , hours or less. Therefore, another naximu in the beat cycle should 


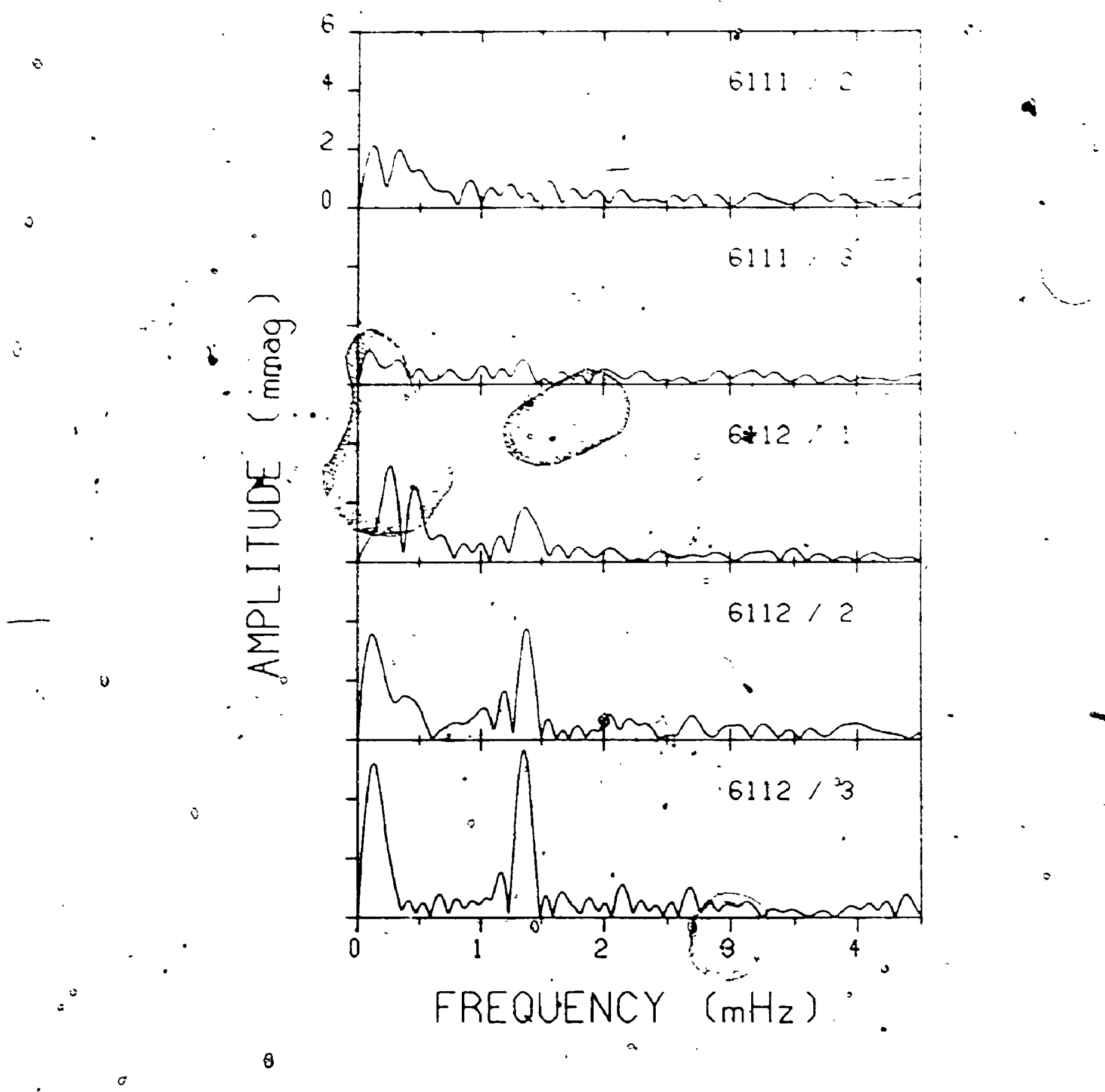$$
\cdots \cdot \because{ }^{2} \cdot
$$

FICURE 6.4 Amplitude spectra of the 11ght curve of HD 60435 from the nights JD 2446111 and 2446112, In which the nightly udata sets have been divided Into thlrde. The rapid apparent growth of osclilations near 1.4 w2 in less than 24 hours is evident. 
occur during-the observing interval on the previous night, but none is observed.

The presence of more thian-two frequencies does not alleviate the discrepency. A comb of equally-spaced frequencles separated by $\Delta$ results in a modulation curre which repests with period $\Delta y^{-1}$. As the number of components in the pattern is increased, the interval during which the net osclilation has a large amplitude beloses proportionally shorter. Beating of any combination of the identified freguenctes, even coupled with the modulation of the $O P M$, does not seen to be able to account for the pronouriced change in amplitude between the two nights. This may be the best evidence far actual growth and decay of pulsation modes in an roAp star. Dolez and Gough (1984) have shown that in a simple model. of a magnẹtc star. pulsation modes with perlods around 10 minutes may have growth and decay times of only a few hours.

3 Splifting of frequericies in the Fourierspectrum (v). Accordtrg to, the OPM, each node with $l-1$ should be split into three equity spaced components, and each with $l-2$ into flve. Since tentefive, fóde Identiflcations were made in Chaptét IV, these iay be $=$ úséd to check whether frequencles 1 lnked with $(n, 1)$ and $(n, 2)$ wodes - have fine structure which is consistent with the model. Unfortunately, only the osclllations tear $\mathbf{P . 4} \mathrm{mz}$ recur often enough to clearby show rotational nodulation and the assofclated frequency splitting; the others are too translent.

Also, the very richness of HD 60435's osclllation spectrum linits one's ablilicy to unambiguously resolve any fine structure. Adjacent frequencles in the overall pattern are epacad by opproxiantely $26 \mu \mathrm{Hz}$. 
One d-1 elleses of " reel frequency in the spectru occur on either 1de et firequency intervals of $\mathrm{n} \times 11.57 \mu \mathrm{Hz}$, where $\mathrm{n}-1.2 .3 \ldots \ldots$ the second allas aldolobes are therefore spaced by about $23 \mu \mathrm{Hz}$ fron the Irue oscilletion frequencles. As a result, one osciliation peak is only $3 \mu \mathrm{Hz}$ fros the $2 \mathrm{~d}^{-1}$ allases of 1 ts nearest neighbours. The Erequency spliteing predicted by the OPH, assuming Prot $-7: 6662$ d is about $1.5 \mu+4 z$. Therefore, the outlying sidelobes of an $l-2$ quintuplet would overlap with these allas poaks, altering the apparent arplitydes and perhaps the measured freqbencles as well. Altermat. vely, an $l$ - 1 triplet could be mistaken for an $l$ - 2 quintuplet because of the coincidental spacing of the nearby alias peaks. The potential for confusion is dranatized by Figure 4.4 , an anplitude spectrum of the 1984 rapid photonetry showing onily those frequencies near $1.4 \mathrm{mz}$. The allases of adjacent oscfllation peaks and their actual'afdelobes have combined to create an apparent frequency triplet at $1.42 \mathrm{mz}$.

The fine etructure of the peaks near $1.4 \mathrm{WHz}$ in figures 4.4 and. 4.11a Is seriously complicated by the allasing. A perlodogran (Ffgure 6.5) of a seller. sample, which covers only twelve sequential nights of CTIO and SAMO photonetry (JD. 2446101-112), should be less affected by the allases, ihlle setll extending over more than lt nodulation cycles. As a result, the frequency sidelobes may be resolved nore clearly. The postefions of frequencles Identifled fron the earlier amalyal: ( $\left.\nu_{n}-\nu\right)$ are labelled in Figure 6.5. One $d^{-1}$ allage of some of these frequenctes (and astoctated sidelobes) areoalso indicated on 0 .. the Elgure.

At frequencles less than about $1.40 \mathrm{mhz}$; the presence of so many. 


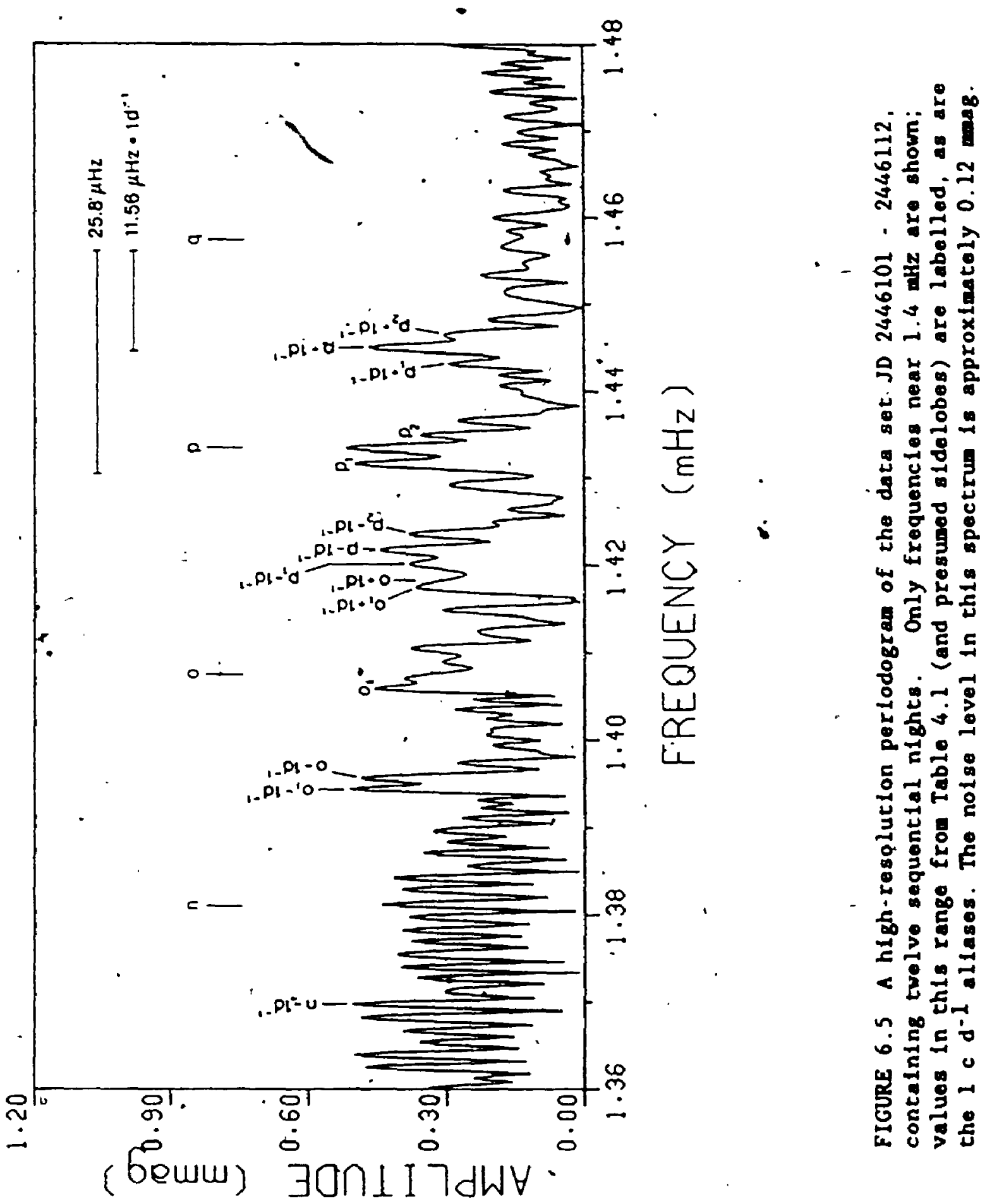


- closely spaced peaks akes an Identification of sidelobe structure uncomvincing. Howevet. since frequency $\nu_{q}$ is not present at any appreclable applitude in this sample, the adjacent frequency $\nu_{p}$ does not appear to suffer from interference by overlapping aliases as , sevesely. It is the most suitable candidate in which to study sidelobe structure. The peaks labelled $p_{1}$ and $p_{2}$ ' in Figure 6.5 are spaced from $\nu_{p}$ by $1.7 \pm 0.2$ and $1.6 \pm 0.2 \mu \mathrm{Hz}$ respectively. (The peak Just above $P_{2}$ in frequency is spaced from it by another $1.7 \mu \mathrm{Hz}$; however, the peak before $p_{1}$ has a $2.4 \mu \mathrm{Hz}$ spacing. All five peaks cannot be part of a pattern of equal frequegncy splitting within the errors. The peak before $p_{1}$ is most likely a $+2-d^{-1}$ allas of $\left.\nu_{0}.\right)$ The average spacing corresponds to a rotation period of $7 \pm 1$ days. The best interpretation 1 s that $\because p$ is an $l$ - 1 mode, having two sidelobes. This is also consistent with. the prediction of equation ( $4.6 b)$.

The sidelobe amplitudes of $\nu_{p}$ are distinctly asymetric. The skewness is pych greater than would be expected solely due to noise and coaddition of weak allases from nearby frequencles. The amplitudes estinated frov Figure 6.3 (and consistent with Figure 4.4) are:

$$
\begin{aligned}
& A\left(p_{1}\right)=0.50 \pm 0.03 \\
& A\left(p_{0}\right)=0.52 \pm 0.03 \\
& A\left(P_{2}\right)=0.35 \pm 0.03
\end{aligned}
$$

These may. be aubstituted into equations $(6.1)$ and $(6.2$.$) , where A\left(p_{1}\right)=$ $A-1, A\left(P_{0}\right)$; $A_{0}$, i and $A\left(P_{2}\right)-A_{1}$.

The reaulting values of tanltans and $c \Omega /\left(w_{1}(l)\right.$ mag - w $(l)$ mag) are given in Table 6.3, Also included are estimates of these parameters for three other roAp stars whose osclllation spectra show frequency triplete consietent with the OPH: HD 6532 (Kurtz and Cropper 1987), HR 1217 (Kurfz et a1. 1985), and kR 3831 (Kurtz and Shtbahash1 1986). 


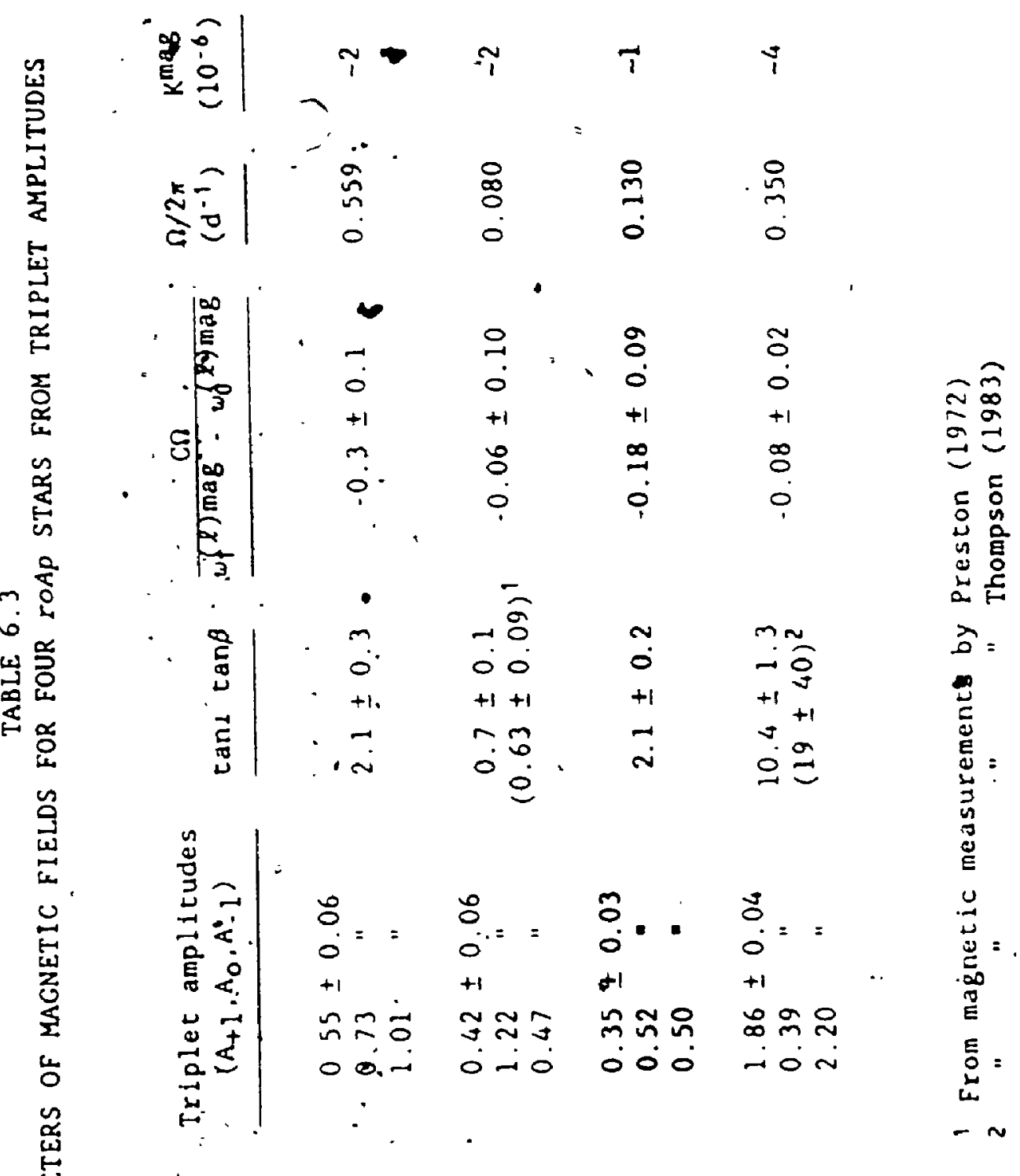


For two of these stars (HR 1217 and HR 3831), periodic agnetic varlations have been detected. The oblique rotator nodel (ORM) predicts that the ratio of agnetic field extrena, $r-H_{e}(n i n) / H_{e}(n a x)$, is related to the stellar geowetry by

$$
\frac{1-r}{1+r}-\tan 1 \tan \beta
$$

Therefore, the magnetic observations can act as a cest of the selfconsistency of the ORM and OPM. In both cases, the two approaches produce values of cantano which agree within their respective uncertainties, although the precision of the $\dot{H R} 3831$ magnetic curve (Thompson 1983) is Inadequate to set a rigourous test.

Using equation (6.5) and the value of $\tan$ tank for HD 60435 from Table 6.3, one finds: $r=-0.35 \pm 0.10$. Therefore, the OPM also. predicts a polarity-reversing magnetic field, as was already inferred fron the mean.light curve. The maxlmu fleld consistent with the direct magnetic neasurements described earlier is $-1300 \mathrm{G}$ at phase 0.99 (F1gure 6.2). The derived value of $r$ then leads to a maximum allowed secondary extremus of $+455 \pm 130 \mathrm{G}$ near phase 0.50 . The direct neasurenent at phase 0.49 permits a maximum field of +610 G (within 1 o). which is certainly compatible with this result.

Inclination and obliquity of HD 60435

The value of tanitang $-2.1 \pm 0.2$ for HD 60435 constrains the allowed values of inclination and obliquity of the star. These are plotted in Figure 6.6. An extimate of vaini, combined with the radius estimate in Chapter IV and the proposed rotation period derived from the wean photomety, would narrow the range of. $(1, \beta)$ values even 

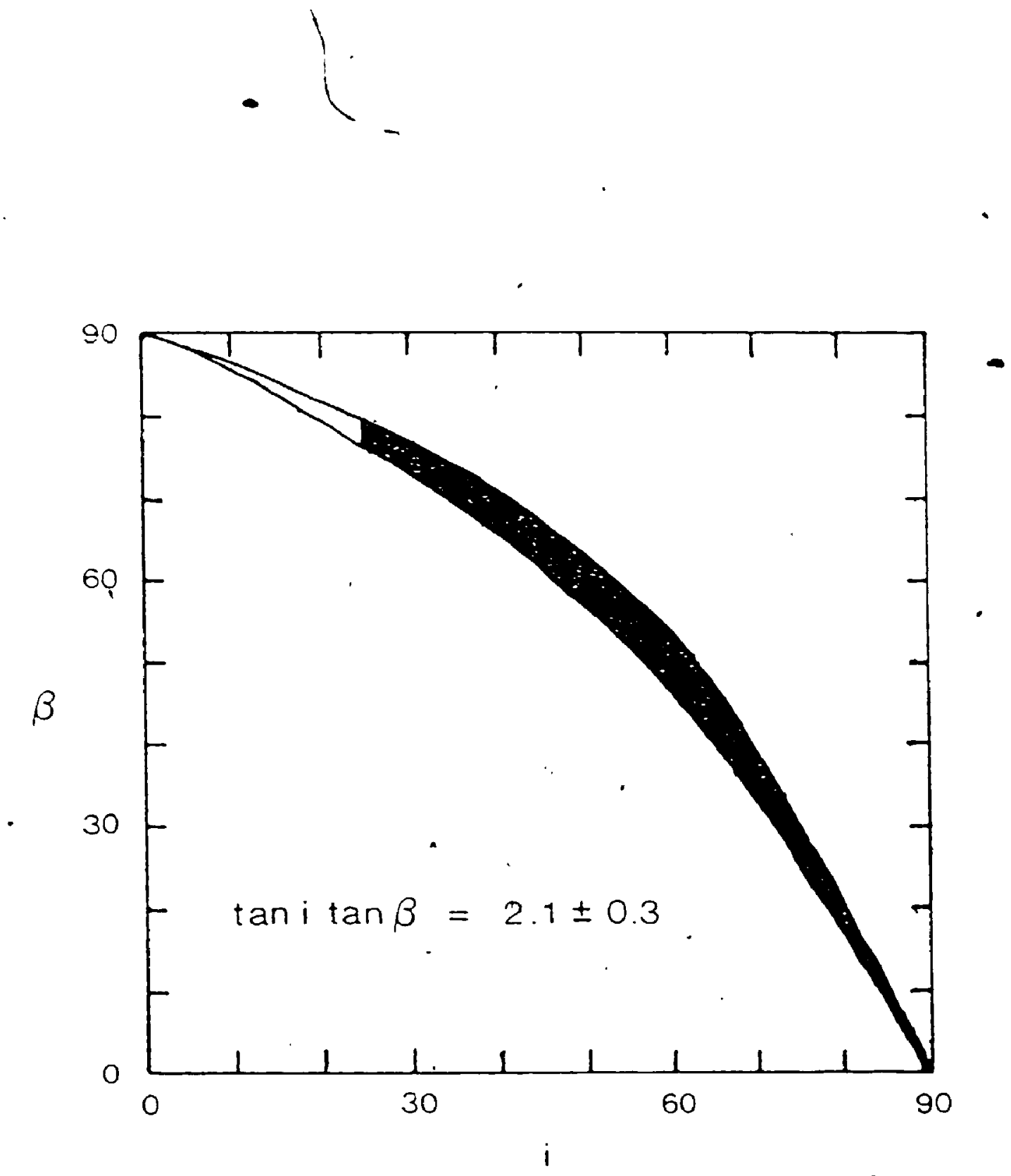

FIGURE 6.6 The values of inclination $i$ and obliquity $\beta$ for HD 60435 allowed by the oblique pulsator model, when applied to the criplet splicting observed in Figure 6.5 . 
further.

Ap stars are characteristically slow rotators. A sample of 24 SrEuCr stars exanined by Abt et a1. (1972) was found to have a mean volnt of $30 \mathrm{~km} \mathrm{~s}^{-1}$; the later types witbin this class had proferentially saller profected velocities. Unfortunately, the classification dispersion (67 A ${ }^{-1}$ ) spectroscopy of HD 60435 described in Chapters II and $V$ is not well suited to the measurement of such small veloci. ties. The wavelength resolution of these spectra is $1.0 \mathrm{~A}(30 \mathrm{~km} \mathrm{~s}-1$. at $5000 \mathrm{~A})$. St1ll, these are the only spectra avallable at present for a voini determination of this star.

slettebak et al. (1975) have provided a system of standard stars (covering the main sequence range 09 - F8) for wstni determinations usling direct measurements of the half-intensity widths of lines on. photographic spectra. The resolution of their spectra is $0 . \dot{2} 5 \mathrm{~A}$. They also provide a theoretical Mg II $\lambda 4481$ line profile for their FOV model convolved with the 0.25 A instrumental profile. By adjusting for the extra width of the instrumental profile of the HD 60435 spectra, the observed half-wtdths of lines can be ralateg the slettebak standards. The half-widths of the $M g$ II line proftle were measured from microdensitoweter tracings and corrected for the different resolution. The resuleing values of vini are in Table 6.4 .

Blending and systematic measurement errors probably make the derlved mean value, valnt $-10 \pm .3 \mathrm{~km} \mathrm{~s}-1$, a slight overestimate. The quoted error is sinply the standard deviation of the numbers in the last colum of Tible 6.4. Given the wavelength resolution of the spec. tra, the actiual uncertainty in vainl is probably wore like 0 - 30 ka ${ }^{-1}$. Since each spectral exposure extended through 8 - 11 oscillation 
TABLE 64

ROTATION VELOCITY ESTIMATES FROM Mg II 14481 LINE

\begin{tabular}{ccc}
$\begin{array}{c}\text { Line width } \\
(\AA)\end{array}$ & $\begin{array}{c}\text { Corrected wideh } \\
(\AA)\end{array}$ & $\begin{array}{c}\text { vsini } \\
\left(\mathrm{km} \mathrm{s} \mathrm{s}^{-1}\right)\end{array}$ \\
\cline { 2 - 2 } 1.39 & 0.64 & 18 \\
1.13 & 0.38 \\
1.26 & 0.51 & 10 \\
1.13 & 0.38 & 12 \\
1.19 & 0.44 & 10 \\
1.19 & 0.44 & 11 \\
1.13 & 0.38 & 11 \\
1.09 & 0.34 & 8 \\
1.09 & 0.34 & 7 \\
1.26 & 0.51 & 12 \\
1.19 & 0.44 & 11 \\
1.13 & 0.38 & 8 \\
\hline
\end{tabular}

$\infty$

$+$


cycles. the star's pulsation would also contribute to the Iine width. The detection of RV oscillations in HR 1217 by Matchews et al. (1987a) ylelds a veloctey-to-lighe anplitude racio of $2 \mathrm{~K} / \Delta \mathrm{m}_{\mathrm{B}}-59 \pm 12 \mathrm{~km} \mathrm{~s}^{-1}$ $\mathrm{mg}^{-1}$. For HD 60435 . this teplies pulsation-induced broadening of onty $-0.5 \mathrm{~s}^{-1}$. Which is unlikely to be a significant factor in the vsins deternination.

Given the equatorial rotation velocity $v$ of a star, its radius is

$$
R-\frac{P \cdot y}{50.6}
$$

where $R$ is in solar radil, and $P$ is the rotation period in days. The arguments in Chapter IV led to a radius for HD 60435 of $R-2.2 \pm 0.3$ $R_{0}$. Substituting this value of $R$, and $P-7.6662 \pm 0.0001 d$, gives an equatorial velocity of $14.5 \pm 2.0 \mathrm{~km} \mathrm{~s} \mathrm{~s}^{-1}$. If vsiri $-10 \pm 3 \mathrm{~km} \mathrm{~s}^{-1}$. then the comblned uncertaintigs perait a range in inclination:

$$
25^{\circ} \leq 1<90^{\circ} . \therefore-
$$

This in Indicated by the shaded portion of Figure 6.6. Coude spectra of $\mathrm{HD} 60435$ with better resolution would improve the accuracy of these results. For exainple, a precision in vsini of $\pm 1 \mathrm{~km} \mathrm{~s}^{-1}$ translates into a range in $i$ of only $-15^{\circ}$.

The restrfetions on $i$ and $\beta$ illustrated by Figure 6.6 also result in a lialted range of $a_{p}$ and $a_{s}$, the line-of-sight angles of the agnetic (- pulsation) axis at primary and secondary magnetic extrema, $\because-$ respetively. These are plotted in Figure 6.7. However, the OPM also. relates the angle a to the observed amplitude of pulsation through equation (1.1). Aasuing 2 - 1 (consistent with the frequency triplet used for the detervination of tant tans in Table 6.3), then that equation seates that the ratio of priary to secondary aximud anplitude of 


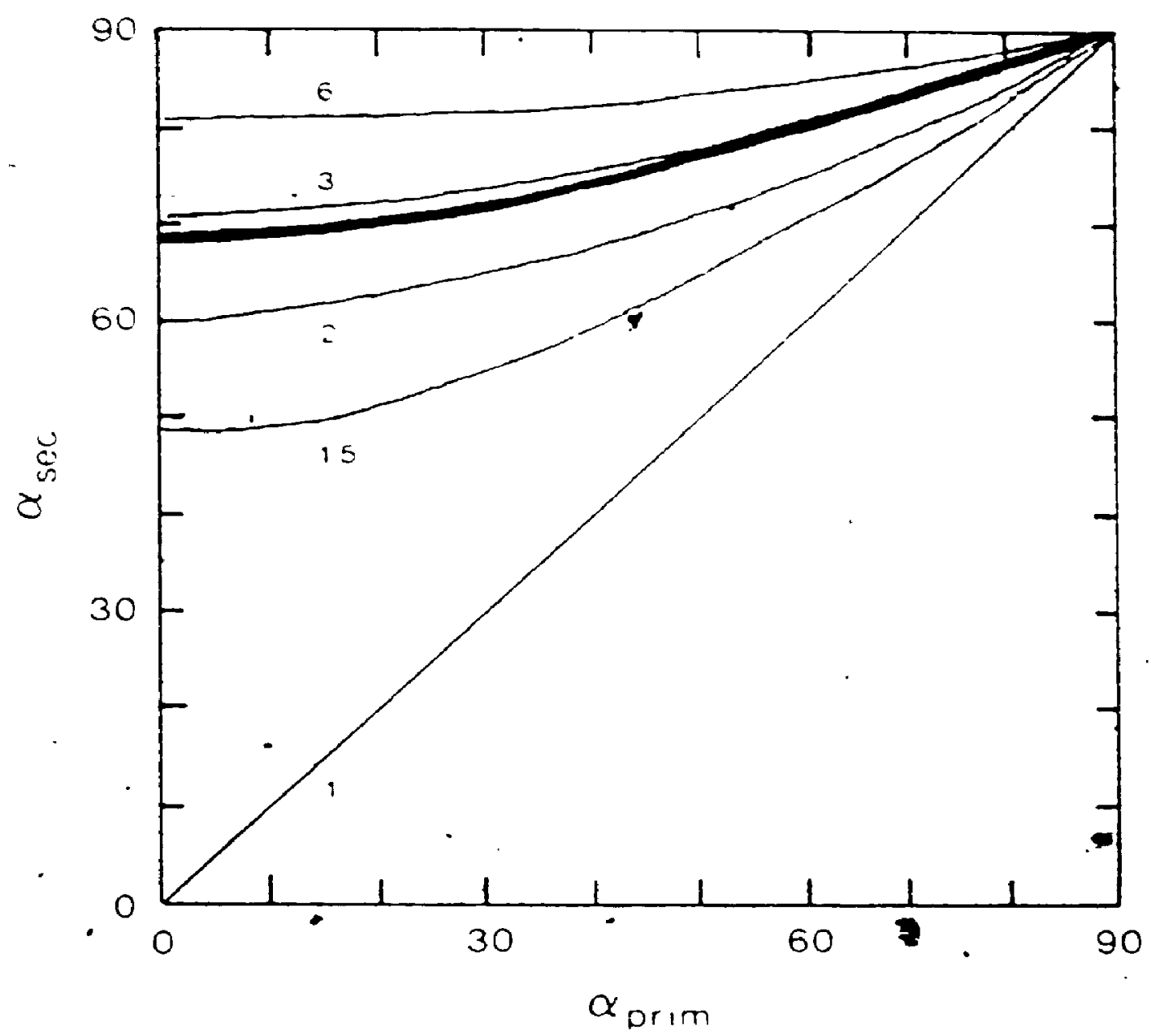

•

,

FIGURE 6.7 A plot of the 1 ine-of-sight angles of the pulsation (magnetic) axis at primary (aprim) and secondary (asec) extrema of the observed field strength and maxima of the osclilation amplitude. The thin lines are the curves predicted by the oblique pulsator model based on the ratio (ranging from 1 to 6) of the primary-to-secondary maximum in oscillation amplftude (equation (6.7)). The thick line is the curve predicted by the dynamical OPM based on the triplet spliteing in the frequency spectrum. $\checkmark$ 
the oscillations is

$$
\frac{\Lambda_{p}}{A_{s}}=\frac{\cos a_{p}}{\cos a_{s}}
$$

The curves corresponding to amplitude ratios of $1,1.5,2,3$, and 6 are shown in Figure 6.7. Since no secondary maximu in oscillation amplitude has been actually detected in the light curves of HD 60435 , only upper liaits to $A_{S}$ - and hence, a lower limit to $A_{p} / A_{s}$ - can be set. In addition. this observed ratio reflects the net amplitude modulation of the many pulsational modes present near $1.4 \mathrm{aHz}$ in HD 60435, whereas the curves of Figure 6.7 assume only a single sode of $l-1$. Therefore, any comparioon must be made with caution. The lower limit to the observed raclo $A_{p} / A_{s}$ derived from nightly amplitude spectra of the oschitations is approxinately 3. The $a_{s}$ vs. $a_{p}$ curve for that ratio falls fust above the curve obtained indirectly from the amplitudes of the $v_{p}$ triplet in Figure 6.5. Any argunent claining significance for such correspondence nay seed clrcular. After all, both curves are based on predictions of the OPM, and use aspects of the observed oscil. lations which are not independent from one another (1.e. amplitude modulation, and frequency splitting related to that modulation). How. ever, this does serve as rough check on the internal consistency of the model.

The global manecic field of HD 60435 .

Dzlemborski and Goode (1984) have shown that, if the gtar has a dipole-like field,.the frequency perturbation should be of the form

$$
v i, a^{20} 8-\frac{l(l+1)-3 a^{2}}{4 l(l+1 \gamma-3} \mathrm{kag}
$$


where $\mathrm{K}^{\mathrm{aag}}$ is a coefficient based on a $\left|\mathrm{Y}_{\ell}\right|^{2}$-weighted integration over the perturbation of the gas by the agnetic fleld. Kag is an indicator of the magnetic fleld strength throughout the oscillating regton of: the star, not nerely at the surface. For $p$-modes of high overtome (Dziembowsk1 and Goode 1984).

$$
\frac{\mathrm{K}^{\mathrm{mag}}}{w 0}-\left\langle\frac{\mathrm{pmag}^{\mathrm{mag}}}{\mathrm{P}_{\mathrm{gas}}}>\quad(6,7)\right.
$$

where parg and pgas are the magnetic and gas pressares. wo is the unperturbed frequency, and $<>$ denotes an querage through the oscillating portion of the star.

For the stars in Table 6.3. rotation frequencies $\Omega$ are inferred from available magnetic and/or photometric vartation periods. If one. assumes both (the presence of a dipole field, a pulsation geometry with $(f, w)-(1,0)$, and a Ledoux constant $C-0.01$ (sn upper limlt based on the long-term synchronism of agnetic and osciliaţion amplitude maxima in HR 1217 (Kurtz et al, 1985)), then values of $K^{\text {thag }}$ can be calculated by substituting equatiọn (6.6) into (6.2). The results are included in.. the last column of the table.

The values should reflect the relative strengths- of the global magnetic flelds. The results suggest that HD 60435 has the weakest internal field of the four stars. The difrect fleld measurements do not contradict this finding (although weak surface fleld does not necessarily iaply a weak one in the interlor). However, it is interesting to observe that - according to Table 6.3 - the fleld strength of HR 3831 should be twice that of KR 1217, whereas direct magnetic measuregents of the longltudinal flelds (Table:1.1) show that the ratio of 
extrean 1. Hax $(3831) / H_{\max }(1217)-0.6$. But note that the value of tanitans 1s. much larger for the former star. This means that, if the inclination of $\mathrm{HR} 3831$ is suall, then the obliquity is large; and vice versa. In elther case, the neasured longltudinal fleld would be const. derably saalker thad the true strength. This geonetric projection effect alone is sufficlent to reconclle the measured field strengths and the predictions of the OPM. 


\section{SUMOARY}

Before this study was undertaken. the list of propertles known for HD 60435 was a rather fort one.

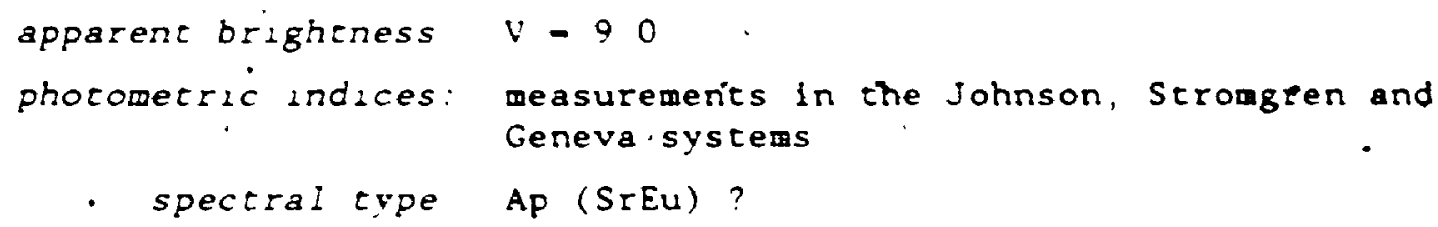

Analysis of the star's rapid oscillations, and of its slow lighe and spectrum variations, has refined and extended the ilst to-include

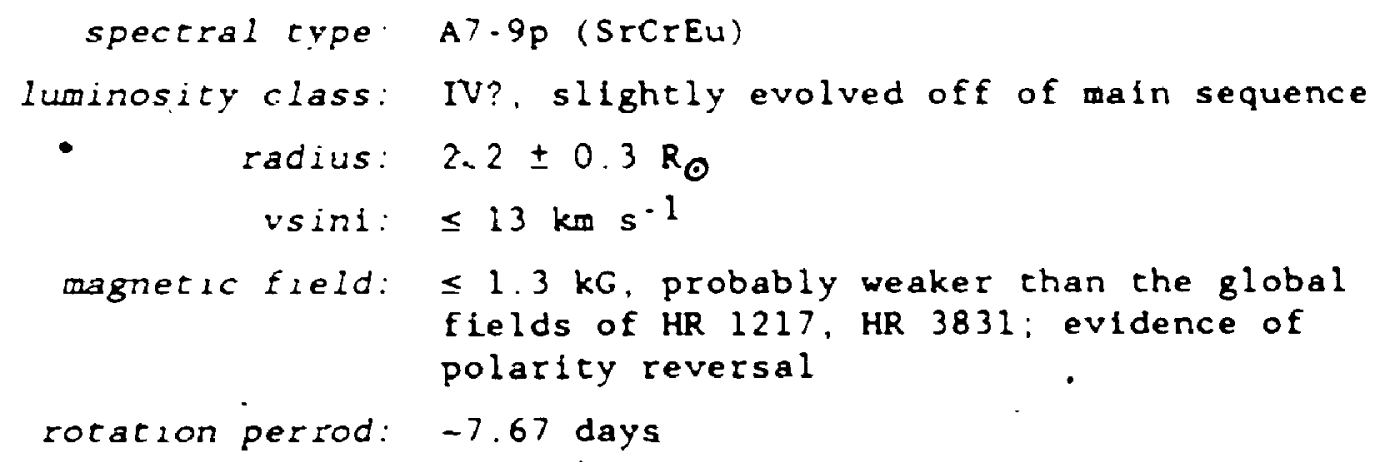


of the many osclllation frequencies detected in the star. those close to $1.4 \mathrm{mHz}(P=12 \mathrm{~min})$ are by far the most persistent. The net smplitude of-these osclilations undergo long-tern modulation with a perlod which closely coincides with the mean photometric period $(7.6662$ \pm 0.0001 d). According to the oblique rotator nodel for Ap stars, this Is the rotation period of $\mathrm{HD} 60435$.

There is also short-cerm amplitude modulation over timescales of hours wich is consistent with the expected beating among the many frequencles spaced by $26 \mu \mathrm{Hz}$ (beat period $=11 \mathrm{hr}$ ). However, at least one instance of a rapid amplitude increase from one night to the next is difficult to explain by beating of the identified frequencies alone. This may be the best evidence for actual growth (and, by infererce, decay) of some modes in HD 60435 with cimescales of only a few hours. It agrees with the predictions of Dolez and Gough (1982), who calculated growth and decay thes of the order of hours for certain rapid nonradial pulsations in a magnetic A star.

\section{HD 60435 as a test of the Oblique Pulsator Model}

The long-ter amplitude modulation can be used to test the valldity of the oblique pulsator nodel for the roAp stars (Kurtz 1982). The OPM predicts that the amplitude of the rapid oscillations will be nodulated with the magnetic period of the star, and that the phases of maximm amplitude and maximun effective magnetic fleld äre identical. Unfortunately, there are no fleld measurements of sufficient accuracy and quantity to test this directly in the case of HD 60435 .

However, the flrst prediction is satisfled by the equality of the periods of modulation and mean 11 ght, since in Ap stars for which there 
are magnetic and photometric data, the mean light perlod is equivalent to the magnetic period. Also, In this spar, maximun oscillation amplitude occurs roughly at the same phase as B light minimun: there are indications that this is also the phase of Sr II line strength maxtmum In the spectrum of the star. Literature surveys of photometry, spec. trosicopy and magnetic measurements of Ap stars suggest that B light minimum and Sr II maximum are usually assoctated with magnetic maxtmum. Hence, the avaif ble data on HD 60435 are also consistent with the second prediction above.

The OPM further predicts that a mode of. degree $l$ in an roAp star should be spIit into a set of $(2 l+1)$ components spaced by the rotation frequency of the stat, as given by the observed frequency of the mean light or magnetic curves. Thus, for HD 60435, this spacing is $(7.6662)^{-1} \mathrm{~d}^{-1}-1.509 \mu \mathrm{Hz}$. The recognition of this type of frequengy splitting in this star is complicated by the aliases of the many individual modes present. However, a high-resolution amplitude spectrum of the oscillations does reveal one frequency ldentified with a mode of $l$ - I which does appear to have been split into a triplet with a spacing of $1.6 \pm 0.2 \mu \mathrm{Hz}$. (The spacing is characteristic of the fine strut. ture seen in other high-resolution periodograms of the HD 60435 osc11. lations.) Again, this is in agreement with the prediction of the OPM, wthin the uncertainties of the frequency resolution of the data.

Application of the dynamical OPM (Dzlembowskl and Goode 1985) to the frequency triplet described above predicts that the rat 10 of the magnetic field extrena of HD 60435 to be $r--0.35 \pm 0.10$. The negative sign signifies polarity reversal. Once pore, the lack of sultable magnetic data prevents confiration of this assertion, but as before, 
the mean 1 ight curve provides some indirect observational support.

That curve has a prinary and a secondary minimum; in other Ap stars,

this has been associated with a polarity-reversing field.

Another test of the polarity-reversal hypothesis would be the search for a secondary maximum in the osclilation amplitude, and determinations of the phases of the oscillation throughout the rotation cycle of the star. An oblique pulsator with a polarity-reversing field is expected to exhibit such a secondary maximum and $180^{\circ}$ phase shifts in the dominant oscillation, as depicted in Figure 1.5. This test is inconclusive for $\mathrm{HD} 60435$, since (1) the amplitudes are so low that a secondary maximum may easily be hidden in the noise, and (ii) the beatIng of the multiple frequencles present introduces apparent phase stitts which obscure any genulne oblique pulsator effects.

Essentally, the case for HD 60435 as an oblique pulsator is one of consistency among the different types of observations of the star currently avallable and the varlous approaches to the analysis of those $\because$ data.

Recommendations for future observations

Clearly, most of the predfctions of the OPM can be tested most sioply by the deteraination of an accurate magnetic curve for HD 60435. However, tue to this star's relative faintiness, measurements with a 1 o precision as poor as 600 gauss still require exposure times of about two hours on a telescope of $2.5 \mathrm{~m}$ aperture. An elght-hour exposure would only reduce the standard deviation to about $300 \mathrm{G}$. Even If the animue field of HD 6.0435 were $-1300 \mathrm{G}$, and the ratio of the extrom watched thet predicted by the OPH at $r-i .35$, manetic readings 
of such precision would only hirrow the value of $r$ tabetween roughly -0.1 and -0.76 . Hardly an "acid test" for the model.

Observations of even $300 \mathrm{G}$ precistion would be of value in perhaps establishing the presence of a magnetic field in HD 60435, or at least setting a more stringent upper limit. However, if future magnetic observations of HD 60435 are to be attempted using photoelectric polarimetry, a telescope of at least 4 maperture seems to be the only practical option.

Tests of the OPM also hinge on reliable determinations of the rotation period from methods independent of the oscillation data. The mean photometry of HD 60435 has provided one estlmate, but a more accurate mean light curve for the star would both refine and lend further weight to that estimate. The Johnson B bandpass used for the differential photometry in this programme was not selected to optimize the detection of long-term light variability; it was prescribed by factors related to the rapid osctllations of roAp stars (see Chapter II). Jones and Wolff (1973) have shown that the Stromgren $v$ fllter is much more sensitive to changes in the mean brightness of many Ap stars. Future studies of the mean light curve of HD 60435 should Incorporate 1 Stromgren photometry. Also, it will be important to monitor one or two check stars in addition to the comparison HD 59994 to ensure that no low-level light variations are present in that star which could contaminate the HD 60435 curve.

Spectroscoplc observations are another means of estinating the 6 perlod. Clearly, spectra of much higher signal-to-nolse and in greater quantity than those obtained in this study are required. Although moderate wavelength resolution should prove adequate for the purpose of 
perlod determination, a few high-resolution spectra would be desireable to accurately deasure vsini.

Better spectroscopy of HD 60435 fid its fellow roAp stars may also be of value in finding an empirical parameter which could be used in photometric or low-resolution spectroscopic searches for new members of the class. For the most part, the spectra of individual roAp stars are not well studied, and the spectroscopic properties of the entire group have not been investigated at all.

One region of the spectrum that may deserve particular attention 1s the $\lambda 5200$ depression which 1 s characteristic of peculiar A stars. This feature appears to change with effective temperature. Pyper and Adelman (1986) have observed that - for the cooler Ap(SrCrEu) stars of interest here - the shape of the red side of this broad feature is falrly uniform from star to star, but there are absorption minima near $5000 \AA$ which occur for only some of the same group. The stromgren (b-y) Index would not be sensitive to such changes in the blueward profile of the $\lambda 5200$ feature. This is an example of the type of discrimi. nant of the rodp phenomenon which may be present in the spectrum but might not manifest itself in photometric surveys.

The author, In collaboration with Drs. T.J. Kreldl (Lowell observatory) and $\dot{W} . H$. Wehlau, has already started planning a spectroscopic and Strongrep photometrlc survey of the roAp stars which would Include observations of HD 60435 as described above.

The oacillation behaviour of HD 60435 is so complicated that addftlonal rapid photometry is essential if that behaviour is to be specí f1ed. If practical, mult-colour measurenents would be a useful extension of the observing programe. The phase lags between the brightness 
variations in different colours may help to independently identify the modes of pulsation present in HD 60435, although thls approach has met with limited success in other roAp stars (Kurtz 1982, Welss 1986).

One of the most important aspects of the oscillation spectrum in both testing and applying the $O P M$ is the fine-scale splitting of fre. quencies. Identification of the number of components for a given mode and accurate measurement of their amplitudes are easiest using ampli. tude spectra which have low nolse levels and high frequency resolution. and are not confused by strong cycle/day aliases. These in turn can only be produced by lang runs of accurate rapid photometry of which major portions are not interrupted by large dally gaps. A more ambltious multi-site observing campaign is called for, involving at least four or five observatories. Such a campalgn, organized by Dr. D.W. Kurtz to monitor the roAp star HR 1217, was recently completed. The success of this programme, in which data were collected from seven sites during October-December 1986, proves that coordinated observations of this type are also feasible for HD 60435.

The importance of HD 60435 to stellar astrophysics

The recommendations above entail a considerable expendlture of observing time on many telescopes. Do the anticlpated returns justify the investment?

The roAp variables represent the only main sequence stars other than the Sun in which rapid oscfllations have been convincingly detected to date. As such, they are the only candidates on the main sequence to which the techniques of. "asteroseismology" may be applied. Comparison of the observed osclllation frequencles and their spacings 
to the elgenfrequency spectra of decalled stellar models which include such features as a differentiated atmosphere and magnetic fleld can be a powerful probe of the physical properties of these stars. This type of forward analysis is only practical when several frequencies are present in the star.

$\sigma$

HR 1217 is a candidate for such modelling, but it has only six identified frequencles. On the other hand, 19 frequencles have been recognized in the $p$-mode oscillation spectruf of HD 60435 . The many frequencles present in this star make it more likely that a unique model solution for at least a restricted range of solutions) may be found for this star.

Therein lies the primary importance of HD 60435. The data on its rapid oscillations are already of suffictent quantity and accuracy for forward analysis. At present, however, the theoretical foundation is lacking. As new and more realistic models of peculiar A stars are developed, HD 60435 w1ll be the best proving ground available to advance theoretical understandying of this interesting retion of the MR diagram. 
APPENDIX A

NONRADIAL PULSATIONS IN STARS

Nonradial pulsations in a star may be treated as waves propagating and reflected within one or more natural resonant cavities in the interior. A pulsation mode is observed when a standing wave is established between the two boundaries of such a cavity. The normal modes are in general characterized by eigenfunctions of the corm:

$$
\xi_{n \ell m}(r, \theta, \phi, \tau)-A_{n}(r) Y_{l}^{m}(\theta, \phi) e^{-2 \pi i \nu t}
$$

where $y^{m}$ is a spherical harmonic for which $\ell-0,1,2, \cdots$ and $\mathbf{m}-0 . \pm 1$. $\pm 2, \cdots, l:$ and $2 \pi \nu$ is the eigenfrequency $(\omega)$. The eigenfrequencles for these modes depend on 2 but in the absence of rotation or perturbations by the magnetic field are $(2 l+1)$-fold degenerate in $m$. Each mode also has a series of harmonics expressed by the radial amplitude term $A_{n}(r)$. All three "quantum numbers" 2 , m, $n$, represent numbers of nodes in the pulsation pattern: the degree 2 is the total number of nodes on the surface of the star; the azimuthal number $m$, the number of those rodes which pass through latitude $\theta-0^{\circ}$ on the star (relative to some physical axis of symmetry, such as the rotation.axis): and the radial order or overtone $n$, the number of nodes in radial displacement counted from the stellar centre. A few representative examples of $(l, w)$ surface pulsation patterns are depicted in Figurè A.l.

The aforementioned degeneracy in may be resolved by rotation of the pulsating star. Ledoux (1951) demonstrated ţhat a frequency $v l, a$ in a star rotating with, angular frequency $n^{+}$, would be perturbed by + The star should be rotating sufficlently slowly that ceritrifugal effects may be safely. neglected.

$: \quad 124 \cdot\left[\begin{array}{c}1 \\ 1 \\ 1 \\ 1 \\ 7\end{array}\right]$




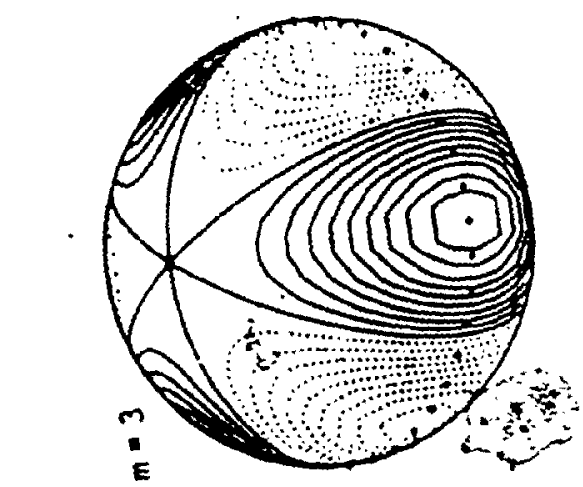

$+$
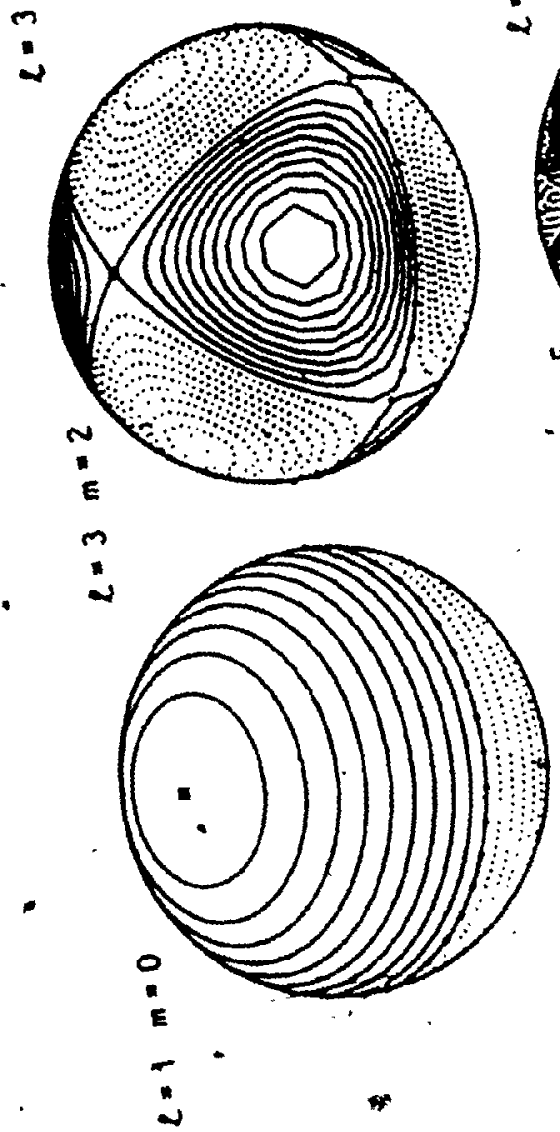

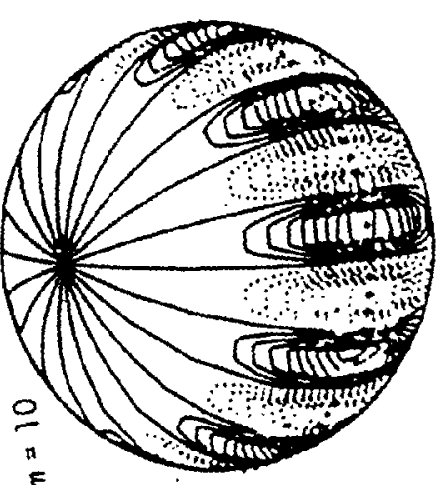

인

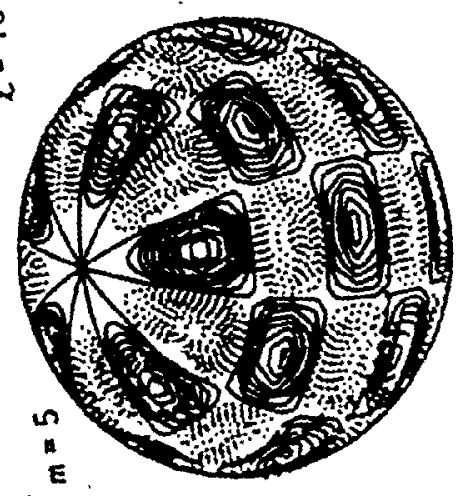

O

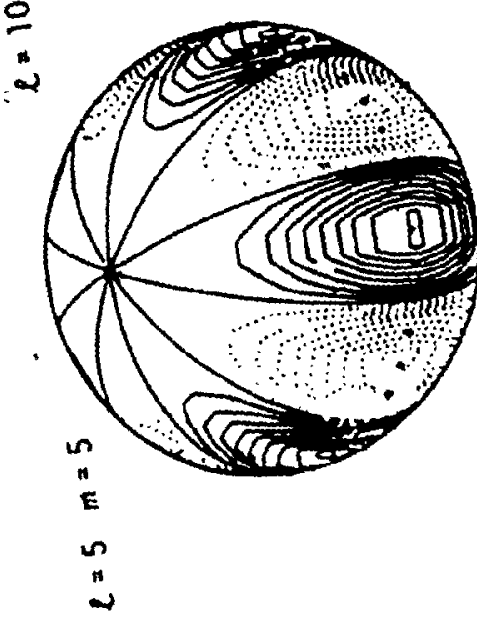

E)

$\approx 2$

过

45

$\stackrel{E}{\Xi}$

$\overline{0}$

ᄃ可

3 ด

o. 5

में

山

o 0

$0 \%$

대

\pm क

出

등

a

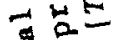

$\stackrel{5}{0}$

\& 0

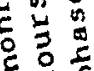

L

त5

\%

30

on

$\omega_{0} 0$

. 0

ث.

눙

E잉

就

这

- 0

$4 \pm 7$

w0

30 出兵 
Coriolis effects and transformation from its rotating frame to an ob. server's inertial frawe such that

$$
\nu_{\ell, \mathrm{m}}=\nu_{\ell, 0}-\operatorname{mog}\left(1-c_{n, \ell)} \frac{\Omega}{2 \pi}\right.
$$

where $\nu_{k}, 0$ is the frequency of a mode with -0 (which is identical to the frequencies of all modes ( $l, m)$ in the non-rotating star), is defined to be positive for a wave travelling in the same sense as the rotation (i.e. prograde). $C_{n, l}$ is the "Ledoux constant" which depends on the structure of the star as well as the degree and overtone of the pulsation, and $(\theta . \phi)$ in equation (A.1) are referred to the rotation ax1s of the star. Aizenman et al. (1984) hove further shown that. If the axis of pulsation is inclined to the rotation axis by an angle $\beta$. chen the above equation beçomes

$$
\nu_{\ell, \pi}-\nu_{2.0}-m\left(1-C_{n, \ell}\right) \frac{n}{2 \pi} \cdot c a \sqrt{\beta}(A .2 a)
$$

$c_{n, z}$ is typically less than 1 . In fact, as 2 and/or $n$ grow large. $c_{n, l}$ approaches zero. For the Sun's five-minute pulsations of high overtone and low degree, $C_{n, l} \propto 0.01$ (Dolez. and Gough 1982).

\section{Pulsation modes}

Two types of waves are thought to be responsible for the global pulsations observed in a variety of stars. They are distingulshed by the restoring forces which maintain the respective osclilations. Sound - wayes are a side-effect of the compressibility of a gas: hence, these vibrations are known as presstire or $p$-modes. Waves drfien by buoyancy set up pulsations which have been dubbed gravity or g-nodes. 
Pressure (p-) aodes

A p-oode 18 produced by atanding wave in an acoustic cavity in the star. The cavicy's upper boundary accurs where the gas density drops off so rapldly that the wave can no longer propagate and is totally reflected. This poirt is equivalent to the surface of the star. A wave penetrating deeper into the star encounters gas of increasing cemperature. Since the local sound speed $c$ increases with temperature such that

-

(where $k$ - Boltzmann's constant and $m$ - the average mass of a particle $c-\left[\frac{k T}{m}\right]^{4}$

in the gas), then the vertical wavelength of the wave also incteases. The wave is eventually refracted such that it is heading back cowards the surface. The "reflection" point corresponds to the depth where the sound speed equals the hortzontal phase speed of th S lve. That speed depends on the frequency $\nu$ and horizontal wavenumber $k_{x}$.

$$
\left.v_{x}-\frac{2 \pi \nu}{k_{x}}-\frac{\left[\ell(l+1]^{h}\right.}{r} \cdot \quad \text { (A. } 4\right)
$$

(Because $\nu$ and $k_{x}$ can be determined from disc-resolved observations of the solar P-mode oscillations, equation (A.4) is the key to helfo-

selsuological estipates of the run of sound speed - and, through equa. tion (A.3), teaperature - with depth in the Sun.)

The vertical wavenumber $k_{2}$ of the osclilation is also constrained by the requirenent for a sanding wave that an integral number of halfwavelengtha must fit exactly between the upper and lower boundarles of the cavity (at radil $r_{u}$ and $r_{1}$ ): 


$$
\int_{r_{1}}^{r_{u}} k_{z} d z-(n+b) \pi
$$

where $n$ is again the number of nodes of zero radial displacement in the standing wave (i.e., the dial overtone)

Equations (A 3), (A.4) and (A.5) lead to an approximate dispersion relation for modes where $\ell \gg n$. In this limit. waves do not penetrate very deeply into the star: the acoustic cavity is relabively. shallow. Therefore. one can safely approximate the temperature at a given depth.. within this nerrow range as

$$
\begin{aligned}
& \text { nerrow range as } \\
& T(r)=\left.\frac{d T}{d z}\right|_{a}(R-r)-\frac{g(r)}{C_{p}}(R-r)
\end{aligned}
$$

- where $\left.\frac{\mathrm{dT}}{\mathrm{dz}}\right|_{a}$ is the adiabatic cemperature gradient, $g(r)$ is the local gravity at radius $r, C_{P}$ is the heat capacity at constant pressure, and: $R$ is the radius of the star. Substituting equation (A 6 ) 1nto. (A. 3) eventualiy yields

$$
c(r)-[(\gamma \cdot 1) g(R-r)]^{2}
$$

where $\gamma-c_{p} / c_{v}$.

Thus, at the depth of the lower boundary of the acoustic cavity.

$$
\omega-2 \pi \nu-k_{x}\left|(\gamma-1) g\left(R-r_{1}\right)\right|^{h} .
$$

Introducing equations (A.7) and (A.8) Into the solution of (A.5), where the thinness of the cavity permits the approxiaction $\int k_{2} d z-k_{z}\left(R-r_{1}\right)$. finally gives the approximate dispersion relation:

$$
v^{2} \propto(n+y) g k_{x} .
$$


The derlvation for $l \ll n$ is stallar but nore involved since seve. ral of the above siupliflcations are no longer valid given che greater extent of the acoustic cavity in this case. The result is a dispersion relation of the same form as that derived by Tassoul. (1980):

$$
\nu_{n l}=\nu_{0}\left(n+\frac{l}{2}+c\right)
$$

where $\nu_{0}-\left[2 \int^{R} \frac{d r}{c}\right]^{-1}$ Therefore, modes of low degree and high overtone are charactertzed by consecutive overtones which are uniformly spacod in frequency.

Gravity (g-) modes

The resonant cavity for gravity waves is defined by the region in the star where the osclilation. frequency is less than the Brunt-Vaisala (or buoyancy) frequency

$$
f_{B V}-\left[\frac{g}{T}\left(\left.\frac{d T}{d z}\right|_{a}-\frac{d T}{d z}\right)\right]^{t}
$$

For these modes, the dispersion relation is of the form (Toomre 1984):

$$
\frac{1}{v_{n \ell}} \approx \frac{1}{\nu_{0}} \frac{n+2 l+c^{\prime}}{[l(l+1)]^{h}}
$$

,

where $\nu_{0}^{\prime}-\frac{1}{2 \pi^{2}}\left[\int_{0}^{r_{u}} \frac{f_{B V}}{r} d r\right]$, such that $r_{u}$ is just below the convective zone of the star (within which gravity waves are evanescent) and $c^{\prime}$ is another sall constant whlch depends on the stellar structure.

Note that consecutive overtones of a $g$-mode of given degree are equally spaced in perlod, not frequency. These modes also have longer perlods than the p-rodes thet would be found in the sane star. Both 
the longer periods and the equal perlod spacing are incompatible with the observations of roAp stars, so the rapid oscillations of those stars have been attributed to p-mode pulsation.

\section{Pulsational dejwing}

Most stars are stable to pulsacion. If a star is, say, compressed from its equilibrium configuration (perhaps by some turbulent process in the atmosphere), the resulting overall decrease in opacity and in. crease in density gradient both allow tbe excess luminosity to escape more easily. When the star then slightiy overshoots its equilibrium state. the opposite occurs. In this way, any oscillation is effectively damped after only a few cycles.

\section{,} However, at certain levels in the atmosphere. this sftuation does not necessarlly hold, Consider the He II lonization zone, which is located at a temperature near $4 \times 10^{4} \mathrm{~K}$. When the star is most highly compressed, mucti of the excess luminostty is absorbed in the lonization of He II to He III. The large opacity of He II dams the outflow of Fadiation and increases the local temperature gradient. The excess pressure drives the puter layers of the star to expand more than Its normal relaxation response. Conversely, at maximum expansion, recomb1nation takes place in the He III region. Not only is He III almost transparent to the UV flux that was blocked before by He II, but the recombination also cools the gas more efficiently. Both the temperature and pressure faIl, as do the outer layers of the star, and the pulsation cycle repeats. This is an oversioplified picture, but it does describe the fundamental mechanisn at work.

All stars have He II Ionization zones, but not all pulsate. If 
the the II zone is too deep in the atmosphere (as in a snaller, cooler star). there is insufficlent driving to wove the weight of the over. lying gas. If the zone is too high (larger, hotter star), theré Is insufficient mass in the upper layers to recompress the star effectively. Also, the region which contains the ionization zorre will be nonadiabatic, so. the density and temperature adjust themselves to keep the luminosity gradient frgm becoming steep enough to drive puisation. The narrow range of effective temperature over which this envelope Iontzation mechanjsin will drive pulsation in stellar models corresponds closely to that observed for the Cepheid instability strip. Where the lower portion of this strip crosses the main sequence are found the $\delta$ Scuti pulsators. This is also the vicintty of the roAp stars, so the He II Ionfzation mechanism may be relevant to these stars, even with thelt anomalous atmospherlc compositions, 

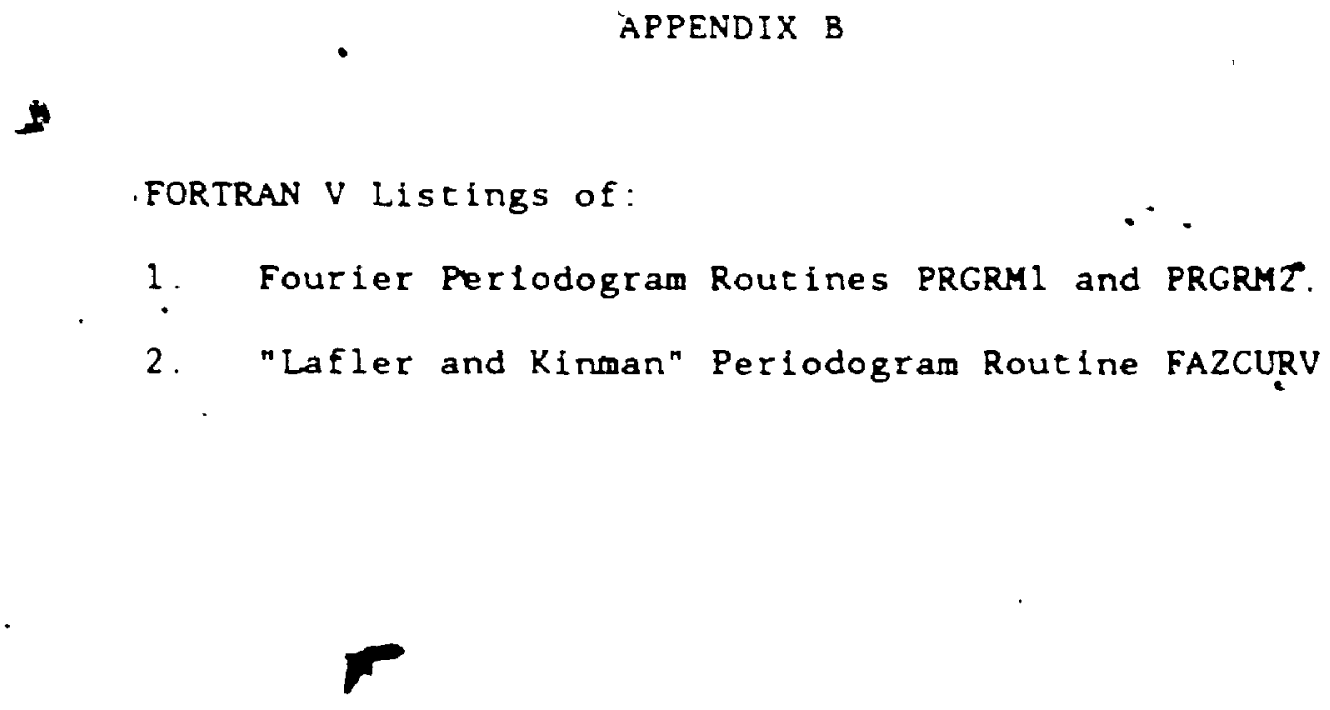

128 


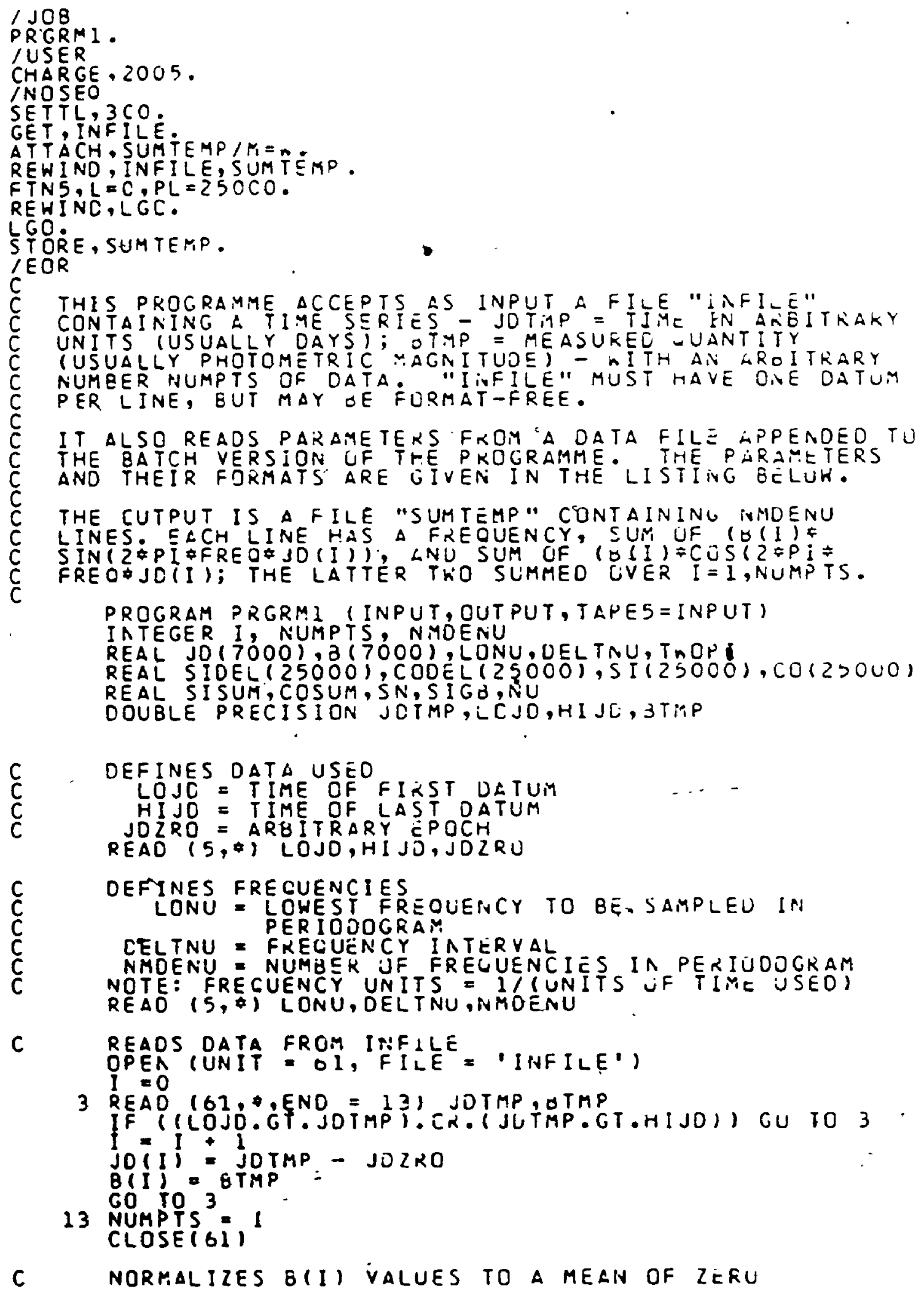


CALL AVG(NUMPTS,B)

CPEN (5O,FILE='SUATEMP')

NAOP! LONTS 2831953

OO O1, $1=1$, NUMPTS

SIII) $=\operatorname{SIN}(T$ INOPI LLVU J J OI)

CUII) = CUS (TAOPI OLLNUFJOLI)

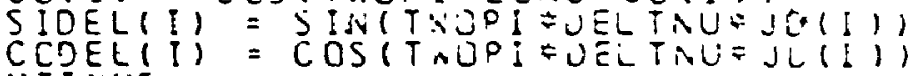

OI CONTINUE

$\begin{aligned} O C \text { SI J } & =1, \text { NMOENL } \\ \text { SISUM } & =0 \\ \text { CCSUM } & =0\end{aligned}$

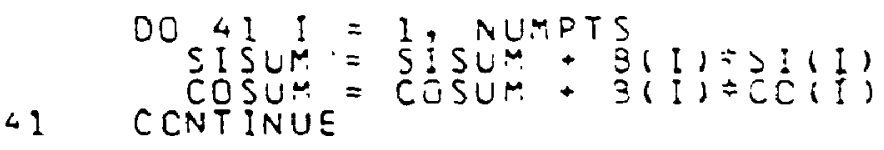

WRITE $(\equiv 0, \approx)$ NU, SISUM, CUSUN

$00 \frac{31}{\operatorname{Sin}}=15 I 1 \frac{1}{5}$; NUMPTS

SI I I = SiNFCOOEL(I) + CO(I) OSIOELII)

31 CONTINUE = CO(I)=CUOEL(I) - SA+SIDEL(I) NU $=N U+$ DELTVU.

51 CCNTINUE

$E \wedge D$

SUBROUTINE LVG (NLMPTS,O)

INTEGER NUMPTS

REAL B(7000), JIGZ.

DO $81 \mathrm{I} I=\operatorname{l} 1$, NUMPTS

81 CCNTINUE

SIGB = SIGB/NUMPTS

DO 8 II, $E=21$ II, NUMPTS

91 CCNTINUE

KEOR
$0.071044 \cdot 1727 ? 0.0$
$0.070 .005 \cdot 420$

IEDR

IEOF 
135

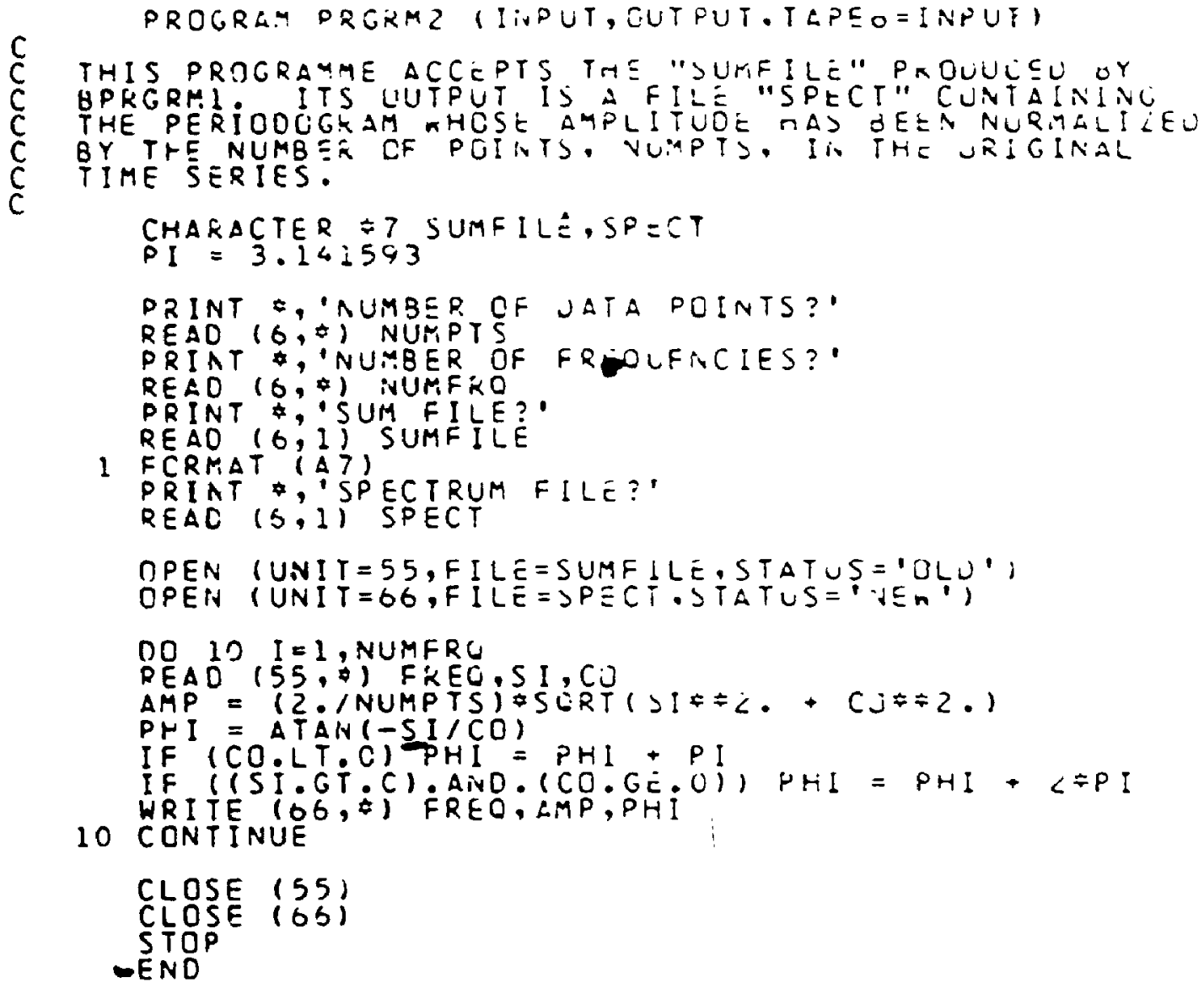


PROCRLM FAZLURVIINPUT, OUTFUT. TAPEO=INPUT)

$c$
$c$
$c$
$c$
$c$
$c$
$c$
$c$
$c$
$c$
$c$
$c$
$c$
$C$
$C$

THIS PROGRLMME CALCULATES a PEKIUDUGRAH GLSELUU UTE

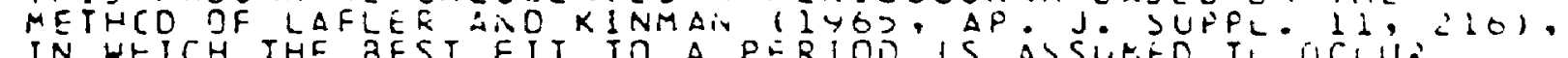
IN HTICH THE OEST FIT TO A PERIOD 1 S ASSURED TL UCLUA WHEN THE SUF OF THE STRING LEA:CTHS BCTAECN TRE DATA ORDEREO IN PHASE ACCURUIING TU THAT PERIOU IS A MINIMUM.

IT DOES THIS FUZ A SET OF NUMP TEIAL PERI CUS SPACEU OY DELTAP ANO STARTING STPO ON TTHE TIME UNITS MUST BE, USUALLY DAYS. AN ARSITRARY EPUCH TIAY OE STECIFIEC FOR THE INPUT TIMES.)

the pERIODUGKais is STOKEU A. A file "OUTHLE".

CHARECTED. OT IHFILE, RUTFILE

REAL JOO JD(200), \& $(200)$, LUN, NUFAZ $(200)$, NUE $1=001, F A Z 1200)$

REAL QTEMP(ZOO)

PRIAT =, 'PHOTOMETRY FILE ?'

READ $(6,1)$ INFILE

1 FORMAT $\{$ IST)

PRINT $\%, '$ CUTPUT FILE?'

READ $(6,1)$, CUTFILE

PRINT t, 'EPOCH?

PEEAD $(6, \%)$ JOO

PRINT F'STARTING PERIOU, INTERVAL, E NU. CF PERIUOS?'

REAC $(6, \%)$ PO, DELTAP,NUMP

C REAOS OATA FROM INFILE

OPEN (UNIT $=55$, FILE = INF.ILS, STATUS = 'OLD')

200

READ $=$ I $55, E N D=100)$ JO (I), 3(I)

$I O C$
$G C$

100 NLESE $\left(5 \frac{1}{5}\right)$

OPEN (UNIT = EG,FILE=LUTFILE,STATUS= 'NE A')

C CALCULATES PHASES RELATIVE TO SHECIFIED PERIOD PO BTEMP(I $=3(1)$ TERM = JU(I)-JDO $) / P O$

20

FAZ (I) = TERM - INT (TERM)

20 CONTINUE (I) LLT.C) FALII) =FAZ(I) $=1$

$N 1=$

C PESORTS DATA IIN ORDER JF INCREASING PMASE

$\begin{array}{rl}\text { OO } 30 & J=I, N \\ \text { LOH } & =F A Z(1) \\ \text { NUM } & =1\end{array}$

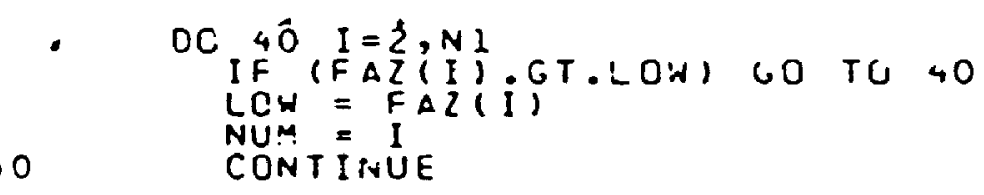

NUFAZ $(J)=$ LOn

KUB(J) = GTEMP(NUM) 
137

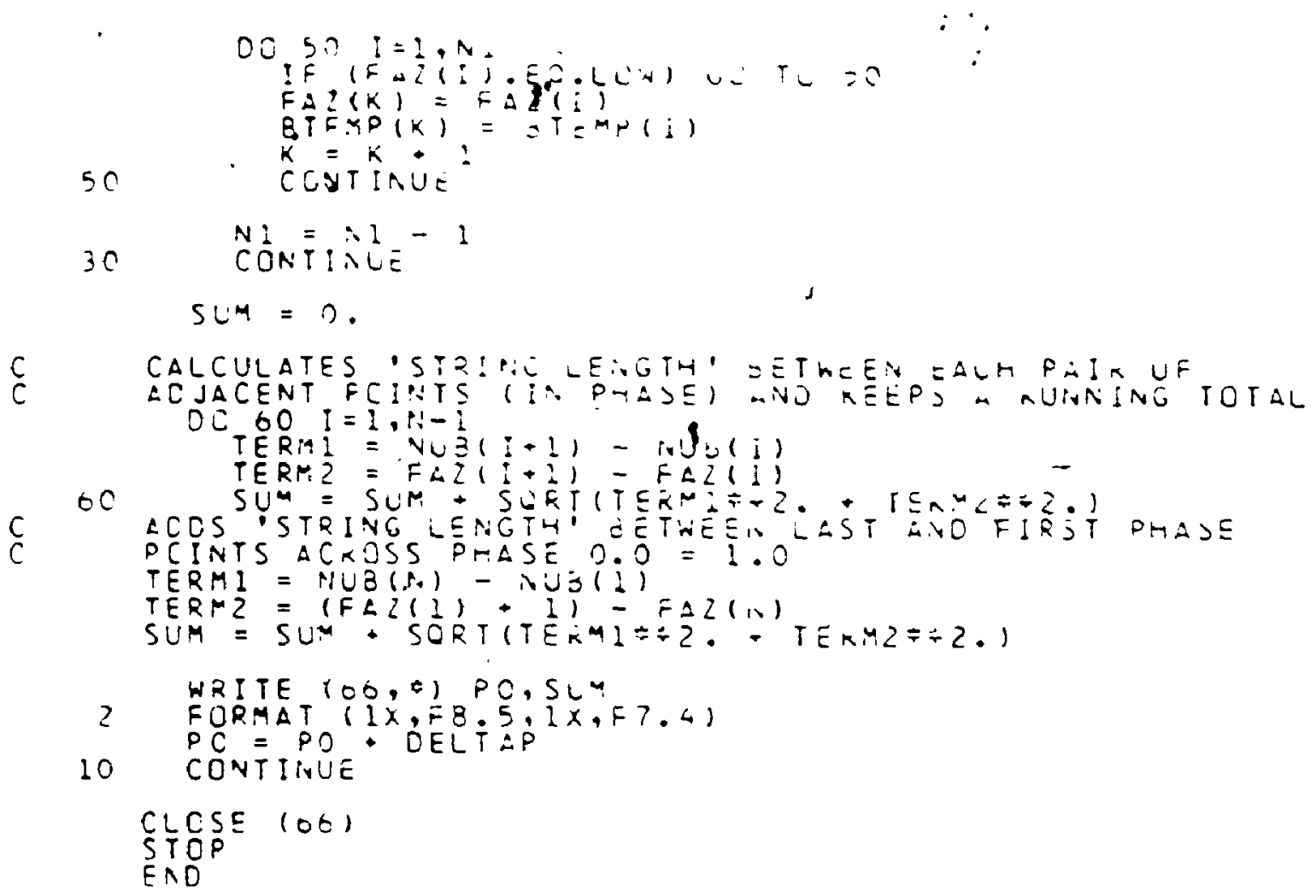




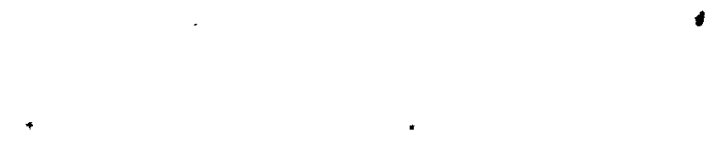

- APPENDIX C

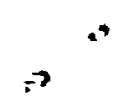

FORTRAN $V$ Listing of Cubic Spline Filter Progmame SPLINE

$>$

1 
PROGRAM SPLINE (INPUT, OUTPUT,TATEU INFUT)

THIS PROCPAMKE FITS A AATUKAL CUOIL SPLINE TL DEI UF

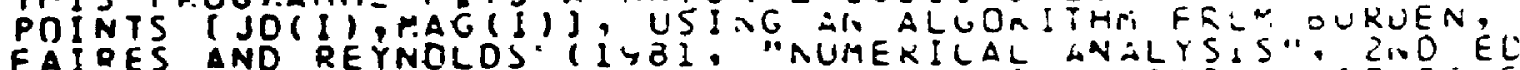

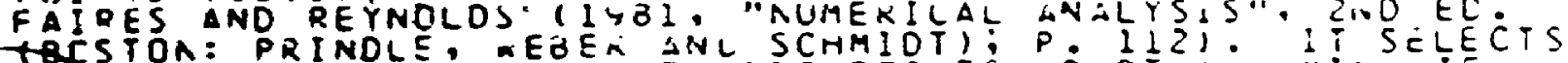
TIAES IN THE ORICINAL UATA 120 PUIPUTS APART ISU MION IF THE PCINTS AKE S AMPLEO EVEKY 20 SEC, AD DUT TRE MO 0043 ? DATA, aNO TAKES OO PJINT AVERAGES CENTREU UN TRJDE TIMES. THESE ARE THE VALUES TO WHICH THE SPLINE IS MATCTEU. IT TAEN SUSTRACTS THAT SPLINE FUNCIIUN FAOG THE URIGINAL DATA/TO PRODUCE L "FLATTEAED" LURVE.

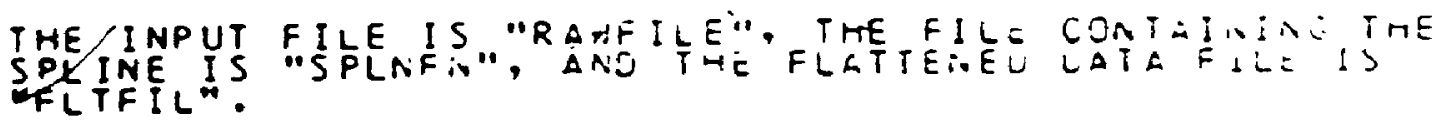

DCUBLE PRECISION JD(2000), MAG $(2400) \times(10), A 120), H(10)$,

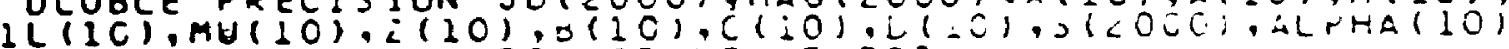
EACTER IL 2AWFIL,SPLNFN,FLTFIL

PRINT *, 'RAR DATA FILE?'

READ $(6,1)$ RLIFIL

1 FORMAT (AT)

PRINT *, SPIINE FUNCTION TO BE STLEED IN?'

READ 16,1$)$ SPLNFN

PRIMT " "FLLTTENED FILE?"'

- RFAD $(6,1)$ FLTFil

OPEN (UNIT $=55$, FILE =RANFIL, STATUS = :OLO')

OPEN (URIT=67,FILE=FLTFIL, STATUS=:NEG')

$\cdot$

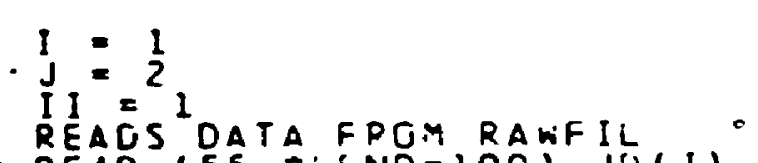

C 200 REAES REATA FPGA RANFIL (I), MAG(I)

100 CLOSE $(55)$

C DETERMINES AVERAGED PCINTS TO BE FIT uY SHLINE

NMAX $I=-1-120$

- $\quad x(1)=$ Jo(1)

- $A(1)=\operatorname{MAC}(1)$

- 3CC IF (II.CT.MPLX) GU TO 400

SLM $=0$.

10

DC $201=11911+\frac{1}{2} 20$

$\Delta(J)=$ SUM/120.

$x(J)=J 0\left(I \frac{1}{1}+00\right)$

II $I=11+240$

G0 $=50$ \% 300

C CAlculates sPLine clrve

$400 \times(j)=70(N)$

$A(J)=\operatorname{MAG}(N)$

H(i) $=x(2)-x(1)$

DC $20, t=2, j=1$

H(I) $=x(I+I)-x(I)$ 


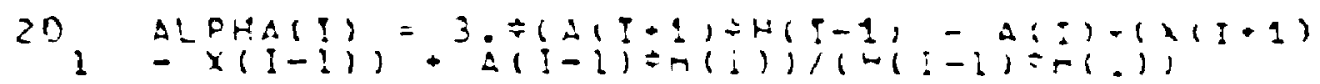

L $(1)=1+i$

$211)=3$.

$C C, 32, !=?, 1-1$

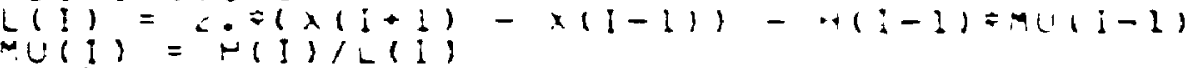

$L(J)=1$.
$Z(J)=\mathrm{C}$.

Cᄃ $40, I=1-1: 1,-i$

$C(I)=(i)-1+U(1) \div C(i+i)$

$E(i)=(j(i+1)-2(j)) / n i j$

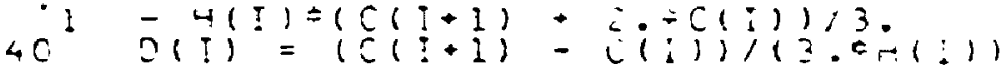

$\dot{I}=\dot{I}$

$S L M=C$.

600 IF (I.GT.N-I) GU TC 700

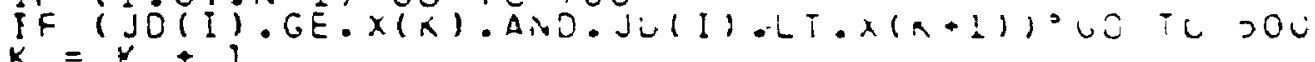

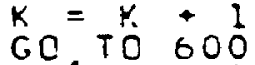

$5 \mathrm{CO} D I F F=J D(I) \cdot-X(K)$

$S(I)=4(K)+B(K)=0 I F F+C(K)=U I F F=E$ * $+U(K)+U I F F+9$. $M L G(I)=M L G(I)-S(I)$

WRITE $(66,7), J D(I), 2(1)$

7 FORMAT (1X.F1O.5, $1 x, F 7.4)$

SUM $=S U M+M A G I I \dot{l}$

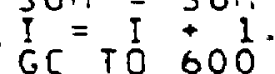

$700 \triangle V E R=(S U Y+M A G(N)) / N$

C

WEITE SPLINE FILTER TO SPLNFN

WRITE $(E G, 7)$ ID(N), MAG (N)

C

HRITE FLATTENED DATA FILE TU FLTFIL

- OO 50 I = $1, N$

MAG (1) $=M A G(1)$ - $A V E R$

SC. MRITE $(\overline{6} 7,7)$ JO( 1$), M A L(I)$

CLOS 106$)$

STOP

END 


\section{REFERENCES}

Abt, H.A., Chaffee, F.H., and Suffolk, G. 1972. Ap. J. 175, 779.

Adeknan, S.J. 1985. Publ. A. S. P. $97,970$.

Alzeman, M.L. MHanser, C.J., Cox, J.P. and Pesnell, W. D. 1984. Astrophys. J. (Letcers) 286. L43.

Babeock, H.N. 1958. Astrophys. J. Suppl. 3, 141.

Baschek, B. and Oke, J.B. 1965. Astrophys. J. 141, 1404.

Beutler, F.J. 1966, S.I.A.H. Rev. 8. 328

Bevington. P.R. 1969: Data Reduction and Errar Ansilysis for the Physlcal Sclences (New York: McGraw-Hill).

Bidelman, U.P. and MaçConnel1, D.J. 1973. Astzon. J. 78, 687.

Blacknan, R.B. and Tukey, J.W. 1958. The Measurement of Power Spectra frow the Polnt of Commications Engineering (New York: Dover).

Blanco, V.M., Deners, S., Douglass, G.G., and.Fltzgerald, M.P. 1970 Pub1. U.S. Naval Obs. 11. 1.

Bonsack, W.K. 1979. Pub1. A. S. P. 91, 648.

Bonsack. H.K. and P1lachowsk1, C.A. 1974. Astrophys. J. 190, 327.

Borra, E.F. and Landetreet, J.D. 1975. Pub1. A. S. P. 87, 961.

Borra, E.F. and Landstreet, J.D. 1980. Astrophys. J. Suppl. 42, 421.

Breger, M. 1979. Publ. A. S. P. 91, 5.

Burg, J.P. 1965. Ph.D. thesis, Stanford University

Clarke D. 1980, H.N.R.A.S. 190, 641 .

Cox, J.P. 1984a. Aetrophys. J, 280, 220.

Cox, J.P. 1984bะ.Publ. A. S. P. 96, 577.

Cramer, N. and Mader. A. 1979. Astron. Astrophys. 78, 305.

Cramer, N. and Maeder,' A. 1980. Artron. Astrophys. 88, 135.

Crawford, D.L. 1958. Aetrophys. J. 128, 190.

Crawford, D.L. 1979. Astron. J. 84, 1858: 
Deening. T.J. 1975. Astrophys. Space Sci. 36. 137

Dolez. N. and Gough, D.O. 1982. In Pulsations in Classical and Cacaclysmic Variables, eds. J.P. Cox and C.J. Hansen (Boulder: JILA), P. 248.

Dziembowski, W. 1977. Acts. Astr, 27, 203.

Dziembowski, W. and Goode, P.R. 1984. Mem. Soc Astr. Italiana SS, 185

Dziembowski, W. and Goode, P.R. 1985. Astrophys. J (Letcers) 296, L27.

Fahlman, G.G. and Ulrych, T.J. 1982. M.N.R.A.S. 199, 53.

Fernie, J.D. 1976. Publ-A. S. P. 88, 969.

Floquet. M. 1979. Astron Astrophys. 74, 250.

Floquet. M. 1981. Astron. Astrophys. 101, 176.

Gabriel, M.. Noels, A. Scuflalre, R., and Mathys, G. 1985. Astron. Astrophys. 143, 206.

Global Oscillation Network Group 1985. A Proposal to Study the Solar Interior by Measuring Global Oscillations with a World-wide Network of Instruments (Sunspot: National Solar Observatory).

Golay. M. 1974a. Introduction to Astronomical Photometry (Dordrecht: Re1de1), p. 199.

Golay, M. 1974b. ibid, p. 26-27.

Gray, D.F. and Desikachary, K. 1973. Astrophys. J. 181, 523.

Hardie, R.H. and Schroeder, N.H. 1963. Astrophys. J. 138, 350.

Harris, D.L., Strand, K.A. and Worley, C.E. 1963. In Basic Astronomical Data - Stars s Stellar Systems III, ed. K.A. Strand (Ch1cago:

University of Chicago Press), p. 273.

Harris, W.E., Fitzgerald, M.P., and Reed, B.C. 1981, Publ. A. S. P. 93. 507.

Rauck, B. and Mernilliod, M. 1975. Astron. Ascrophys. Supp1. 22, 235

Hauck, B. and Mermil11od, M. 1980. Astron. Astrophys. SuppI. 40, 1.

Hauck, B. and North, P. 1982. Astron. Astrophýs. 114, 23.

H111, R.J. 1986. M.Sc, thes 1s, Univerelty of Wistern Ontarto.

Hoffle1t, D. 1982. Bright Star Catalogue, 4th Ed., Yale University Observatory. 
Horne, J.H. and Ballunas, S.L. 1986: Astrophys. J. 302, 757.

Houk, N. 1982. Hichlgan Spectral Catalogue, Vol. 3 (Ann Arbor: University of Michigan.

Houk, N. and Cowley, A.P. 1975. Hichigan Spectral Caralogue, Vol. 1 (Ann Arbor: University of Michigan).

Jarzebowsk1, I. 1960. Acta. Astr. 10, 31.

Jenkins, G.M. and Watts, D.G. 1968. Spectral Aralysis and its Implications, (San Francisco: Holden-Day).

Joncas, G. and Borra, E.F. 1981. Astron Astrophys. 94, 134.

Jones, T.J. and Wolff, S.C. 1973. Publ. A. S. P. 85, 760.

Kreidl, T.J. 1985a. Inform. Bull, Var. Stars $\$ 2739$.

Rreldl, T.J. 1985b. M.N.R.A.S. 216, 1013.

Kreidl, T.J. 1987. Lecture Notes in Physics 274, "Stellar Pulsation", eds. A.N. Cox et al. (Berlin: Springer-Verlag), p. 134.

Kurtz, D.W. 1978. Infor. Bull. Var. Stars $\$ 1436$.

Kurtz, D.W. 1982. M.N.R.A.S. 200, 807.

Kurtz, D.W. 1983a. M.N.R.A.S. 202, 1.

Kurtz, D.U. 19836. M.N.R.A.S. 205, 3.

Kurtz, D.W. 1984, M.N.R.A.S. 209, 841.

Kurtz, D.W. 1985. preprint.

Kurtz, D.W. 1986. In the proceedings of the NATO Workshop on Seismology of the Sun and Distant Stars, ed. D.O. Gough (Cambridge: CUP).

Kurtz, D.W. and Cropper, M. 1987. preprlnt.

Kurtz, D.H. and Marang, F. 1987 . preprint.

Kurtz, D.W. and Seeman, J. 1983. H.N.R.A.S. 20S, 11.

Kurtz, D.H. and Shibghashi, H. 1986. M.N.R.A.S. 223, 557.

Kurtz, D.H. and Hegriar, G. 1979. Astrophys. J. 232, 510.

Kurtz, D.H., Schneider, H., and Welss, W.W. 1985. M.N.R.A.S. 215. 77.

Kurucz, R.L. 1979. Astrophys. J. Supp1. 40, 1.

Lafler, J. and Kinan, T.D. 1965. Actrophys. J. Suppl. 11, 216. 
Ledoux, P. 1951. Astrophys. J, 114, 373.

Macthews, J.M., Kuricz, D.W. and Wehlau, W.H. 1986. Astrophys. J. 300. 348.

Matthews. J.M : Kurtz, D.W. and Wehlau, W.H. 1987. Astrophys. J. 313. 782.

Matthews, J.M., Slawson, R.W. and Wehlau, W.H. 1986. In Hydrogen Deficient Stars and Related objects, ed. K. Hunger et al. '(Dordrecht: Reidel), P. 313.

Matthews, J.M. and Wehlau, W.H. 1985. Pub1. A. S. P. 97, 841.

Matchews, J.M., Wehlau, W.H., Walker, G.A.H., and Yang, S. 1987 a. Astrophys. $J$., submitted.

Olsen, E.H. 1983. Astron. Astrophys. Supp1. 54, 55.

Olsen, E.H. and Perry, C.L. 1984. Astron. Astrophys. Suppl. 56, 229.

Papoulis, A. 1977, Signal Analysis (New York: McGraw-Hill)

Preston, G.W. 1969. Astrophys. J. 158, 243.

Preston, G.W. 1972. Astrophys. J. 175, 465.

Preston, G.W. and Pyper, D. 1965, Astrophys, J. 142, 983.

Preston, G.W. and stepien, K. 1968a. Astrophys, J. 151, 577.

Preston, G.W. and Steplen, K. 1968b. Astrophys. J. 151, 583.

Preston, G.W. and Stepien, K. 1968c. Astrophys. J. 154, 971.

Preston, G.W. and Wolff, S.C. 1970. Astrophys. J. 160, 1071.

Preston, G.W., Stepien, K, and Wolff, S.C.1969. Astrophys, J. 156. 653 .

Pyper, D. and Adelman, S. 1986. In Upper Main Sequence Stars With Anomalous Abundances, eds. C.R. Cowley et al. (Dordrecht: Reldel).

Rakos, K.D. 1962. Zs. f. Astrophys. 56, 153.

- Scargle. J.D. 1982. Astrophys. J. 263, 835.

Scholz, G. 1979. Astr. Nachr. 300, 213.

Shibahaqhi, H. 1983. Asarophys. J. (Letters) 275, L5.

Shibahash1, H. 1987. Lecture Notes In Physlcs 274, "Stellar Pulsation", eds. A.N. Cox et al. (Berlin: Springer-Verlag). 
Shibahashi, H, and Sa10, H, 1985. Publ. A. S. Japan 37, 245.

Shibahash1, H., Noels, A., and Gabriel. M. 1983. Astron. Astrophys. 123, 283.

Sinnerstad, U. 1961. Stockhola Obs. Ann. 21, 6.

Slettebak, A., Collins, G.H., Boyce, P.B., White, N.M., and Parkinson, 1975. Astrophys. J. Suppl. 29, 137.

Stellingwerf, R.F. 1978. Astrophys. J. 224, 953.

Stepión, K. 1968. Astrophys. J. 154, 945.

- Steptén. K. and Muthsan, H. 1980. Astron. Astrophys. 92, 171.

Tassoul, M. 1980. Astrophys. J. Suppi. 43, 469

Thoupson, I.B. 1983. M.N.R.A.S. 205, 430.

Thoupson, I.B., Landstreet, J.D. and Brown, D. 1986. preprint.

Toonre, J. 1984. In Solar Seisaology from Space, JPL Publication 84-84, eds. R.K. Ulrlch et al. (Pasadena: NASA), P. 7.

Trasco, J.D. 1972. Astrophys. J. 171, 569.

Vogt, N. and Faundez,. M. 1979. Astzon. Astrophys. Suppl. 36, 477.

Wehlau, H.H, and Leung, K, C. 1964. Astrophys. J. 139, 843.

He1sa, W.W. 1986. In IAU Colloqulun *90, Upper Main Sequence Sears with Anomalous Abundances, (Dordrecht: Reldel).

Helss, W.W. and Kurtz, D.H. 1987. In preparation.

Winzer, J.E. 1974. Ph.D. thesis, University of Toronto.

Wolff. S.C. 1967. Astrophys. J. Supp1. 15, 21.

WolfE, S.C. 1975. Astrophys. J. 202, 127.

Wolfe, S.C. 1983. The A-stars: Problems and.Perspectives, NASA Monograph SP-463.

Dolff, S.C. and Hagon, W. 1976. Publ. A. S. P. 88, 119.

Wolff, S.C. and Wolff, R.J. 1970. Astrophys. J. 160, 1049.

WolfE, S.C. and Wolff, R.J. 1971. Astron. J. 76, 422.

Wolff, S.C, and Wolff, R.J. 1972. Astrophys. J. 176, 433.

Hood, H.J. and Canpunano, L.B. 1975. Astron. Astrophys. 45, 303. 